\title{
Review
}

\section{Recent Advances in the Production of Genome-Edited Rats}

\author{
Masahiro Sato ${ }^{1, * \mathbb{D}}$, Shingo Nakamura ${ }^{2} \mathbb{D}$, Emi Inada ${ }^{3}$ and Shuji Takabayashi ${ }^{4, * \mathbb{D}}$
}

1 Department of Genome Medicine, National Center for Child Health and Development, Tokyo 157-8535, Japan

2 Division of Biomedical Engineering, National Defense Medical College Research Institute, Saitama 359-8513, Japan; snaka@ndmc.ac.jp

3 Department of Pediatric Dentistry, Graduate School of Medical and Dental Sciences, Kagoshima University, Kagoshima 890-8544, Japan; inada@dent.kagoshima-u.ac.jp

4 Laboratory Animal Facilities \& Services, Preeminent Medical Photonics Education \& Research Center, Hamamatsu University School of Medicine, Hamamatsu, Shizuoka 431-3192, Japan

* Correspondence: sato-masa@ncchd.go.jp (M.S.); shuji@hama-med.ac.jp (S.T.); Tel.: +81-3-3416-0181 (M.S.); +81-53-435-2001 (S.T.)

Citation: Sato, M.; Nakamura, S.; Inada, E.; Takabayashi, S. Recent Advances in the Production of Genome-Edited Rats. Int. J. Mol. Sci. 2022, 23, 2548. https://doi.org/ $10.3390 /$ ijms 23052548

Academic Editor: Alvaro Galli

Received: 31 January 2022

Accepted: 21 February 2022

Published: 25 February 2022

Publisher's Note: MDPI stays neutral with regard to jurisdictional claims in published maps and institutional affiliations.

Copyright: (C) 2022 by the authors. Licensee MDPI, Basel, Switzerland. This article is an open access article distributed under the terms and conditions of the Creative Commons Attribution (CC BY) license (https:// creativecommons.org/licenses/by/ $4.0 /)$.

\begin{abstract}
The rat is an important animal model for understanding gene function and developing human disease models. Knocking out a gene function in rats was difficult until recently, when a series of genome editing (GE) technologies, including zinc-finger nucleases (ZFNs), transcription activator-like effector nucleases (TALENs), and the type II bacterial clustered regularly interspaced short palindromic repeats (CRISPR)/CRISPR-associated Cas9 (CRISPR/Cas9) systems were successfully applied for gene modification (as exemplified by gene-specific knockout and knock-in) in the endogenous target genes of various organisms including rats. Owing to its simple application for gene modification and its ease of use, the CRISPR/Cas9 system is now commonly used worldwide. The most important aspect of this process is the selection of the method used to deliver GE components to rat embryos. In earlier stages, the microinjection (MI) of GE components into the cytoplasm and/or nuclei of a zygote was frequently employed. However, this method is associated with the use of an expensive manipulator system, the skills required to operate it, and the egg transfer (ET) of MI-treated embryos to recipient females for further development. In vitro electroporation (EP) of zygotes is next recognized as a simple and rapid method to introduce GE components to produce GE animals. Furthermore, in vitro transduction of rat embryos with adeno-associated viruses is potentially effective for obtaining GE rats. However, these two approaches also require ET. The use of gene-engineered embryonic stem cells or spermatogonial stem cells appears to be of interest to obtain GE rats; however, the procedure itself is difficult and laborious. Genome-editing via oviductal nucleic acids delivery (GONAD) (or improved GONAD ( $i$-GONAD)) is a novel method allowing for the in situ production of GE zygotes existing within the oviductal lumen. This can be performed by the simple intraoviductal injection of GE components and subsequent in vivo EP toward the injected oviducts and does not require ET. In this review, we describe the development of various approaches for producing GE rats together with an assessment of their technical advantages and limitations, and present new GE-related technologies and current achievements using those rats in relation to human diseases.
\end{abstract}

Keywords: genome editing; CRISPR/Cas9; ZFNs; TALENs; rats; microinjection; electroporation; embryonic stem cell; adeno-associated virus; GONAD/i-GONAD

\section{Introduction}

Rats (Rattus norvegicus) and mice (Mus musculus) belong to the same rodent family and have been the most widely used models in biomedical research for many years. However, there are several differences between these two animals. For example, the rat is larger (roughly about eight- to ten-fold) in size than the mouse, which provides a number of practical advantages, as exemplified by easier and more rapid microsurgery, multiple 
sampling of larger blood and tissue volumes, and precise injection of substances into blood vessels or the brain (reviewed by Kjell and Olson [1]). Additionally, mice and rats differ in their physiology, behavior, and neurology. Therefore, rats are considered as useful animals suitable for toxicological, neurobehavioral, and cardiovascular studies compared with other currently available experimental animals (reviewed by Jacob [2]).

There are some examples for the production of genetically modified (GM) rats reported approximately 20 years ago. These GM rats were transgenic (Tg) rats as a "gain of function" model to examine the role of plasma membrane calmodulin-dependent calcium ATPase isoform 4 (PMCA4) cDNA under control of the cardiac-specific promoter [3] or sarcoplasmic reticulum $\mathrm{Ca}^{2+}$-ATPase $(S E R C A 2 a)$ under control of the ubiquitous promoter [4]. Unfortunately, the production of GM rats, as exemplified by knockout (KO) or knock-in (KI) rats, has not been possible until about 10 years ago. The main reason for this is the inability to establish and maintain rat embryonic stem (ES) cells, which is much more complicated when compared with establishing and maintaining mouse ES cells. For example, in mice, ES cells were already available in the late 1980s [5,6], whereas rat ES cell production began in the late 2000s [7,8]. Since the establishment of rat ES cells, ES cell-mediated gene targeting was performed in rats for the production of $\mathrm{KO}$ [9-12] and KI rats [13-15]. For cases in which ES cells are still absent, several alternative approaches, such as transposon-mediated mutagenesis and chemical mutagenesis using N-ethyl-N-nitrosourea, have been developed to assess gene function (reviewed by Zan et al. [16]).

During the period of 2009 to 2013, genome editing (GE) technologies, such as zincfinger nucleases (ZFNs), transcription activator-like effector nucleases (TALENs), and clustered regularly interspaced short palindromic repeat-associated protein 9 (CRISPR/Cas9) nucleases systems, all of which can induce a double-stranded break (DSB) at a specific site in the genome, appeared; since then, the production of GM rats was accelerated. Using these GE systems, many GM rats have been produced using the direct microinjection (MI) of GE components (including engineered endonucleases) into the cytoplasm or nucleus of a zygote (fertilized one-cell embryo), in vitro electroporation (EP) of isolated zygotes in the presence of GE components, and in vivo EP after the instillation of GE components into the oviductal lumen of a pregnant female (corresponding to zygote to the 2-cell stage), which is termed "genome-editing via oviductal nucleic acids delivery (GONAD) (or improved GONAD (i-GONAD))". Furthermore, it has become possible to engineer the genome of cultured spermatogonial stem cells (SSCs), precursor cells for spermatogenesis. The transplantation of these GM SSCs into the recipient male rat testes and subsequent mating of these transplanted males with wild-type (WT) females led to the production of GM rats.

In this review, we first describe the delivery method of GE components into rat zygotes for producing GM rats. Second, we describe the novel techniques that may be potentially useful for efficient production of GM rats with multiple functions. Third, we highlight that those GE technologies are useful for producing many types of rat models for human genetic diseases.

\section{What Is GE Technology?}

As mentioned above, site-specific engineered nucleases are used in GE techniques. ZFN, TALEN, and CRISPR/Cas9 can all bind DNA and induce DSBs, which are subsequently repaired by non-homologous end joining (NHEJ) mechanisms or by homologydirected repair (HDR). In the case when the template DNA is absent, the DSB is repaired via the NHEJ pathway where insertion or deletion of nucleotides (hereafter called "indels") frequently occurs in the cleaved area (reviewed by Harrison et al. [17] and Hsu et al. [18]). The indels often generate frameshift mutations of the amino acid sequence (thus leading to the generation of abnormal proteins) or the formation of a premature stop codon (thus leading to stoppage of protein synthesis). In contrast, in the presence of the template DNA (also called donor DNA) that is homologous to the target site, the template DNA is inserted into the cleaved area through HDR. Notably, HDR-mediated editing preferentially occurs 
in dividing cells. In contrast, NHEJ-mediated editing occurs in cells independent of the cell cycle [19].

ZFN consists of two components: the DNA-binding domain of ZF protein (capable of binding to the target DNA) and the DNA cleavage domain of Fok I endonuclease (capable of cleaving the target DNA). ZF protein contains three to six Cys2-His2 fingers, which recognize a triplet nucleotide code. After recognizing the binding site, it becomes a dimetric form, activates Fok I, and then cleaves DNA [20,21].

Similar to ZFN, TALEN comprises two components: transcriptional activator-like effector (TALE) protein and Fok I nuclease (termed TALE nucleases) [22-24]. TALE contains a 33-35 amino acid sequence that flanks a central DNA-binding region (amino acids 12 and 13). Notably, the design and engineering of TALENs are simpler than that of ZFN and, thus, TALENs can be engineered faster.

CRISPR/Cas9 contains two components: single-guide RNA (sgRNA) and the Cas9 protein. sgRNA comprises two components, a target-specific CRISPR RNA (crRNA) and a trans-activating crRNA (tracrRNA). These two parts can be mixed as a crRNA/tracrRNA duplex and work to guide the Cas9 protein to bind to a specific chromosomal DNA site [25-27]. After binding to the specific site, Cas9 cleaves one of the three bases upstream of the protospacer adjacent motif (PAM) of the DNA strand to induce a DSB. This system is different from the other GE tools such as ZFN and TALEN, and the synthesis of sgRNA is a prerequisite for this system. This development dramatically reduces both the complexity and time required for the design and implementation of gene editing.

In Table 1, a summary of GE rats produced from 2009 to 2021 is provided.

Table 1. Summary of the production of genome-edited (GE) rats from 2009 to 2021.

\begin{tabular}{|c|c|c|c|c|c|}
\hline $\begin{array}{l}\text { Method for Gene } \\
\text { Modification }\end{array}$ & $\begin{array}{l}\text { GE Tool (Mode } \\
\text { for Gene } \\
\text { Modification) }\end{array}$ & Rat Strain & Outcome & Target Gene & References \\
\hline $\begin{array}{c}\text { MI } \\
\text { DNA or mRNA }\end{array}$ & ZFNs (indels) & $\begin{array}{l}\text { SS } \\
\text { FHH } \\
\text { SD }\end{array}$ & $\begin{array}{l}\text { Knockout (KO) rats first } \\
\text { produced using ZFN } \\
\text { technology with high frequency } \\
\text { ( } 25 \text { to } 100 \% \text { disruption); } \\
\text { showing successful germ-line } \\
\text { transmission. }\end{array}$ & $\begin{array}{l}\operatorname{IgM} \\
\operatorname{Rab38}\end{array}$ & $\begin{array}{l}\text { Geurts et al. } \\
(2009) \text { [28] }\end{array}$ \\
\hline $\begin{array}{c}\text { MI } \\
\text { mRNA }\end{array}$ & ZFNs (indels) & $\begin{array}{l}\text { F344/Stm } \\
\text { TM/Kyo }\end{array}$ & $\begin{array}{l}\text { KO rats generated as a model } \\
\text { for X-linked severe combined } \\
\text { immunodeficiency (X-SCID) } \\
\text { with rates greater than } 20 \% \text {; } \\
\text { showing successful germ-line } \\
\text { transmission. }\end{array}$ & $I l 2 r g$ & $\begin{array}{l}\text { Mashimo et al. } \\
\text { (2010) [29] }\end{array}$ \\
\hline $\begin{array}{c}\text { MI } \\
\text { mRNA }\end{array}$ & ZFNs (indels) & SD & $\begin{array}{l}\text { KO rats generated to show the } \\
\text { absence of antibody-mediated } \\
\text { hyperacute allograft rejection; } \\
\text { can be used for biomedical } \\
\text { research. }\end{array}$ & $\operatorname{Ig} M$ & $\begin{array}{l}\text { Ménoret et al. } \\
\text { (2010) [30] }\end{array}$ \\
\hline $\begin{array}{c}\text { MI } \\
\text { mRNA }\end{array}$ & ZFNs (indels) & SS & $\begin{array}{l}\text { Renin-angiotensin } \\
\text { system-related KO rats first } \\
\text { produced. }\end{array}$ & Ren & $\begin{array}{l}\text { Moreno et al. } \\
\text { (2011) [31] }\end{array}$ \\
\hline $\begin{array}{c}\text { MI } \\
\text { mRNA or plasmid } \\
\text { DNA }\end{array}$ & TALENs (indels) & Unknown & $\begin{array}{l}\text { KO rats first produced using } \\
\text { TALEN technology. }\end{array}$ & $\operatorname{Ig} M$ & $\begin{array}{l}\text { Tesson et al. } \\
(2011) \text { [32] }\end{array}$ \\
\hline
\end{tabular}


Table 1. Cont.

\begin{tabular}{|c|c|c|c|c|c|}
\hline $\begin{array}{l}\text { Method for Gene } \\
\text { Modification }\end{array}$ & $\begin{array}{l}\text { GE Tool (Mode } \\
\text { for Gene } \\
\text { Modification) }\end{array}$ & Rat Strain & Outcome & Target Gene & References \\
\hline $\begin{array}{c}\text { MI } \\
\text { mRNA/plasmid } \\
\text { DNA }\end{array}$ & $\begin{array}{l}\mathrm{ZFN} \\
(\mathrm{KI})\end{array}$ & $\begin{array}{l}\text { SD } \\
\mathrm{LEH}\end{array}$ & $\begin{array}{c}\text { Knock-in (KI) rats first } \\
\text { produced using ZFN } \\
\text { technology; showing successful } \\
\text { germ-line transmission of KI } \\
\text { phenotype. }\end{array}$ & $\begin{array}{c}\text { Mdr1a } \\
\operatorname{Pxr}\end{array}$ & $\begin{array}{c}\text { Cui et al. (2011) } \\
\text { [33] }\end{array}$ \\
\hline $\begin{array}{c}\text { MI } \\
\text { mRNA }\end{array}$ & $\begin{array}{l}\text { ZFNs } \\
\text { (indels) }\end{array}$ & F344/Stm WI & $\begin{array}{c}\text { KO rats lacking either } \\
\text { DNA-dependent protein kinase } \\
\text { catalytic subunit (Prkdc) or } \\
\text { Prkdc and interleukin } 2 \text { receptor } \\
\text { gamma (Il2rg) generated; } \\
\text { double knockout (DKO) } \\
\text { F344-scid gamma (FSG) rats } \\
\text { showed more } \\
\text { immunocompromised } \\
\text { phenotypes, such as the } \\
\text { abolishment of natural killer } \\
\text { cells. }\end{array}$ & $\begin{array}{l}\text { Prkdc } \\
I l 2 r g\end{array}$ & $\begin{array}{l}\text { Mashimo et al. } \\
\text { (2012) [34] }\end{array}$ \\
\hline $\begin{array}{c}\text { MI } \\
\text { plasmid DNA }\end{array}$ & $\begin{array}{c}\text { Engineered } \\
\text { meganuclease }\end{array}$ & SD & $\begin{array}{l}\text { KO immunodeficient rats first } \\
\text { produced using meganucleases; } \\
\text { showing decreased numbers of } \\
\text { immature and mature T and B } \\
\text { lymphocytes and normal } \\
\text { natural killer cells. }\end{array}$ & Rag1 & $\begin{array}{l}\text { Ménoret et al. } \\
\text { (2013) [35] }\end{array}$ \\
\hline $\begin{array}{c}\text { MI } \\
\text { mRNA/plasmid } \\
\text { DNA }\end{array}$ & $\begin{array}{l}\text { ZFNs } \\
(\mathrm{KI})\end{array}$ & SD & $\begin{array}{l}\text { LoxP-flanked (floxed) rats first } \\
\text { produced using ZFN } \\
\text { technology; can be useful for } \\
\text { Cre-dependent gene disruption } \\
\text { in vivo. }\end{array}$ & $\begin{array}{l}\text { Grin1 } \\
\text { Crhr1 } \\
\text { Tp53 }\end{array}$ & $\begin{array}{l}\text { Brown et al. } \\
(2013) \text { [36] }\end{array}$ \\
\hline $\begin{array}{c}\text { MI } \\
\text { mRNA/sgRNAs }\end{array}$ & $\begin{array}{l}\text { CRISPR/Cas9 } \\
\text { (indels) }\end{array}$ & SD & $\begin{array}{l}\text { KO rats first produced using } \\
\text { CRISPR/Cas9 technology with } \\
\text { multiple gene mutations } \\
\text { (melanocortin } 3 \text { receptor }(M c 3 r) \\
\text { and melanocortin } 4 \text { receptor } \\
(M c 4 r)) \text { in a germ-line } \\
\text { competent manner. }\end{array}$ & $\begin{array}{l}M c 3 r \\
M c 4 r\end{array}$ & $\begin{array}{c}\text { Li D et al. (2013) } \\
\text { [37] }\end{array}$ \\
\hline $\begin{array}{c}\text { MI } \\
\text { mRNA/sgRNAs }\end{array}$ & $\begin{array}{l}\text { CRISPR/Cas9 } \\
\text { (indels) }\end{array}$ & SD & $\begin{array}{c}\text { KO rats first produced using } \\
\text { CRISPR/Cas9 technology with } \\
\text { multiple gene mutations (Tet } \\
\text { methylcytosine dioxygenase } 1 \\
\text { (Tet1), Tet methylcytosine } \\
\text { dioxygenase } 2 \text { (Tet2) and Tet } \\
\text { methylcytosine dioxygenase } 3 \\
\text { (Tet3)) in a germ-line competent } \\
\text { manner. }\end{array}$ & $\begin{array}{l}\text { Tet1 } \\
\text { Tet2 } \\
\text { Tet3 }\end{array}$ & $\begin{array}{l}\text { Li W et al. (2013) } \\
\text { [38] }\end{array}$ \\
\hline $\begin{array}{c}\text { MI } \\
\text { mRNAs }\end{array}$ & TALENs (indels) & WI & $\begin{array}{l}\text { KO rats generated with a } \\
\text { markedly attenuated response } \\
\text { to a lipopolysaccharide } \\
\text { challenge; can be used as a } \\
\text { model for studying ethanol } \\
\text { action and general } \\
\text { inflammatory conditions } \\
\text { including septic shock. }\end{array}$ & Tlr4 & $\begin{array}{l}\text { Ferguson et al. } \\
\text { (2013) [39] }\end{array}$ \\
\hline
\end{tabular}


Table 1. Cont.

\begin{tabular}{|c|c|c|c|c|c|}
\hline $\begin{array}{l}\text { Method for Gene } \\
\text { Modification }\end{array}$ & $\begin{array}{l}\text { GE Tool (Mode } \\
\text { for Gene } \\
\text { Modification) }\end{array}$ & Rat Strain & Outcome & Target Gene & References \\
\hline $\begin{array}{c}\text { MI } \\
\text { mRNA }\end{array}$ & ZFNs (indels) & SD & $\begin{array}{l}\text { KO rats generated to examine } \\
\text { the roles of aryl hydrocarbon } \\
\text { receptor }(A h r) \text {; showing } \\
\text { alterations to the urinary tract, } \\
\text { including hydronephrosis and } \\
\text { hydroureter; suggesting a role } \\
\text { of } A h r \text { in tissue development, } \\
\text { homeostasis, and toxicity. }\end{array}$ & $A h r$ & $\begin{array}{l}\text { Harrill et al. } \\
\text { (2013) [40] }\end{array}$ \\
\hline $\begin{array}{c}\text { MI } \\
\text { mRNA }\end{array}$ & ZFNs (indels) & SD & $\begin{array}{l}\text { KO rats generated as a model } \\
\text { for hemophilia A; showing a } \\
\text { prolonged activated partial } \\
\text { thromboplastin time and clot } \\
\text { formation time; can be useful } \\
\text { for the study to treat } \\
\text { hemophilia A. }\end{array}$ & F8 & $\begin{array}{l}\text { Nielsen et al. } \\
\text { (2013) [41] }\end{array}$ \\
\hline $\begin{array}{c}\text { MI } \\
\text { mRNA }\end{array}$ & ZFNs (indels) & Unknown & $\begin{array}{l}\text { KO rat lines generated as a } \\
\text { model for autism spectrum } \\
\text { disorder (ASD); showing } \\
\text { abnormalities in ASD-relevant } \\
\text { phenotypes including juvenile } \\
\text { play, perseverative behaviors, } \\
\text { and sensorimotor gating. }\end{array}$ & $\begin{array}{l}\text { Fmrp } \\
\text { Nlgn3 }\end{array}$ & $\begin{array}{l}\text { Hamilton et al. } \\
\text { (2013) [42] }\end{array}$ \\
\hline $\begin{array}{c}\text { In vitro EP } \\
\text { mRNA/gRNA }\end{array}$ & $\begin{array}{l}\text { ZFN (indels) } \\
\text { TALEN (indels) } \\
\text { CRISPR/Cas9 } \\
\text { (indels) }\end{array}$ & F344/Stm & $\begin{array}{c}\text { KO rats first produced using } \\
\text { in vitro electroporation (EP) } \\
\text { (called “Technique for Animal } \\
\text { Knockout system by } \\
\text { Electroporation (TAKE)"); } \\
\text { in vitro EP resulted in an } \\
\text { embryonic survival rate }(91 \%) \\
\text { and a GE rate }(73 \%) .\end{array}$ & Il $2 r g$ & $\begin{array}{l}\text { Kaneko et al. } \\
\text { (2014) [43] }\end{array}$ \\
\hline $\begin{array}{l}\text { MI } \\
\text { mRNA/DNA } \\
\text { donor }\end{array}$ & $\begin{array}{l}\text { TALENs } \\
(\mathrm{KI})\end{array}$ & SD & $\begin{array}{l}\text { Homology-directed repair } \\
\text { (HDR)-modified KI rats } \\
\text { generated with multiple gene } \\
\text { mutations with high efficiency } \\
\quad(0.62 \%-5.13 \%) .\end{array}$ & $\begin{array}{l}\text { Hprt1 } \\
\text { Rosa26 } \\
\text { Ighm }\end{array}$ & $\begin{array}{l}\text { Remy et al. } \\
(2014) \text { [44] }\end{array}$ \\
\hline $\begin{array}{c}\text { MI } \\
\text { mRNA/sgRNAs }\end{array}$ & $\begin{array}{c}\text { CRISPR/Cas9 } \\
(\mathrm{KI})\end{array}$ & SD & $\begin{array}{l}\text { KI rats first generated using } \\
\text { CRISPR/Cas9-based two-cut } \\
\text { strategy with an efficiency up to } \\
54 \% \text {. }\end{array}$ & $\begin{array}{l}\text { Trdmt1 } \\
\text { Nes } \\
\text { Cck }\end{array}$ & $\begin{array}{c}\text { Ma et al. (2014) } \\
\text { [45] }\end{array}$ \\
\hline $\begin{array}{c}\text { MI } \\
\text { mRNA/sgRNAs }\end{array}$ & $\begin{array}{l}\text { CRISPR/Cas9 } \\
\text { (indels, KI) }\end{array}$ & $\begin{array}{c}\text { F344/Stm DA } \\
\text { PVG }\end{array}$ & $\begin{array}{l}\text { Using single-stranded } \\
\text { oligodeoxynucleotide (ssODN) } \\
\text { donor as templates, three } \\
\text { recessive phenotypes (including } \\
\text { the albino phenotype by } \\
\text { single-nucleotide } \\
\text { polymorphism (SNP) exchange, } \\
\text { the non-agouti phenotype by } \\
\text { integration of a 19-bp DNA } \\
\text { fragment, and the hooded } \\
\text { phenotype by removal of a } \\
\text { retrovirus-derived insertional } \\
\text { DNA fragment) were } \\
\text { successfully corrected. }\end{array}$ & $\begin{array}{l}\text { Tyr } \\
\text { Asip } \\
\text { Kit }\end{array}$ & $\begin{array}{l}\text { Yoshimi et al. } \\
\text { (2014) [46] }\end{array}$ \\
\hline
\end{tabular}


Table 1. Cont.

\begin{tabular}{|c|c|c|c|c|c|}
\hline $\begin{array}{l}\text { Method for Gene } \\
\text { Modification }\end{array}$ & $\begin{array}{l}\text { GE Tool (Mode } \\
\text { for Gene } \\
\text { Modification) }\end{array}$ & Rat Strain & Outcome & Target Gene & References \\
\hline $\begin{array}{c}\text { MI } \\
\text { mRNA/sgRNAs }\end{array}$ & $\begin{array}{l}\text { CRISPR/Cas9 } \\
\text { (indels) }\end{array}$ & SD & $\begin{array}{l}\text { KO rats generated with multiple } \\
\text { gene mutations (four genes) in a } \\
\text { germ-line competent manner. }\end{array}$ & $\begin{array}{l}\text { ApoE } \\
\text { B2m } \\
\text { Prf1 } \\
\text { Prkdc }\end{array}$ & $\begin{array}{c}\text { Ma et al. (2014) } \\
\text { [47] }\end{array}$ \\
\hline $\begin{array}{c}\text { MI } \\
\text { mRNAs }\end{array}$ & $\begin{array}{l}\text { ZFNs } \\
\text { (indels) }\end{array}$ & SD & $\begin{array}{l}\text { KO rats generated to examine } \\
\text { the function of estrogen } \\
\text { receptor } 1(E s r 1) \text {; showing } \\
\text { infertility, due to small testes in } \\
\text { males, and large polycystic } \\
\text { ovaries, thread-like uteri, and } \\
\text { poorly developed mammary } \\
\text { glands in females; can be a new } \\
\text { tool for investigating the } \\
\text { pathophysiology of estrogen } \\
\text { action. }\end{array}$ & Esr1 & $\begin{array}{c}\text { Rumi et al. (2014) } \\
\text { [48] }\end{array}$ \\
\hline $\begin{array}{l}\text { MI } \\
\text { mRNAs/DNA } \\
\text { donor }\end{array}$ & $\begin{array}{l}\text { TALENs } \\
(\mathrm{KI})\end{array}$ & SD & $\begin{array}{l}\text { KI rats (carrying a pA476T } \\
\text { mutation) first produced using } \\
\text { TALEN technology with an } \\
\text { efficiency of } 17 \% .\end{array}$ & $N r 3 c 1$ & $\begin{array}{l}\text { Ponce de Leon } \\
\text { et al. (2014) [49] }\end{array}$ \\
\hline $\begin{array}{c}\text { MI } \\
\text { mRNA/gRNAs }\end{array}$ & $\begin{array}{l}\text { CRISPR/Cas9 } \\
\text { (indels) }\end{array}$ & WI-IM & $\begin{array}{l}\text { KO rats generated as a model } \\
\text { for Duchenne muscular } \\
\text { dystrophy (DMD); showing a } \\
\text { decline in muscle strength, and } \\
\text { the emergence of } \\
\text { degenerative/regenerative } \\
\text { phenotypes in the skeletal } \\
\text { muscle, heart, and diaphragm; } \\
\text { can be useful for developing } \\
\text { therapeutic methods to treat } \\
\text { DMD. }\end{array}$ & Dmd & $\begin{array}{l}\text { Nakamura et al. } \\
\text { (2014) [50] }\end{array}$ \\
\hline $\begin{array}{c}\text { MI } \\
\text { mRNA }\end{array}$ & $\begin{array}{l}\text { TALENs } \\
\text { (indels) }\end{array}$ & SD & $\begin{array}{l}\text { KO rats generated as a model } \\
\text { for DMD; showing reduction in } \\
\text { muscle strength and a decrease } \\
\text { in spontaneous motor activity } \\
\text { with dilated cardiomyopathy; } \\
\text { can be useful as an animal } \\
\text { model of DMD. }\end{array}$ & Dmd & $\begin{array}{l}\text { Larcher et al. } \\
\text { (2014) [51] }\end{array}$ \\
\hline $\begin{array}{c}\text { MI } \\
\text { mRNA }\end{array}$ & $\begin{array}{l}\text { ZFNs } \\
\text { (indels) }\end{array}$ & SD & $\begin{array}{l}\text { KO rats generated as a model } \\
\text { for cystic fibrosis (CF); showing } \\
\text { abnormalities in the ileum and } \\
\text { increased intracellular mucus in } \\
\text { the proximal nasal septa as well } \\
\text { as reduced airway surface } \\
\text { liquid and periciliary liquid } \\
\text { depth; recapitulating many } \\
\text { aspects of CF disease. }\end{array}$ & Cftr & $\begin{array}{l}\text { Tuggle et al. } \\
\text { (2014) [52] }\end{array}$ \\
\hline
\end{tabular}


Table 1. Cont.

\begin{tabular}{|c|c|c|c|c|c|}
\hline $\begin{array}{l}\text { Method for Gene } \\
\text { Modification }\end{array}$ & $\begin{array}{l}\text { GE Tool (Mode } \\
\text { for Gene } \\
\text { Modification) }\end{array}$ & Rat Strain & Outcome & Target Gene & References \\
\hline $\begin{array}{c}\text { MI } \\
\text { mRNA }\end{array}$ & $\begin{array}{l}\text { ZFNs } \\
\text { (indels) }\end{array}$ & SD & $\begin{array}{l}\text { KO rats generated to know that } \\
\text { the bone morphogenetic protein } \\
\text { receptor } 2(B m p r 2) \text { mutations } \\
\text { are linked to pulmonary arterial } \\
\text { hypertension (PAH); displaying } \\
\text { an intense pulmonary vascular } \\
\text { remodeling at } 3 \text { months; } \\
\text { suggesting that } \\
\text { endothelial-to-mesenchymal } \\
\text { transition (EndoMT) is linked to } \\
\text { alterations in BPMR2 signaling. }\end{array}$ & Bmpr2 & $\begin{array}{l}\text { Ranchoux et al. } \\
\text { (2015) [53] }\end{array}$ \\
\hline $\begin{array}{c}\text { In vitro EP } \\
\text { mRNA/gRNA/ssODN }\end{array}$ & $\begin{array}{l}\text { CRISPR/Cas9 } \\
\text { N (indels, KI) }\end{array}$ & WI & $\begin{array}{l}\text { KI and KO rats produced } \\
\text { through in vitro EP in the } \\
\text { presence of CRISPR/Cas } 9 \\
\text { components with efficiencies of } \\
33 \% \text { and } 88 \% \text {, respectively. }\end{array}$ & Il $2 \mathrm{rg}$ & $\begin{array}{c}\text { Kaneko and } \\
\text { Mashimo (2015) } \\
\text { [54] }\end{array}$ \\
\hline $\begin{array}{c}\text { MI } \\
\text { mRNAs }\end{array}$ & TALENs (indels) & Unknown & $\begin{array}{l}\text { KO rats generated to examine } \\
\text { the function of cold-inducible } \\
\text { RNA-binding protein (Cirp) in } \\
\text { heart; CIRP modulates cardiac } \\
\text { repolarization by negatively } \\
\text { adjusting the expression and } \\
\text { function of Ito channels. }\end{array}$ & Cirp & $\begin{array}{c}\text { Li et al. (2015) } \\
\text { [55] }\end{array}$ \\
\hline $\begin{array}{c}\text { MI } \\
\text { mRNAs }\end{array}$ & TALENs (indels) & SD & $\begin{array}{c}\text { KO rats displayed typical } \\
\text { dyslipidemia, although no } \\
\text { obvious atherosclerotic lesion } \\
\text { was noted in the enface aortas } \\
\text { and aortic root; can be a novel } \\
\text { model for dyslipidemia and is } \\
\text { used in the research of } \\
\text { atherosclerosis. }\end{array}$ & ApoE & $\begin{array}{l}\text { Wei et al. (2015) } \\
\text { [56] }\end{array}$ \\
\hline $\begin{array}{c}\text { MI } \\
\text { protein/gRNA }\end{array}$ & $\begin{array}{c}\text { CRISPR/Cas9 } \\
\text { (KI) } \\
\text { TALENs } \\
\text { (KI) }\end{array}$ & SD & $\begin{array}{l}\text { Cas9 protein was more efficient } \\
\text { at HDR than Cas } 9 \text { mRNA, while } \\
\text { TALEN protein was less } \\
\text { efficient than TALEN mRNA for } \\
\text { inducing HDR. }\end{array}$ & $\begin{array}{l}\text { Rosa26 } \\
\text { Foxp3 } \\
\text { Anks3 }\end{array}$ & $\begin{array}{l}\text { Ménoret et al. } \\
\text { (2015) [57] }\end{array}$ \\
\hline $\begin{array}{c}\text { MI } \\
\text { protein/sgRNA/DNA } \\
\text { donor }\end{array}$ & $\begin{array}{l}\text { CRISPR/Cas9 } \\
(\mathrm{KI})\end{array}$ & SD & $\begin{array}{l}\text { A DNA cassette (composed of a } \\
\text { green fluorescent protein (GFP) } \\
\text { reporter sequence flanked by } \\
\text { the two pairs of lox sites) was } \\
\text { successfully inserted in the } \\
\text { reverse orientation into the } \\
\text { target (leucine-rich } \\
\text { repeat-containing G-protein } \\
\text { coupled receptor } 5 \text { (Lgr5)) locus, } \\
\text { which was later inverted by } \\
\text { Cre-mediated recombination. }\end{array}$ & $\operatorname{Lgr} 5$ & $\begin{array}{l}\text { Wang et al. } \\
(2015)[58]\end{array}$ \\
\hline
\end{tabular}


Table 1. Cont.

\begin{tabular}{|c|c|c|c|c|c|}
\hline $\begin{array}{l}\text { Method for Gene } \\
\text { Modification }\end{array}$ & $\begin{array}{l}\text { GE Tool (Mode } \\
\text { for Gene } \\
\text { Modification) }\end{array}$ & Rat Strain & Outcome & Target Gene & References \\
\hline $\begin{array}{c}\text { ES cell-mediated } \\
\text { GE } \\
\text { plasmid DNA }\end{array}$ & $\begin{array}{c}\text { CRISPR/Cas9 } \\
(\mathrm{KI})\end{array}$ & ES cells & $\begin{array}{l}\text { The first production of KI rats } \\
\text { using CRISPR/Cas9-engineered } \\
\text { embryonic stem (ES) cells; } \\
\text { in vitro EP of Cas9 plasmid, } \\
\text { sgRNA plasmid, and a KI } \\
\text { vector led to enhanced } \\
\text { homologous recombination } \\
\text { (HR) efficiency up to } 36 \% \text {. }\end{array}$ & Kat II & $\begin{array}{l}\text { Yamamoto et al. } \\
\text { (2015) [14] }\end{array}$ \\
\hline $\begin{array}{c}\text { MI } \\
\text { mRNA/gRNA }\end{array}$ & $\begin{array}{l}\text { CRISPR/Cas9 } \\
\text { (indels) }\end{array}$ & SD & $\begin{array}{l}\text { KO rats generated as a model } \\
\text { for obesity; showing obesity, } \\
\text { hyperphagia, hyperglycemia, } \\
\text { glucose intolerance, } \\
\text { hyperinsulinemia, and } \\
\text { dyslipidemia, as well as a } \\
\text { decrease in bone volume and } \\
\text { bone mineral density of the } \\
\text { femur; can be useful for the } \\
\text { research on obesity and } \\
\text { diabetes. }\end{array}$ & Lepr & $\begin{array}{c}\text { Bao et al. (2015) } \\
\text { [59] }\end{array}$ \\
\hline $\begin{array}{l}\text { SSC-mediated GE } \\
\text { plasmid DNA }\end{array}$ & $\begin{array}{l}\text { CRISPR/Cas9 } \\
\text { (indels) }\end{array}$ & $\begin{array}{l}\text { SD-derived } \\
\text { SSCs }\end{array}$ & $\begin{array}{l}\text { The first creation of } \\
\text { spermatogonial stem cell } \\
\text { (SSC)-derived GE KO rats; } \\
\text { when recipient male rats were } \\
\text { transplanted with engineered } \\
\text { SSCs into seminiferous tubules } \\
\text { (STs), and then mated with } \\
\text { wild-type (WT) females, the } \\
\text { resulting progeny harbored } \\
\text { indels with } \sim 10 \% \text { efficiency. }\end{array}$ & $\begin{array}{l}\text { Epsti1 } \\
\text { Erbb3 }\end{array}$ & $\begin{array}{c}\text { Chapman et al. } \\
\text { (2015) [60] }\end{array}$ \\
\hline $\begin{array}{c}\text { MI } \\
\text { mRNA/sgRNA }\end{array}$ & $\begin{array}{l}\text { CRISPR/Cas9 } \\
\text { (indels) }\end{array}$ & SD & $\begin{array}{l}\text { KO rats generated as a model } \\
\text { for Rett syndrome (RS); } \\
\text { showing body weight loss, } \\
\text { anxiety tendency, and cognitive } \\
\text { deficits; recapitulating the major } \\
\text { symptoms of RS patients. }\end{array}$ & Mecp2 & $\begin{array}{c}\text { Zhai et al. (2016) } \\
\text { [61] }\end{array}$ \\
\hline $\begin{array}{c}\text { MI } \\
\text { mRNA }\end{array}$ & $\begin{array}{l}\text { ZFNs } \\
\text { (indels) }\end{array}$ & SD & $\begin{array}{l}\text { KO rats generated as a model } \\
\text { for RS; showing behavioral and } \\
\text { motor deficits in male and } \\
\text { female rats; can be used in RS } \\
\text { research. }\end{array}$ & Mecp2 & $\begin{array}{l}\text { Patterson et al. } \\
\text { (2016) [62] }\end{array}$ \\
\hline $\begin{array}{c}\text { MI } \\
\text { mRNA/sgRNA }\end{array}$ & $\begin{array}{l}\text { CRISPR/Cas9 } \\
\text { (indels) }\end{array}$ & SD & $\begin{array}{l}\text { KO rats generated as a model } \\
\text { for hereditary tyrosinemia type } \\
\text { I (HT1); showing major } \\
\text { phenotypic manifestations of } \\
\text { human HT1, including } \\
\text { hypertyrosinemia, liver failure, } \\
\text { and renal tubular damage; also } \\
\text { showing remarkable liver } \\
\text { fibrosis and cirrhosis; can be } \\
\text { used as a model of HT1 with } \\
\text { liver cirrhosis. }\end{array}$ & Fah & $\begin{array}{l}\text { Zhang et al. } \\
\text { (2016) [63] }\end{array}$ \\
\hline
\end{tabular}


Table 1. Cont.

\begin{tabular}{|c|c|c|c|c|c|}
\hline $\begin{array}{l}\text { Method for Gene } \\
\text { Modification }\end{array}$ & $\begin{array}{l}\text { GE Tool (Mode } \\
\text { for Gene } \\
\text { Modification) }\end{array}$ & Rat Strain & Outcome & Target Gene & References \\
\hline $\begin{array}{c}\text { MI } \\
\text { mRNA/gRNA/ } \\
\text { lssODN }\end{array}$ & $\begin{array}{c}\text { CRISPR/Cas9 } \\
(\mathrm{KI})\end{array}$ & F344/Stm & $\begin{array}{l}\text { The ssODN-mediated KI rats } \\
\text { were successfully generated } \\
\text { through two-hit by gRNA and } \\
\text { two-oligo with plasmid } \\
\text { (2H2OP) system; can be applied } \\
\text { to any target site with any } \\
\text { donor vector without the need } \\
\text { to construct homology arms, } \\
\text { thus simplifying genome } \\
\text { engineering in living organisms. }\end{array}$ & $\begin{array}{c}\text { Tyr } \\
\text { Thy1 } \\
\text { Rosa26 } \\
\text { Cyp2d } \\
\text { Sirpa }\end{array}$ & $\begin{array}{l}\text { Yoshimi et al. } \\
\text { (2016) [64] }\end{array}$ \\
\hline $\begin{array}{c}\text { MI } \\
\text { mRNA/gRNA/ } \\
\text { ssODN }\end{array}$ & $\begin{array}{l}\text { CRISPR/Cas9 } \\
\text { (KI) }\end{array}$ & SD & $\begin{array}{l}\text { Usage of chemically modified } \\
\text { (phosphorothioate-modified) } \\
\text { ssODN donors is shown to be } \\
\text { effective in improving KI } \\
\text { efficiency. }\end{array}$ & Cftr & $\begin{array}{l}\text { Renaud et al. } \\
\text { (2016) [65] }\end{array}$ \\
\hline $\begin{array}{c}\text { MI } \\
\text { mRNA }\end{array}$ & $\begin{array}{l}\text { TALENs } \\
\text { (indels) }\end{array}$ & SD & $\begin{array}{l}\text { Homozygous KO rats are } \\
\text { embryonically lethal; both male } \\
\text { and female fumarate hydratase } \\
(F h)+/-\mathrm{KO} \text { rats exhibited } \\
\text { reduced litter size; also showing } \\
\text { hematopoietic and kidney } \\
\text { dysfunction; Fh+/- KO rats can } \\
\text { be useful for further functional } \\
\text { fumarate hydratase studies. }\end{array}$ & $F h$ & $\begin{array}{l}\text { Yu et al. (2016) } \\
{[66]}\end{array}$ \\
\hline $\begin{array}{c}\text { MI } \\
\text { mRNA }\end{array}$ & $\begin{array}{l}\text { TALENs } \\
\text { (indels) }\end{array}$ & F344 & $\begin{array}{c}\text { Homozygous KO rats are } \\
\text { embryonically lethal; DEP } \\
\text { domain-containing } 5 \\
(\text { Depdc5)(+/-) rats developed } \\
\text { normally and exhibited no } \\
\text { spontaneous electroclinical } \\
\text { seizures, but had altered cortical } \\
\text { neuron excitability and firing } \\
\text { patterns; can be a model for } \\
\text { mTORopathy. }\end{array}$ & Depdc5 & $\begin{array}{l}\text { Marsan et al. } \\
\text { (2016) [67] }\end{array}$ \\
\hline $\begin{array}{c}\text { MI } \\
\text { protein (or } \\
\text { mRNA)/sgRNA/donor } \\
\text { plasmid }\end{array}$ & $\begin{array}{l}\text { CRISPR/Cas9 } \\
\text { (KI) }\end{array}$ & SD & $\begin{array}{l}\text { Both Scr7 (non-homologous end } \\
\text { joining (NHEJ) inhibitor) and } \\
\text { Cas9 protein were used to } \\
\text { increase KI efficiency; } \\
\text { consequently, this combination } \\
\text { successfully increased the } \\
\text { HR-mediated precise } \\
\text { modification. }\end{array}$ & $\begin{array}{c}\text { Fabp2 } \\
\text { Dbndd1 }\end{array}$ & $\begin{array}{c}\text { Ma et al. (2016) } \\
{[68]}\end{array}$ \\
\hline $\begin{array}{c}\text { MI } \\
\text { mRNA/sgRNAs }\end{array}$ & $\begin{array}{l}\text { CRISPR/Cas9 } \\
\text { (indels) }\end{array}$ & WI & $\begin{array}{l}\text { KO rats generated to examine } \\
\text { the function of forkhead box N1 } \\
\text { (Foxn1) that is known to a } \\
\text { critical factor for differentiation } \\
\text { of thymic and skin epithelial } \\
\text { cells; showing thymus } \\
\text { deficiency and incomplete } \\
\text { hairless. }\end{array}$ & Foxn1 & $\begin{array}{c}\text { Goto et al. (2016) } \\
\text { [69] }\end{array}$ \\
\hline
\end{tabular}


Table 1. Cont.

\begin{tabular}{|c|c|c|c|c|c|}
\hline $\begin{array}{l}\text { Method for Gene } \\
\text { Modification }\end{array}$ & $\begin{array}{l}\text { GE Tool (Mode } \\
\text { for Gene } \\
\text { Modification) }\end{array}$ & Rat Strain & Outcome & Target Gene & References \\
\hline $\begin{array}{c}\text { MI } \\
\text { mRNA/sgRNAs }\end{array}$ & $\begin{array}{l}\text { CRISPR/Cas9 } \\
\text { (indels) }\end{array}$ & SD & $\begin{array}{c}M c 3 r \text { and } M c 4 r \text { single-KO or } \\
\text { DKO rats generated to examine } \\
M c 3 r \text { and } M c 4 r \text { more deeply; } \\
M c 3 r \text { KO rats displayed } \\
\text { hypophagia and decreased } \\
\text { body weight, while } M c 4 r \mathrm{KO} \\
\text { and DKO exhibited } \\
\text { hyperphagia and increased } \\
\text { body weight; both } M c 4 r \text { KO and } \\
\text { DKO are good models for } \\
\text { obesity and diabetes research. }\end{array}$ & $M c 3 r M c 4 r$ & $\begin{array}{c}\text { You et al. (2016) } \\
\text { [70] }\end{array}$ \\
\hline $\begin{array}{c}\text { MI } \\
\text { mRNA }\end{array}$ & $\begin{array}{l}\text { TALENs } \\
\text { (indels) }\end{array}$ & SD & $\begin{array}{l}\text { KO rats generated to evaluate } \\
\text { the role of reduced nuclear } \\
\text { factor (erythroid-derived } \\
\text { 2)-like-2 (NRF2)-regulated } \\
\text { antioxidant defenses; } \\
\text { suppression of NRF2 } \\
\text { antioxidant defenses plays a } \\
\text { role in the development of } \\
\text { salt-induced oxidant stress, } \\
\text { endothelial dysfunction, and } \\
\text { microvessel rarefaction; can be } \\
\text { used as therapeutics to } \\
\text { ameliorate vascular oxidant } \\
\text { stress in humans. }\end{array}$ & Nrf2 & $\begin{array}{l}\text { Priestley et al. } \\
\text { (2016) [71] }\end{array}$ \\
\hline $\begin{array}{c}\text { MI } \\
\text { mRNA }\end{array}$ & $\begin{array}{l}\text { ZFNs } \\
\text { (indels) }\end{array}$ & F344/Stm & $\begin{array}{l}\text { KO rats generated to evaluate } \\
\text { the role of reduced } \\
\text { NRF2-regulated antioxidant } \\
\text { defenses were sensitive to } \\
\text { aflatoxin B1 toxicity; can be a } \\
\text { new model animal in } \\
\text { toxicology. }\end{array}$ & $N r f 2$ & $\begin{array}{l}\text { Taguchi et al. } \\
\text { (2016) [72] }\end{array}$ \\
\hline $\begin{array}{c}\text { MI } \\
\text { mRNA/gRNA }\end{array}$ & $\begin{array}{l}\text { CRISPR/Cas9 } \\
\text { (indels) }\end{array}$ & Unknown & $\begin{array}{l}\text { KO rats generated to investigate } \\
\text { the functions of cytochrome } \\
\text { P450 2E1 (CYP2E1) were viable } \\
\text { and fertile and did not display } \\
\text { any obvious physiological } \\
\text { abnormities; can be a powerful } \\
\text { tool for the study of CYP2E1 in } \\
\text { the chemical metabolism, } \\
\text { toxicity, carcinogenicity. }\end{array}$ & Cyp2e1 & $\begin{array}{l}\text { Wang et al. } \\
(2016) \text { [73] }\end{array}$ \\
\hline $\begin{array}{c}\text { MI } \\
\text { mRNA/gRNA }\end{array}$ & $\begin{array}{l}\text { CRISPR/Cas9 } \\
\text { (indels) }\end{array}$ & WI & $\begin{array}{l}\text { KO rats generated to examine } \\
\text { the function of Mohawk } \\
\text { homeobox }(M k x) \text { in tenogenesis; } \\
\text { showing systemic hypoplasia of } \\
\text { tendons and earlier heterotopic } \\
\text { ossification of the Achilles } \\
\text { tendon; can be used for } \\
\text { studying tendon physiology } \\
\text { and tissue engineering. }\end{array}$ & $M k x$ & $\begin{array}{l}\text { Suzuki et al. } \\
\text { (2016) [74] }\end{array}$ \\
\hline
\end{tabular}


Table 1. Cont.

\begin{tabular}{|c|c|c|c|c|c|}
\hline $\begin{array}{l}\text { Method for Gene } \\
\text { Modification }\end{array}$ & $\begin{array}{l}\text { GE Tool (Mode } \\
\text { for Gene } \\
\text { Modification) }\end{array}$ & Rat Strain & Outcome & Target Gene & References \\
\hline $\begin{array}{c}\text { MI } \\
\text { mRNA }\end{array}$ & $\begin{array}{l}\text { ZFNs } \\
\text { (indels) }\end{array}$ & SD & $\begin{array}{c}\text { KO rats generated as a model } \\
\text { for pseudoxanthoma elasticum, } \\
\text { a heritable ectopic } \\
\text { mineralization disorder; } \\
\text { showing reduced levels of } \\
\text { plasma inorganic } \\
\text { pyrophosphate (PPi), } \\
\text { suggesting a critical role of } \\
\text { hepatic ATP binding cassette } \\
\text { subtype C number } 6 \text { (ABCC6) } \\
\text { in contributing to plasma PPi } \\
\text { levels. }\end{array}$ & $A b c c 6$ & $\begin{array}{l}\text { Li et al. (2017) } \\
\text { [75] }\end{array}$ \\
\hline $\begin{array}{c}\text { MI } \\
\text { mRNA }\end{array}$ & $\begin{array}{l}\text { ZFNs } \\
\text { (indels) }\end{array}$ & SD & $\begin{array}{l}\text { KO rats generated as model of } \\
\text { Wolfram syndrome (WS), a rare } \\
\text { autosomal-recessive disorder } \\
\text { characterized by juvenile-onset } \\
\text { diabetes, optic atrophy, and } \\
\text { hearing loss; exhibiting the core } \\
\text { symptoms of WS. }\end{array}$ & $W f_{s} 1$ & $\begin{array}{c}\text { Plaas et al. (2017) } \\
\text { [76] }\end{array}$ \\
\hline $\begin{array}{c}\text { MI } \\
\text { mRNA/sgRNA }\end{array}$ & $\begin{array}{l}\text { CRISPR/Cas9 } \\
\text { (indels) }\end{array}$ & SD & $\begin{array}{l}\text { KO rats specifically impairs } \\
\text { long-term synaptic plasticity } \\
\text { and hippocampus-dependent } \\
\text { learning in a manner } \\
\text { resembling the key symptoms } \\
\text { of Fragile X syndrome (FXS). }\end{array}$ & Fmr1 & $\begin{array}{c}\text { Tian et al. (2017) } \\
\text { [77] }\end{array}$ \\
\hline $\begin{array}{c}\text { MI } \\
\text { mRNA/gRNA }\end{array}$ & $\begin{array}{l}\text { CRISPR/Cas9 } \\
\text { (indels) }\end{array}$ & Unknown & $\begin{array}{l}\text { KO rats generated to investigate } \\
\text { the role of myosin light-chain } 4 \\
\text { (MYL4) in atrial } \\
\text { cardiomyopathy; showing } \\
\text { progressive atrial } \\
\text { cardiomyopathy; suggesting } \\
\text { that Myl4 is as a key gene } \\
\text { required for atrial contractile, } \\
\text { electrical, and structural } \\
\text { integrity. }\end{array}$ & Myl4 & $\begin{array}{c}\text { Peng et al. (2017) } \\
\text { [78] }\end{array}$ \\
\hline $\begin{array}{c}\text { MI } \\
\text { mRNA }\end{array}$ & TALENs (indels) & SD & $\begin{array}{c}\text { KO rats generated as obese rat } \\
\text { model; showing early onset of } \\
\text { obesity and infertility. }\end{array}$ & Lepr & $\begin{array}{c}\text { Chen et al. (2017) } \\
\text { [79] }\end{array}$ \\
\hline $\begin{array}{c}\text { MI } \\
\text { mRNA/gRNA }\end{array}$ & $\begin{array}{l}\text { CRISPR/Cas9 } \\
\text { (indels) }\end{array}$ & SD & $\begin{array}{l}\text { KO rats generated to determine } \\
\text { the function of patatin-like } \\
\text { phospholipase domain } \\
\text { containing 5 (Pnpla5); were } \\
\text { viable, but showed a variety of } \\
\text { abnormalities related to lipid } \\
\text { metabolism; can be a possibly } \\
\text { model for the treatment of } \\
\text { cardiovascular diseases. }\end{array}$ & Pnpla5 & $\begin{array}{l}\text { Liu et al. (2017) } \\
\text { [80] }\end{array}$ \\
\hline
\end{tabular}


Table 1. Cont.

\begin{tabular}{|c|c|c|c|c|c|}
\hline $\begin{array}{l}\text { Method for Gene } \\
\text { Modification }\end{array}$ & $\begin{array}{l}\text { GE Tool (Mode } \\
\text { for Gene } \\
\text { Modification) }\end{array}$ & Rat Strain & Outcome & Target Gene & References \\
\hline $\begin{array}{c}\text { MI } \\
\text { mRNA }\end{array}$ & $\begin{array}{l}\text { ZFNs } \\
\text { (indels) }\end{array}$ & SD & $\begin{array}{l}\text { KO rats generated as a model } \\
\text { for Phelan-McDermid } \\
\text { syndrome (PMS); exhibit } \\
\text { impaired long-term social } \\
\text { recognition memory and } \\
\text { attention, and reduced synaptic } \\
\text { plasticity in the } \\
\text { hippocampal-medial prefrontal } \\
\text { cortex pathway. }\end{array}$ & Shank3 & $\begin{array}{l}\text { Harony-Nicolas } \\
\text { et al. (2017) [81] }\end{array}$ \\
\hline $\begin{array}{l}\text { MI } \\
\text { mRNA/gRNA (or } \\
\text { mRNA/gRNA/ssODN }\end{array}$ & $\begin{array}{l}\text { CRISPR/Cas9 } \\
\text { N) }\end{array}$ & SS & $\begin{array}{l}\text { GM rats generated to assess the } \\
\text { candidacy of a novel predicted } \\
\text { long non-coding RNA (lncRNA) } \\
\text { showing strong association of } \\
\text { cardiac QT-interval; KO rats } \\
\text { showed aberrant, short } \\
\text { QT-intervals, and elevated } \\
\text { blood pressure; KI rats showed } \\
\text { the rescued phenotype. }\end{array}$ & Rffl-lnc1 & $\begin{array}{l}\text { Cheng et al. } \\
\text { (2017) [82] }\end{array}$ \\
\hline $\begin{array}{c}\text { MI } \\
\text { mRNA }\end{array}$ & TALENs (indels) & SD & $\begin{array}{l}\text { KO rats generated to examine } \\
\text { why rats are naturally resistant } \\
\text { to Schistosoma japonicum } \\
\text { infection; high expression levels } \\
\text { of inducible nitric oxide } \\
\text { synthase (iNOS) in rats play an } \\
\text { important role in blocking the } \\
\text { egg-induced granuloma } \\
\text { formation of } S \text {. japonicum; } \\
\text { providing insights for } \\
\text { understanding the pathogenesis } \\
\text { of human schistosomiasis. }\end{array}$ & iNOS & $\begin{array}{c}\text { Shen et al. (2017) } \\
\text { [83] }\end{array}$ \\
\hline $\begin{array}{c}\text { MI } \\
\text { mRNA }\end{array}$ & $\begin{array}{l}\text { ZFNs } \\
\text { (indels) }\end{array}$ & SS & $\begin{array}{c}\text { KO rats generated to define the } \\
\text { importance of Kir5.1 (encoded } \\
\text { by potassium } \\
\text { inwardly-rectifying channel, } \\
\text { subfamily J, member } 16 \\
(\text { Kcnj16)) in blood pressure } \\
\text { control under salt-induced } \\
\text { hypertension; exhibiting } \\
\text { hypokalemia and reduced } \\
\text { blood pressure, and } 100 \% \\
\text { mortality within a few days } \\
\text { triggered by salt wasting; } \\
\text { demonstrating that Kir5.1 } \\
\text { channels are key regulators of } \\
\text { renal salt handling. }\end{array}$ & Kcnj16 & $\begin{array}{l}\text { Palygin et al. } \\
\text { (2017) [84] }\end{array}$ \\
\hline
\end{tabular}


Table 1. Cont.

\begin{tabular}{|c|c|c|c|c|c|}
\hline $\begin{array}{l}\text { Method for Gene } \\
\text { Modification }\end{array}$ & $\begin{array}{l}\text { GE Tool (Mode } \\
\text { for Gene } \\
\text { Modification) }\end{array}$ & Rat Strain & Outcome & Target Gene & References \\
\hline $\begin{array}{c}\text { ES cell-mediated } \\
\text { GE } \\
\text { plasmid }\end{array}$ & $\begin{array}{l}\text { CRISPR/Cas9 } \\
(\mathrm{KI})\end{array}$ & ES cells & $\begin{array}{l}\text { KI rats derived from the } \\
\text { CRISPR/Cas9-engineered ES } \\
\text { cells; two clones showing } \\
\text { non-disruptive KI of Discosoma } \\
\text { coral red fluorescent protein } \\
\text { (dsRed) at the Sry-box } \\
\text { transcription factor } 10 \text { (Sox10) } \\
\text { locus produced germ-line } \\
\text { chimeras; showing expression } \\
\text { of } d s \text { Red in the Sox10-expressing } \\
\text { cells (oligodendrocyte lineage } \\
\text { cells) in vivo. }\end{array}$ & Sox10 & $\begin{array}{c}\text { Chen et al. (2017) } \\
\text { [15] }\end{array}$ \\
\hline $\begin{array}{c}\text { MI } \\
\text { mRNA/gRNA }\end{array}$ & $\begin{array}{l}\text { CRISPR/Cas9 } \\
\text { (indels) }\end{array}$ & SD & $\begin{array}{l}\text { DKO rats generated to } \\
\text { investigate cytochrome P450 3A } \\
\text { (CYP3A) functions; were viable } \\
\text { and fertile, and had no obvious } \\
\text { physiological abnormities; can } \\
\text { be a powerful tool for the study } \\
\text { of the physiological and } \\
\text { pharmacological roles of } \\
\text { CYP3A, especially in drug and } \\
\text { chemical metabolism in vivo. }\end{array}$ & $\begin{array}{l}\text { Сур3a1 } \\
\text { Сyp3a2 }\end{array}$ & $\begin{array}{l}\text { Lu et al. (2017) } \\
\text { [85] }\end{array}$ \\
\hline $\begin{array}{c}\text { MI } \\
\text { mRNA }\end{array}$ & $\begin{array}{c}\text { ZFNs } \\
\text { (indels) }\end{array}$ & $\mathrm{BN}$ & $\begin{array}{l}\text { KO rats generated as a model } \\
\text { for autoimmune } \\
\text { polyendocrinopathy- } \\
\text { candidiasis-ectodermal } \\
\text { dystrophy (APECED); } \\
\text { displaying several of the key } \\
\text { symptoms of APECED, } \\
\text { including alopecia, skin } \\
\text { depigmentation, and nail } \\
\text { dystrophy }\end{array}$ & Aire & $\begin{array}{l}\text { Ossart et al. } \\
(2018) \text { [86] }\end{array}$ \\
\hline $\begin{array}{c}\text { MI } \\
\text { mRNA/gRNA/ssODN }\end{array}$ & $\begin{array}{l}\text { CRISPR/Cas9 } \\
\mathrm{N} \quad(\mathrm{KI})\end{array}$ & SD & $\begin{array}{l}\text { KI rats (carrying a Fused in } \\
\text { sarcoma (Fus)-point mutation } \\
\text { (R521C)) generated as a model } \\
\text { for amyotrophic lateral sclerosis } \\
\text { (ALS); developing adult-onset } \\
\text { learning and memory } \\
\text { behavioral deficits cognitive } \\
\text { impairment; suggesting a new } \\
\text { role of FUS in sleep and } \\
\text { circadian regulation. }\end{array}$ & Fus & $\begin{array}{l}\text { Zhang et al. } \\
(2018) \text { [87] }\end{array}$ \\
\hline $\begin{array}{c}\text { MI } \\
\text { mRNA }\end{array}$ & TALENs (indels) & SD & $\begin{array}{c}\text { Immunodeficient rats with } \\
\text { DKO rats generated for } \\
\text { obtaining more profound } \\
\text { immunosuppressed phenotype; } \\
\text { can be useful as recipients for } \\
\text { long-term studies concerning } \\
\text { tissue humanization of different } \\
\text { tissues. }\end{array}$ & $\begin{array}{l}I l 2 r g \\
\operatorname{Rag} 1\end{array}$ & $\begin{array}{l}\text { Ménoret et al. } \\
\text { (2018) [88] }\end{array}$ \\
\hline
\end{tabular}


Table 1. Cont.

\begin{tabular}{|c|c|c|c|c|c|}
\hline $\begin{array}{l}\text { Method for Gene } \\
\text { Modification }\end{array}$ & $\begin{array}{l}\text { GE Tool (Mode } \\
\text { for Gene } \\
\text { Modification) }\end{array}$ & Rat Strain & Outcome & Target Gene & References \\
\hline $\begin{array}{c}\text { MI } \\
\text { mRNA/gRNA }\end{array}$ & $\begin{array}{l}\text { CRISPR/Cas9 } \\
\text { (indels) }\end{array}$ & F344/Stm & $\begin{array}{l}\text { KO rats generated to clarify the } \\
\text { roles of angiopoietin-like } \\
\text { protein } 8 \text { (ANGPTL8) in glucose } \\
\text { and lipid metabolism; showing } \\
\text { lower body weight and fat } \\
\text { content, associated with } \\
\text { impaired lipogenesis in } \\
\text { adipocytes; can be an important } \\
\text { therapeutic target for obesity } \\
\text { and dyslipidemia. }\end{array}$ & Angptls & $\begin{array}{l}\text { Izumi et al. } \\
(2018) \text { [89] }\end{array}$ \\
\hline $\begin{array}{c}\text { i-GONAD } \\
\text { protein/gRNA (or } \\
\text { pro- } \\
\text { tein/gRNA/ssODN) }\end{array}$ & $\begin{array}{l}\text { CRISPR/Cas9 } \\
\text { (indels, KI) }\end{array}$ & $\begin{array}{l}\text { SD } \\
\text { LEW } \\
\text { BN }\end{array}$ & $\begin{array}{c}\text { Improved GONAD ( } i \text {-GONAD) } \\
\text { was found useful for producing } \\
\text { KO and KI rats with efficiencies } \\
\text { of } 62 \text { to } 97 \% \text { and } 9 \%, \\
\text { respectively. }\end{array}$ & $\begin{array}{c}\text { Tyr } \\
\text { Sox16 }\end{array}$ & $\begin{array}{l}\text { Takabayashi et al. } \\
\text { (2018) [90] }\end{array}$ \\
\hline $\begin{array}{c}\text { i-GONAD } \\
\text { (rGONAD) } \\
\text { protein/gRNA (or } \\
\text { pro- } \\
\text { tein/gRNA/ssODN) }\end{array}$ & $\begin{array}{l}\text { CRISPR/Cas9 } \\
\text { (indels, KI) }\end{array}$ & $\begin{array}{l}\text { WKY } \\
\text { DA }\end{array}$ & $\begin{array}{l}\text { Most suitable condition for } \\
\text { in vivo gene delivery towards } \\
\text { rat preimplantation embryos } \\
\text { was assessed; } i \text {-GONAD was } \\
\text { found useful for producing KO } \\
\text { and KI rats with relative high } \\
\text { efficiency. }\end{array}$ & Tyr & $\begin{array}{l}\text { Kobayashi et al. } \\
\text { (2018) [91] }\end{array}$ \\
\hline $\begin{array}{c}\text { MI } \\
\text { mRNA/gRNA }\end{array}$ & $\begin{array}{l}\text { CRISPR/Cas9 } \\
\text { (indels) }\end{array}$ & Unknown & $\begin{array}{c}\text { DKO rats (lacking both } \\
\text { apolipoprotein E }(A p o E) \text { and } \\
\text { low-density lipoprotein receptor } \\
(L d l r)) \text { generated as a model for } \\
\text { familial hypercholesterolemia; } \\
\text { showing hypercholesterolemia, } \\
\text { hepatosteatosis, and } \\
\text { atherosclerosis. }\end{array}$ & $\begin{array}{l}\text { ApoE } \\
\text { Ldlr }\end{array}$ & $\begin{array}{c}\text { Zhao et al. (2018) } \\
\text { [92] }\end{array}$ \\
\hline $\begin{array}{c}\text { MI } \\
\text { mRNA/gRNA }\end{array}$ & $\begin{array}{l}\text { CRISPR/Cas9 } \\
\text { (indels) }\end{array}$ & SD & $\begin{array}{l}\text { KO rats generated to investigate } \\
\text { whether Cas9 nickase } \\
\text { (Cas9n)-mediated GE can } \\
\text { efficiently correct the HT1; } \\
\text { tail-vein injection of adenoviral } \\
\text { vectors carrying Cas9n, repair } \\
\text { donor template, and sgRNA } \\
\text { successfully corrected the } \\
\text { phenotype of } \\
\text { fumarylacetoacetate hydrolase } \\
\text { (Fah) KO rats. }\end{array}$ & Fah & $\begin{array}{c}\text { Shao et al. (2018) } \\
\text { [93] }\end{array}$ \\
\hline $\begin{array}{c}\text { MI } \\
\text { mRNA/gRNA }\end{array}$ & $\begin{array}{l}\text { CRISPR/Cas9 } \\
\text { (indels) }\end{array}$ & Unknown & $\begin{array}{l}\text { KO rats generated as a model } \\
\text { for primary hyperoxaluria type } \\
1 \text { (PH1); showing crystalluria } \\
\text { with abnormal phenotypes, } \\
\text { such as a slight dilatation of } \\
\text { renal tubules with mild fibrosis } \\
\text { in the kidney; suggesting } \\
\text { impairment of glyoxylic acid } \\
\text { metabolism; can be a useful tool } \\
\text { for the development and } \\
\text { evaluation of drugs and } \\
\text { therapeutics. }\end{array}$ & Agxt & $\begin{array}{l}\text { Zheng et al. } \\
\text { (2018) [94] }\end{array}$ \\
\hline
\end{tabular}


Table 1. Cont.

\begin{tabular}{|c|c|c|c|c|c|}
\hline $\begin{array}{l}\text { Method for Gene } \\
\text { Modification }\end{array}$ & $\begin{array}{l}\text { GE Tool (Mode } \\
\text { for Gene } \\
\text { Modification) }\end{array}$ & Rat Strain & Outcome & Target Gene & References \\
\hline $\begin{array}{c}\text { In vitro EP } \\
\text { (protein/gRNAs/lss }\end{array}$ & $\begin{array}{l}\text { CRISPR/Cas9 } \\
\text { ONA) (KI) }\end{array}$ & F344 & $\begin{array}{l}\text { Efficient approaches enabling } \\
\text { the quick generation of floxed } \\
\text { alleles in mice and rats were } \\
\text { taken using in vitro EP in the } \\
\text { presence of Cas9 protein, } \\
\text { gRNAs, and long } \\
\text { single-stranded DNA (lssDNA); } \\
\text { homozygous KI oocytes } \\
\text { carrying tissue-specific Cre gene } \\
\text { were successfully obtained with } \\
\text { high efficiency. }\end{array}$ & $V a p b$ & $\begin{array}{l}\text { Miyasaka et al. } \\
\text { (2018) [95] }\end{array}$ \\
\hline $\begin{array}{c}\text { MI } \\
\text { mRNA/sgRNA }\end{array}$ & $\begin{array}{l}\text { CRISPR/Cas9 } \\
\text { (indels) }\end{array}$ & SD & $\begin{array}{l}\text { KO rats generated as a model } \\
\text { for RNase T2 deficiency; } \\
\text { showing no evidence of cystic } \\
\text { lesions, but hippocampal } \\
\text { neuroinflammation, altered } \\
\text { lysosomal function, and } \\
\text { cognitive defects; can be a } \\
\text { useful model to study the } \\
\text { RNase T2 function. }\end{array}$ & RNase T2 & $\begin{array}{l}\text { Sinkevicius et al. } \\
\text { (2018) [96] }\end{array}$ \\
\hline $\begin{array}{c}\text { MI } \\
\text { mRNA/sgRNA }\end{array}$ & $\begin{array}{l}\text { ABEs } \\
\text { (indels) }\end{array}$ & Unknown & $\begin{array}{l}\text { KO rats generated as a model } \\
\text { for Glycogen storage disease } \\
\text { type II (GSDII) with an } \\
\text { efficiency of } 85 \% \text {; the adenine } \\
\text { base editor (ABE) system is a } \\
\text { powerful and convenient tool to } \\
\text { introduce precise base } \\
\text { conversions in rodents. }\end{array}$ & Gaa & $\begin{array}{c}\text { Yang et al. (2018) } \\
\text { [97] }\end{array}$ \\
\hline $\begin{array}{c}\text { MI } \\
\text { plasmid DNA }\end{array}$ & $\begin{array}{l}\text { CRISPR/Cas9 } \\
\text { (indels) }\end{array}$ & DA & $\begin{array}{l}\text { KO rats generated as a model } \\
\text { for Fabry disease (FD); showing } \\
\text { substantial serum and tissue } \\
\text { accumulation of } \alpha \text {-galactosyl } \\
\text { glycosphingolipids and had } \\
\text { pronounced mechanical pain } \\
\text { behavior. }\end{array}$ & $\alpha$-Gal $A$ & $\begin{array}{l}\text { Miller et al. } \\
(2018) \text { [98] }\end{array}$ \\
\hline $\begin{array}{c}\text { MI } \\
\text { mRNA }\end{array}$ & TALENs (indels) & SD & $\begin{array}{l}\text { Oxoglutarate dehydrogenase } \\
(O g d h)-/- \text { rats are lethal; } \\
\text { Ogdh+/- rats had higher body } \\
\text { weight; treatment of } O g d h+/- \\
\text { rats with a high-fat diet resulted } \\
\text { in liver dysfunction; } O g d h+/- \\
\text { rats can be used as model for } \\
\text { investigations of metabolic } \\
\text { syndrome and obesity-related } \\
\text { hepatic carcinogenesis. }\end{array}$ & $O g d h$ & $\begin{array}{c}\text { Fan et al. (2018) } \\
\text { [99] }\end{array}$ \\
\hline $\begin{array}{c}\text { MI } \\
\text { mRNA }\end{array}$ & $\begin{array}{l}\text { ZFNs } \\
\text { (indels) }\end{array}$ & WI & $\begin{array}{l}\text { KO rats developed normally, } \\
\text { but exhibited spontaneous } \\
\text { locomotor hyperactivity and } \\
\text { cognitive dysfunctions; can be a } \\
\text { model for human diseases } \\
\text { involving aberrant dopamine } \\
\text { functions. }\end{array}$ & Dat & $\begin{array}{l}\text { Leo et al. (2018) } \\
\text { [100] }\end{array}$ \\
\hline
\end{tabular}


Table 1. Cont.

\begin{tabular}{|c|c|c|c|c|c|}
\hline $\begin{array}{l}\text { Method for Gene } \\
\text { Modification }\end{array}$ & $\begin{array}{l}\text { GE Tool (Mode } \\
\text { for Gene } \\
\text { Modification) }\end{array}$ & Rat Strain & Outcome & Target Gene & References \\
\hline $\begin{array}{c}\text { MI } \\
\text { plasmid }\end{array}$ & $\begin{array}{l}\text { CRISPR/Cas9 } \\
\text { (indels) }\end{array}$ & $\begin{array}{c}\text { F344 } \\
\text { SD }\end{array}$ & $\begin{array}{l}\text { KO rats generated to know the } \\
\text { role of complement in } \\
\text { chemotherapy-induced } \\
\text { peripheral neuropathy (CIPN); } \\
\text { suggesting that complement } \\
\text { may be a new target for the } \\
\text { development of novel } \\
\text { therapeutics to manage CIPN. }\end{array}$ & C3 & $\begin{array}{c}\text { Xu et al. (2018) } \\
\text { [101] }\end{array}$ \\
\hline $\begin{array}{l}\text { SSC-mediated GE } \\
\text { plasmid }\end{array}$ & TALENs (indels) & $\begin{array}{l}\text { SD-derived } \\
\text { SSCs }\end{array}$ & $\begin{array}{l}\text { SSCs-derived GE KO rats } \\
\text { showed immunodeficiency with } \\
\text { lacked mature B and T cells; } \\
\text { allowing growth of human } \\
\text { tumors; can be used for } \\
\text { xenograft studies. }\end{array}$ & Rag2 & $\begin{array}{c}\text { Noto et al. (2018) } \\
\text { [102] }\end{array}$ \\
\hline $\begin{array}{c}\text { MI } \\
\text { mRNA/sgRNAs }\end{array}$ & $\begin{array}{l}\text { CRISPR/Cas9 } \\
\text { (indels) }\end{array}$ & Unknown & $\begin{array}{l}\text { Multiple-gene KO rats } \\
\text { generated to examine the } \\
\text { function of defensin beta (Defb) } \\
\text { expressed abundantly in the } \\
\text { epididymis; showing } \\
\text { subfertility and decreased } \\
\text { motility of sperm; suggesting } \\
\text { that Defb family members affect } \\
\text { sperm maturation by a } \\
\text { synergistic pattern in the } \\
\text { epididymis. }\end{array}$ & $\begin{array}{c}\text { Defb23 Defb26 } \\
\text { Defb42 }\end{array}$ & $\begin{array}{l}\text { Zhang et al. } \\
\text { (2018) [103] }\end{array}$ \\
\hline $\begin{array}{c}\text { MI } \\
\text { mRNA/sgRNA }\end{array}$ & $\begin{array}{c}\mathrm{ABE} \\
\text { (indels) }\end{array}$ & SD & $\begin{array}{l}\text { For hemogen (Hemgn) targeting, } \\
\text { out of } 15 \text { rats obtained, } 14 \\
\text { contained an A to G conversion } \\
\text { at the } 14 \text { th base distal from the } \\
\text { protospacer adjacent motif } \\
\text { (PAM), indicating the high } \\
\text { base-editing efficiency. }\end{array}$ & $\begin{array}{l}\text { Hemgn } \\
\text { Ndst1 } \\
\text { Ndst4 }\end{array}$ & $\begin{array}{c}\text { Ma et al. (2018) } \\
\text { [104] }\end{array}$ \\
\hline $\begin{array}{c}\text { MI } \\
\text { mRNA/sgRNA }\end{array}$ & $\begin{array}{l}\text { CRISPR/Cas9 } \\
\text { (indels) }\end{array}$ & SD & $\begin{array}{l}\text { KO rats generated to assess the } \\
\text { roles of cytochrome P450, } \\
\text { subfamily 2, polypeptide } 11 \\
\text { (CYP2C11); were viable and had } \\
\text { no obvious abnormalities, with } \\
\text { the exception of reduced } \\
\text { fertility; can be a valuable tool } \\
\text { to study the in vivo function of } \\
\text { CYP2C11. }\end{array}$ & Cyp2c11 & $\begin{array}{l}\text { Wei et al. (2018) } \\
\text { [105] }\end{array}$ \\
\hline $\begin{array}{c}\text { MI } \\
\text { mRNA/gRNA (or } \\
\text { mRNA/gRNA } \\
\text { ssODN) }\end{array}$ & $\begin{array}{l}\text { CRISPR/Cas9 } \\
\text { (indels, KI) }\end{array}$ & Unknown & $\begin{array}{l}\text { KI (carrying F508del mutation) } \\
\text { and KO rats generated as a } \\
\text { model for CF; both rats exhibit } \\
\text { CF phenotypic anomalies such } \\
\text { as vas deferens agenesis and } \\
\text { tooth enamel defects; can be } \\
\text { used as a novel resource to } \\
\text { advance the development of CF } \\
\text { therapeutics. }\end{array}$ & Cftr & $\begin{array}{l}\text { Dreano et al. } \\
(2019) \text { [106] }\end{array}$ \\
\hline
\end{tabular}


Table 1. Cont.

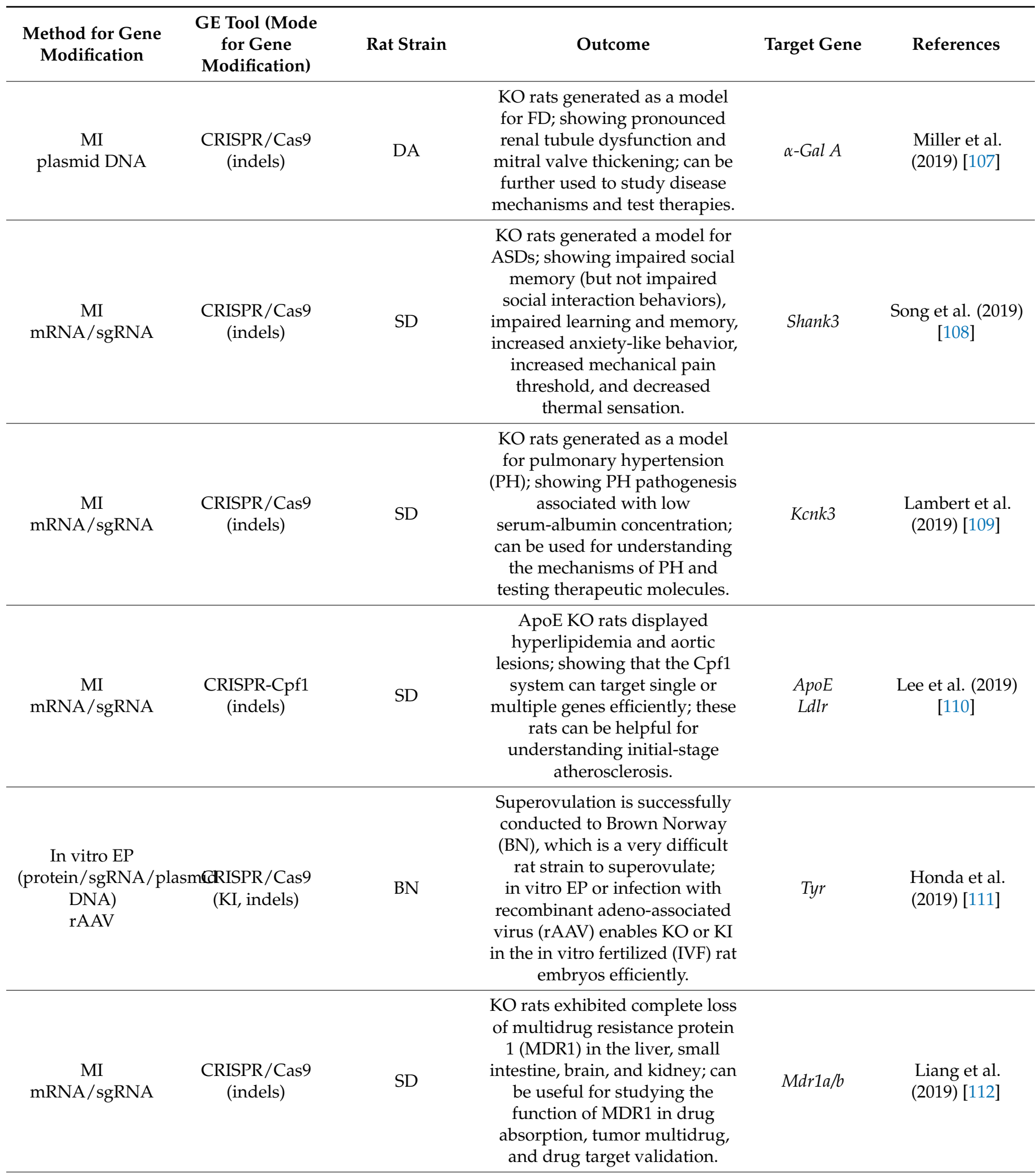


Table 1. Cont.

\begin{tabular}{|c|c|c|c|c|c|}
\hline $\begin{array}{l}\text { Method for Gene } \\
\text { Modification }\end{array}$ & $\begin{array}{l}\text { GE Tool (Mode } \\
\text { for Gene } \\
\text { Modification) }\end{array}$ & Rat Strain & Outcome & Target Gene & References \\
\hline $\begin{array}{c}\text { MI } \\
\text { protein/sgRNA }\end{array}$ & $\begin{array}{l}\text { CRISPR/Cas9 } \\
\text { (indels) }\end{array}$ & SD & $\begin{array}{c}\text { KO rats generated as a model } \\
\text { for X-linked hydrocephalus } \\
\text { (XLH); hemizygous male } \\
\text { mutants developed } \\
\text { hydrocephalus and delayed } \\
\text { development. }\end{array}$ & L1cam & $\begin{array}{l}\text { Emmert et al. } \\
(2019) \text { [113] }\end{array}$ \\
\hline $\begin{array}{c}\text { MI } \\
\text { mRNA/sgRNA/ssODN }\end{array}$ & $\begin{array}{l}\text { CRISPR/Cas9 } \\
N \quad \text { (KI) }\end{array}$ & SD & $\begin{array}{c}\text { KI rats (carrying a R571X } \\
\text { mutation) generated to mimic } \\
\text { Cockayne syndrome (CS); } \\
\text { showing atrophy and } \\
\text { dysmyelination in the cerebellar } \\
\text { cortex; RNA-seq suggests that } \\
\text { transcription dysregulation } \\
\text { could contribute to the CS } \\
\text { pathogenesis. }\end{array}$ & Csb & $\begin{array}{c}\text { Xu et al. (2019) } \\
\text { [114] }\end{array}$ \\
\hline
\end{tabular}

$\mathrm{KO}$ rats generated to understand the mechanisms leading to iron excess in $\mathrm{HA}$; showing decreased iron concentration and transferrin saturation; suggesting that the reported role of ceruloplasmin $(C p)$ cannot fully explain the iron hepatosplenic phenotype in hereditary

aceruloplasminemia (HA).

$\mathrm{KO}$ rats generated as a model for PAH; showing age-dependent spontaneous $\mathrm{PAH}$ with a low penetrance $(16 \%-27 \%)$, similar to that in humans; can be a promising tool to study the pathogenesis of PAH.

$\mathrm{KO}$ rats generated to examine the role of 5-hydroxytryptamine receptor 7 (Htr7) in blood pressure regulation; neither the male nor female $\mathrm{KO}$ rats were
In vitro EP protein/gRNA

CRISPR/Cas9
(indels)
(indels)
SD different in body size, fat weights, or mass of organs (kidney, heart, and brain) important to blood pressure; can be used to investigate the importance of $\mathrm{Htr} 7$ in blood pressure regulation.
$\mathrm{KI}$ rats generated to create $\mathrm{a}$ conditional glucocorticoid receptors (GR) knockdown using a dual sgRNA strategy; affording high-precision variety of contexts, ranging from neuronal depletion to circuit-wide manipulations. knockdown of GR across a
Bmpr2 Hautefort et al (2019) [116]
Cp $\quad \begin{aligned} & \text { Kenawi et al. } \\ & \text { (2019) [115] }\end{aligned}$
mRNA/two sgRNAs/donor plasmid containing two flanking loxP sites

CRISPR/Cas9
(KI)


Table 1. Cont.

\begin{tabular}{|c|c|c|c|c|c|}
\hline $\begin{array}{l}\text { Method for Gene } \\
\text { Modification }\end{array}$ & $\begin{array}{l}\text { GE Tool (Mode } \\
\text { for Gene } \\
\text { Modification) }\end{array}$ & Rat Strain & Outcome & Target Gene & References \\
\hline $\begin{array}{c}\text { MI } \\
\text { mRNA/ } \\
\text { sgRNA/donor } \\
\text { plasmid }\end{array}$ & $\begin{array}{l}\text { CRISPR/Cas9 } \\
(\mathrm{KI})\end{array}$ & LE & $\begin{array}{l}\text { Two KI rat lines (D1-Cre and } \\
\text { A2a-Cre) generated for } \\
\text { Cre-mediated gene } \\
\text { manipulation; will be used to } \\
\text { study both normal brain } \\
\text { functions and neurological and } \\
\text { psychiatric pathophysiology. }\end{array}$ & $\begin{array}{c}\text { Drd1a } \\
\text { Adora2a }\end{array}$ & $\begin{array}{l}\text { Pettibone et al. } \\
\text { (2019) [119] }\end{array}$ \\
\hline $\begin{array}{c}\text { MI } \\
\text { mRNA/gRNA }\end{array}$ & $\begin{array}{l}\text { CRISPR/Cas9 } \\
\text { (indels) }\end{array}$ & SS & $\begin{array}{l}\text { KO rats generated as a model } \\
\text { for hemophilia; showing } \\
\text { spontaneous bleeding in the } \\
\text { soft tissue, muscles, or joints } \\
\text { occurred in } 100 \% \text { of factor } 8 \\
(F 8)-/- \text { rats; bone marrow } \\
\text { reconstitution rescued the } \\
\text { spontaneous bleeding in rat HA } \\
\text { hemophilia. }\end{array}$ & F8 & $\begin{array}{c}\text { Shi et al. (2020) } \\
\text { [120] }\end{array}$ \\
\hline $\begin{array}{c}i \text {-GONAD } \\
\text { protein/gRNAs }\end{array}$ & $\begin{array}{l}\text { CRISPR/Cas9 } \\
\text { (indels) }\end{array}$ & $\mathrm{BN}$ & $\begin{array}{l}i \text {-GONAD under EP conditions } \\
\text { with current values ranging } \\
\text { from } 150 \text { to } 200 \mathrm{~mA} \text { enabled } \\
\text { production of } \mathrm{KO} \text { rats with } \\
\text { efficiencies ranging from } 75 \% \text { to } \\
24 \% \text {. }\end{array}$ & Tyr & $\begin{array}{l}\text { Takabayashi et al. } \\
\text { (2020) [121] }\end{array}$ \\
\hline $\begin{array}{c}\text { MI } \\
\text { mRNA/gRNA }\end{array}$ & $\begin{array}{l}\text { CRISPR/Cas9 } \\
\text { (indels) }\end{array}$ & SD & $\begin{array}{l}\text { KO rats generated as a model } \\
\text { for Angelman syndrome (AS); } \\
\text { showing deficits in motor } \\
\text { coordination as well as learning } \\
\text { and memory, phenotypically } \\
\text { mirroring human AS; can be a } \\
\text { model for the study of AS. }\end{array}$ & Ube3a & $\begin{array}{l}\text { Dodge et al. } \\
(2020)[122]\end{array}$ \\
\hline $\begin{array}{c}\text { MI } \\
\text { mRNA/gRNA }\end{array}$ & $\begin{array}{l}\text { CRISPR/Cas9 } \\
\text { (indels) }\end{array}$ & SD & $\begin{array}{l}\text { KO rats generated to explore } \\
\text { the function of complexin I } \\
\text { (Cplx1); showing a complex } \\
\text { neurobehavioral phenotype } \\
\text { including profound ataxia, } \\
\text { dystonia, movement and } \\
\text { exploratory deficits, and } \\
\text { increased anxiety and sensory } \\
\text { deficits, but had normal } \\
\text { cognitive function. }\end{array}$ & Cplx1 & $\begin{array}{c}\text { Xu et al. (2020) } \\
\text { [123] }\end{array}$ \\
\hline $\begin{array}{c}\text { MI } \\
\text { mRNA (or pro- } \\
\text { tein)/gRNAs/plasmid } \\
\text { donor }\end{array}$ & $\begin{array}{l}\text { Cas12a/Cpf1 } \\
\text { (MAD7) } \\
\text { (indels, KI) }\end{array}$ & SD & $\begin{array}{l}\text { MAD7 is capable of generating } \\
\text { indels, small DNA insertion, } \\
\text { and fluorescent gene tagging of } \\
\text { endogenous genes, such as } \\
\text { Cas9; causing indels with } 20 \% \\
\text { efficiency in rats; MAD7 can } \\
\text { expand the CRISPR toolbox for } \\
\text { genome engineering. }\end{array}$ & Calb2 & $\begin{array}{l}\text { Liu et al. (2020) } \\
\text { [124] }\end{array}$ \\
\hline
\end{tabular}


Table 1. Cont.

\begin{tabular}{|c|c|c|c|c|c|}
\hline $\begin{array}{l}\text { Method for Gene } \\
\text { Modification }\end{array}$ & $\begin{array}{l}\text { GE Tool (Mode } \\
\text { for Gene } \\
\text { Modification) }\end{array}$ & Rat Strain & Outcome & Target Gene & References \\
\hline $\begin{array}{c}\text { In vitro EP } \\
\text { mRNA/gRNA (or } \\
\text { mRNA/gRNA/ } \\
\text { lssDNA) }\end{array}$ & $\begin{array}{l}\text { CRISPR/Cas9 } \\
\text { (indels, KI) }\end{array}$ & LE & $\begin{array}{l}\text { KO rats generated to know the } \\
\text { role of glutamate decarboxylase } \\
1 \text { (GAD1) deficiency in } \\
\text { pathogenesis of schizophrenia; } \\
\text { showing complex behavioral } \\
\text { changes, such as hypoactivity in } \\
\text { a novel environment and } \\
\text { decreased preference for social } \\
\text { novelty; can be a model for } \\
\text { studying the mechanism of } \\
\text { schizophrenia. }\end{array}$ & Gad1 & $\begin{array}{l}\text { Fujihara et al. } \\
(2020)[125]\end{array}$ \\
\hline $\begin{array}{c}\text { MI } \\
\text { protein/sgRNA/ssODN }\end{array}$ & $\begin{array}{l}\text { CRISPR/Cas9 } \\
\mathrm{N} \quad(\mathrm{KI})\end{array}$ & SD & $\begin{array}{l}\text { KI rats (carrying a R350P } \\
\text { mutation) generated as a model } \\
\text { for desminopathy; showing the } \\
\text { phenotype of desminopathy; } \\
\text { can be a useful tool for } \\
\text { understanding of the disease } \\
\text { and testing therapeutic } \\
\text { approaches to delay disease } \\
\text { progression. }\end{array}$ & Des & $\begin{array}{l}\text { Langer et al. } \\
(2020) \text { [126] }\end{array}$ \\
\hline
\end{tabular}

KI rats (carrying a D205N mutation) generated as a model for primary hyperoxaluria type 1 (PH1); showing hyperoxaluria $\begin{array}{ccc}\text { MI } & \text { CRISPR/Cas9 } & \text { at } 1 \text { month of age and exhibited } \\ \text { mRNA/sgRNA/ssODN } & \text { severe renal calcium oxalate } \\ & & \text { deposition after ethylene glycol } \\ & \text { challenge; can be a useful model } \\ & \text { for understanding the disease } \\ & \text { and developing therapeutics. }\end{array}$

Agxt Zheng et al. (2020) [127]
$\mathrm{KO}$ rats generated a model for hyperuricemia; were apparently healthy with more than a $95 \%$ survival up to one year and showed renal abnormality such as mild glomerular/tubular lesions; can be useful for studying hyperuricemia.

$\begin{array}{cc}\text { MI } & \begin{array}{c}\text { CRISPR/Cas9 } \\ \text { (indels) }\end{array}\end{array}$

MI

mRNA/sgRNA (or mRNA/sgRNA/ssODN) ${ }^{(\mathrm{KI}, \text { indels) }}$
Cytochrome P450 family 27 subfamily B member 1

(Cyp27b1) KO, vitamin D receptor $(V d r) \mathrm{KO}$, and $V d r \mathrm{KI}$ (carrying a R270L mutation) rats generated as a model for human type II rickets; showing growth retardation and abnormal bone formation; can be useful for elucidating the molecular mechanism of vitamin D action.

$\begin{array}{cc}\text { Cyp27b1 } & \text { Nishikawa et al. } \\ V d r & (2020)[129]\end{array}$

[128] 
Table 1. Cont.

\begin{tabular}{|c|c|c|c|c|c|}
\hline $\begin{array}{l}\text { Method for Gene } \\
\text { Modification }\end{array}$ & $\begin{array}{l}\text { GE Tool (Mode } \\
\text { for Gene } \\
\text { Modification) }\end{array}$ & Rat Strain & Outcome & Target Gene & References \\
\hline $\begin{array}{c}\text { MI } \\
\text { mRNA/donor } \\
\text { DNA }\end{array}$ & $\begin{array}{l}\text { ZFNs } \\
(\mathrm{KI})\end{array}$ & SD & $\begin{array}{l}\text { KI rats (carrying a G551D } \\
\text { variant) generated as a model } \\
\text { for CF; showing that the } \\
\text { epithelia recapitulates the } \\
\text { expected absence of cystic } \\
\text { fibrosis transmembrane } \\
\text { conductance regulator (CFTR) } \\
\text { activity, which was restored } \\
\text { with ivacaftor, a medication } \\
\text { used to treat CF. }\end{array}$ & Cftr & $\begin{array}{l}\text { Birket et al. } \\
(2020) \text { [130] }\end{array}$ \\
\hline $\begin{array}{c}\text { In vitro EP } \\
\text { protein/gRNA }\end{array}$ & $\begin{array}{l}\text { CRISPR/Cas9 } \\
\text { (indels) }\end{array}$ & SD & $\begin{array}{l}\text { KO rats generated to investigate } \\
\text { the role of monocarboxylate } \\
\text { transporter } 8 \text { (MCT8) (encoded } \\
\text { by solute carrier family } 16 \\
\text { member } 2 \text { coding for } \\
\text { monocarboxylate transporter } 8 \\
\text { (Slc16a2)) during } \\
\text { spermatogenesis; showing } \\
\text { growth delay during postnatal } \\
\text { development with reduced } \\
\text { sperm motility and viability; } \\
\text { suggesting the role of MCT8 in } \\
\text { spermatogenesis. }\end{array}$ & Slc16a2 & $\begin{array}{c}\text { Bae et al. (2020) } \\
\text { [131] }\end{array}$ \\
\hline $\begin{array}{c}\text { MI } \\
\text { mRNA }\end{array}$ & $\begin{array}{l}\text { ZFNs } \\
\text { (indels) }\end{array}$ & WI & $\begin{array}{l}\text { KO rats generated to examine } \\
\text { whether dopamine plays a key } \\
\text { role in sexual behavior; } \\
\text { showing more rapid acquisition } \\
\text { of stable sexual activity levels } \\
\text { and to higher levels of sexual } \\
\text { motivation and activity; can be } \\
\text { confirmed that dopamine has a } \\
\text { key role in sexual behavior. }\end{array}$ & Dat & $\begin{array}{l}\text { Sanna et al. } \\
(2020) \text { [132] }\end{array}$ \\
\hline $\begin{array}{c}\text { MI } \\
\text { mRNA/sgRNA }\end{array}$ & $\begin{array}{l}\text { CRISPR/Cas9 } \\
\text { (indels) }\end{array}$ & SD & $\begin{array}{l}\text { KO rats generated to enable } \\
\text { more sophisticated modeling of } \\
\text { pain, itch, and asthma; showing } \\
\text { apparently normal behavioral } \\
\text { responses to pain and itch, } \\
\text { although transient receptor } \\
\text { potential family member } \\
\text { ankyrin } 1 \text { (TRPA1)-dependent } \\
\text { immune cell infiltration into the } \\
\text { lung was seen under the } \\
\text { asthma-inducing condition; } \\
\text { useful for studying that TRPA1 } \\
\text { can be as a drug target. }\end{array}$ & Trpa1 & $\begin{array}{c}\text { Reese et al. (2020) } \\
\text { [133] }\end{array}$ \\
\hline $\begin{array}{c}\text { MI } \\
\text { mRNA/sgRNA }\end{array}$ & $\begin{array}{l}\text { CRISPR/Cas9 } \\
\text { (indels) }\end{array}$ & SD & $\begin{array}{l}\text { KO rats generated to study the } \\
\text { function of cytochrome P450 } \\
\text { family } 2 \text { subfamily J (Cyp2J) } \\
\text { isoform genes in vivo; were } \\
\text { viable and fertile; can be a } \\
\text { useful tool to study the function } \\
\text { of Cyp2J in drug metabolism } \\
\text { and cardiovascular disease. }\end{array}$ & $\begin{array}{l}\text { Сур2J2 } \\
\text { Сyp2J3 } \\
\text { Сyp2J10 }\end{array}$ & $\begin{array}{l}\text { Lu et al. (2020) } \\
\text { [134] }\end{array}$ \\
\hline
\end{tabular}


Table 1. Cont.

\begin{tabular}{|c|c|c|c|c|c|}
\hline $\begin{array}{l}\text { Method for Gene } \\
\text { Modification }\end{array}$ & $\begin{array}{l}\text { GE Tool (Mode } \\
\text { for Gene } \\
\text { Modification) }\end{array}$ & Rat Strain & Outcome & Target Gene & References \\
\hline $\begin{array}{c}\text { MI } \\
\text { mRNA }\end{array}$ & TALENs (indels) & F344 & $\begin{array}{l}\text { KO rats generated to study the } \\
\text { role of coiled-coil domain } \\
\text { containing } 85 C(C c d c 85 c) \text { in the } \\
\text { pathogenesis of spontaneous } \\
\text { hydrocephalus shown in } \\
\text { hemorrhagic hydrocephalus ( } h h y) \\
\text { mice; showing non-obstructive } \\
\text { hydrocephalus, subcortical } \\
\text { heterotopia, and intracranial } \\
\text { hemorrhage; suggesting a role } \\
\text { of } C c d c 85 c \text { in cerebral } \\
\text { development. }\end{array}$ & Ccdc85c & $\begin{array}{l}\text { Konishi et al. } \\
(2020) \text { [135] }\end{array}$ \\
\hline $\begin{array}{c}\text { MI } \\
\text { mRNA/gRNA/ssODN }\end{array}$ & $\begin{array}{l}\text { CRISPR/Cas9 } \\
\mathrm{N} \quad(\mathrm{KI})\end{array}$ & LE & $\begin{array}{l}\text { KI rats (carrying a Psen1LF } \\
\text { mutation) generated to } \\
\text { determine potential early } \\
\text { pathogenic changes caused by } \\
\text { this mutation; survived into } \\
\text { adulthood; showing increased } \\
\text { levels of } A \beta 43 \text {, a longer and } \\
\text { potentially more amyloidogenic } \\
\text { A } \beta \text { form. }\end{array}$ & Psen1 & $\begin{array}{c}\text { Tambini and } \\
\text { D'Adamio (2020) } \\
{[136]}\end{array}$ \\
\hline $\begin{array}{c}\text { MI } \\
\text { protein/sgRNAs/dono } \\
\text { DNA }\end{array}$ & $\begin{array}{c}\text { or CRISPR/Cas9 } \\
(\mathrm{KI})\end{array}$ & SD & $\begin{array}{l}\text { KI rats (carrying GGGGCC } \\
\text { (G4C2) repeats) generated as a } \\
\text { model for ALS; showing motor } \\
\text { deficits from } 4 \text { months of age; } \\
\text { can be used for investigating } \\
\text { the neurotoxicity in } \\
\text { chromosome } 9 \text { open reading } \\
\text { frame } 72 \text { (C9orf } 72 \text { )-related ALS. }\end{array}$ & C9orf72 & $\begin{array}{c}\text { Dong et al. (2020) } \\
\text { [137] }\end{array}$ \\
\hline $\begin{array}{c}\text { MI } \\
\text { protein/sgRNAs/dono } \\
\text { DNA }\end{array}$ & 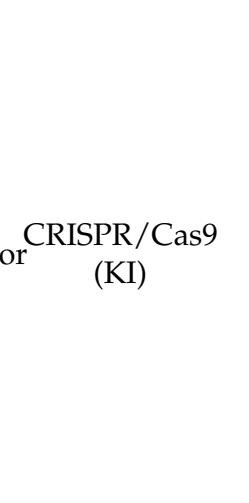 & SD & $\begin{array}{l}\text { KI rats generated as a model for } \\
\text { the Mediterranean SNP } \\
\text { G6PDS188F; showing } \\
\text { glucose-6-phosphate } \\
\text { dehydrogenase (G6PD) activity, } \\
\text { but not expression, was reduced } \\
\text { to } 20 \% \text { of WT littermates; } \\
\text { replacement of a single amino } \\
\text { acid (S188F) in G6PD, a } \\
\text { rate-limiting enzyme in the } \\
\text { pentose phosphate pathway, } \\
\text { may be related to pathogenesis } \\
\text { of vascular diseases. }\end{array}$ & G6pd & $\begin{array}{l}\text { Kitagawa et al. } \\
(2020)[138]\end{array}$ \\
\hline
\end{tabular}


Table 1. Cont.

\begin{tabular}{|c|c|c|c|c|c|}
\hline $\begin{array}{l}\text { Method for Gene } \\
\text { Modification }\end{array}$ & $\begin{array}{l}\text { GE Tool (Mode } \\
\text { for Gene } \\
\text { Modification) }\end{array}$ & Rat Strain & Outcome & Target Gene & References \\
\hline $\begin{array}{c}\text { MI } \\
\text { mRNA/sgRNA }\end{array}$ & $\begin{array}{l}\text { CRISPR/Cas9 } \\
\text { (indels) }\end{array}$ & SD & $\begin{array}{l}\text { KO rats generated to examine } \\
\text { the role of solute carrier organic } \\
\text { anion transporter family } \\
\text { member 1B2 (Slco1b2); in those } \\
\text { rats, the serum levels of } \\
\text { bilirubin and bile acids, the } \\
\text { substrates of organic anion } \\
\text { transporting polypeptide } \\
\text { organic anion transport } \\
\text { polypeptide 1b2 (OATP1B2), } \\
\text { increased; can be a disease } \\
\text { model to study } \\
\text { hyperbilirubinemia-related } \\
\text { diseases. }\end{array}$ & Slco1b2 & $\begin{array}{c}\text { Ma et al. (2020) } \\
\text { [139] }\end{array}$ \\
\hline
\end{tabular}

A new powerful method, called

Combi-CRISPR, was developed

for achieving plasmid-based KI in rat embryos using the

MI, in vitro EP mRNA/sgRNAs/dsDNARISPR/Cas9 donor vectors (or (KI)

F344 mRNA/sgRNAs/lssDNA)
CRISPR/Cas9 system; in other words, this method is the combination of highly efficient editing via NHEJ and the low-efficiency but precise editing via HDR.
Effects of 3 gRNAs (which recognize different portions of the target locus, but also overlap each other in the target locus) and of commercially available KI-enhancing drugs on the KI efficiency; KI efficiency largely depends on the type of gRNA used; none of drugs are significantly effective for KI efficiency.

$\begin{array}{cc}\begin{array}{c}\text { i-GONAD } \\ \text { protein/gRNA/ssODN }\end{array} & \begin{array}{c}\text { CRISPR/Cas9 } \\ \text { (KI) }\end{array} \\ & \\ \text { MI } & \text { CRISPR/Cas9 } \\ \text { protein/gRNA (or } \\ \text { pro- } \\ \text { tein/gRNA/ssODN) }\end{array}$

MI

mRNA/sgRNA
SD

$\mathrm{BN}$

WI

$\mathrm{KO}$ rats generated as a model for retinal dystrophy (RD); showing reduced vision and structural abnormalities, such as overall retinal thinning; can be new animal model for retinal dystrophy.

$\begin{array}{cc}\text { Pvalb } & \text { Yoshimi et al. } \\ \text { Th } & \text { (2021) [140] }\end{array}$

$\mathrm{KO}$ rats generated to investigate cytochrome P450 family 24 subfamily A member 1

(CYP24A1)-dependent or -independent metabolism of $25(\mathrm{OH}) \mathrm{D}_{3}$, the prohormone of (2021) [141] calcitriol; found to be valuable for metabolic studies of vitamin

Koster et al. (2021) [142] $\begin{array}{ll}\text { Cyp24a1 } & \text { Yasuda et al. } \\ \text { (2021) [143] }\end{array}$ 
Table 1. Cont.

\begin{tabular}{|c|c|c|c|c|c|}
\hline $\begin{array}{l}\text { Method for Gene } \\
\text { Modification }\end{array}$ & $\begin{array}{l}\text { GE Tool (Mode } \\
\text { for Gene } \\
\text { Modification) }\end{array}$ & Rat Strain & Outcome & Target Gene & References \\
\hline $\begin{array}{l}\text { In vitro EP } \\
\text { mRNA }\end{array}$ & TALENs (indels) & SD & $\begin{array}{l}\text { KO rats generated to elucidate } \\
\text { the functions of NK3 homeobox } \\
1 \text { (Nkx3.1); showing reduced } \\
\text { fertility, decreased prostate } \\
\text { weights, and increased } \\
\text { epithelial cell layers; can be a } \\
\text { model for studying the role of } \\
\text { Nkx3.1 in decreased prostate } \\
\text { weights, fertility, and breast } \\
\text { cancer, as well as in prostate } \\
\text { cancer. }\end{array}$ & $N k \times 3.1$ & $\begin{array}{c}\text { Lee et al. (2021) } \\
{[144]}\end{array}$ \\
\hline $\begin{array}{c}\text { MI } \\
\text { mRNA/sgRNA }\end{array}$ & $\begin{array}{l}\text { CRISPR/Cas9 } \\
\text { (indels) }\end{array}$ & Unknown & $\begin{array}{l}\text { KO rats generated to elucidate } \\
\text { the roles of } \\
\text { alpha/beta-hydrolase domain } 6 \\
\text { (ABHD6) in vivo; showing } \\
\text { normal appearance, but caused } \\
\text { more frequent urination in the } \\
\text { stimulated bladder. }\end{array}$ & Abhd6 & $\begin{array}{l}\text { Noguchi et al. } \\
\text { (2021) [145] }\end{array}$ \\
\hline $\begin{array}{c}\text { MI } \\
\text { plasmid }\end{array}$ & $\begin{array}{l}\text { CRISPR/Cas9 } \\
\text { (indels) }\end{array}$ & SS & $\begin{array}{l}\text { KO rats lacking adaptor protein } \\
1 \text { (shc1), encodes } 3 \text { main protein } \\
\text { isoforms ( } p 52 S h c \text { and } p 46 S h c \\
\text { isoforms) generated to further } \\
\text { investigate the function of } S h c 1 \text {; } \\
\text { showing severe gait } \\
\text { abnormalities accompanied by } \\
\text { dilated cardiomyopathy. }\end{array}$ & $\begin{array}{l}\text { p52Shc } \\
\text { p46Shc }\end{array}$ & $\begin{array}{l}\text { Miller et al. } \\
(2021) \text { [146] }\end{array}$ \\
\hline $\begin{array}{c}\text { MI } \\
\text { mRNA/sgRNAs }\end{array}$ & $\begin{array}{l}\text { CRISPR/Cas9 } \\
\text { (indels) }\end{array}$ & WI & $\begin{array}{l}\text { KO rats generated to investigate } \\
\text { the in vivo roles of carnosine } \\
\text { synthase } 1 \text { (Carns1); showing a } \\
\text { significant impairment of } \\
\text { contractile function in the } \\
\text { cardiac muscle; suggesting a } \\
\text { role of high-cholesterol diet } \\
\text { (HCD) in the regulation of } \mathrm{Ca}^{2+} \\
\text { handling and } \\
\text { excitation-contraction coupling } \\
\text { of cardiac muscle. }\end{array}$ & Carns1 & $\begin{array}{c}\text { de Souza } \\
\text { Gonçalves et al. } \\
(2021) \text { [147] }\end{array}$ \\
\hline $\begin{array}{c}\text { MI } \\
\text { mRNA/sgRNAs }\end{array}$ & $\begin{array}{l}\text { CRISPR/Cas9 } \\
\text { (indels) }\end{array}$ & SD & $\begin{array}{l}\text { KO rats generated to examine } \\
\text { the function of transient } \\
\text { receptor potential cation } \\
\text { channel subfamily V member } 4 \\
\text { (Trpv4) in regulating } \\
\text { osteoarthritic pain; showing } \\
\text { suppression of joint pain under } \\
\text { the monoiodoacetate-induced } \\
\text { osteoarthritic pain model; } \\
\text { suggesting that inhibition of } \\
\text { TRPV4 might be a novel potent } \\
\text { analgesic strategy for treating } \\
\text { osteoarthritic pain. }\end{array}$ & Trpv4 & $\begin{array}{c}\text { Soga et al. (2021) } \\
{[148]}\end{array}$ \\
\hline
\end{tabular}


Table 1. Cont.

\begin{tabular}{|c|c|c|c|c|c|}
\hline $\begin{array}{l}\text { Method for Gene } \\
\text { Modification }\end{array}$ & $\begin{array}{l}\text { GE Tool (Mode } \\
\text { for Gene } \\
\text { Modification) }\end{array}$ & Rat Strain & Outcome & Target Gene & References \\
\hline $\begin{array}{c}\text { MI } \\
\text { mRNA/sgRNAs }\end{array}$ & $\begin{array}{l}\text { CRISPR/Cas9 } \\
\text { (indels) }\end{array}$ & SD & $\begin{array}{l}\text { KO rats generated to examine } \\
\text { the function of transient } \\
\text { receptor potential cation } \\
\text { channel subfamily V member } 4 \\
\text { (Trpv4) in regulating } \\
\text { osteoarthritic pain; showing } \\
\text { suppression of joint pain under } \\
\text { the monoiodoacetate-induced } \\
\text { osteoarthritic pain model; } \\
\text { suggesting that inhibition of } \\
\text { TRPV4 might be a novel potent } \\
\text { analgesic strategy for treating } \\
\text { osteoarthritic pain. }\end{array}$ & Trpv4 & $\begin{array}{c}\text { Soga et al. (2021) } \\
{[148]}\end{array}$ \\
\hline $\begin{array}{c}\text { MI } \\
\text { mRNA/sgRNAs }\end{array}$ & $\begin{array}{l}\text { CRISPR/Cas9 } \\
\text { (indels) }\end{array}$ & SD & $\begin{array}{l}\text { KO rats generated to examine } \\
\text { the role of carboxylesterase } 2 \mathrm{~A} \\
\text { (Ces } 2 a \text { ) in drug metabolism } \\
\text { mediated by carboxylesterase } 2 \\
\text { (CES2); showing obesity, insulin } \\
\text { resistance, and liver fat } \\
\text { accumulation, which are } \\
\text { consistent with the symptoms } \\
\text { of nonalcoholic fatty liver } \\
\text { disease (NAFLD); can be used } \\
\text { as a model for NAFLD. }\end{array}$ & Ces $2 a$ & $\begin{array}{c}\text { Liu et al. (2021) } \\
\text { [149] }\end{array}$ \\
\hline
\end{tabular}

$\mathrm{MI}$

protein/two

plasmids (one containing gRNA and the other containing CreERT2-mCherry cassette as donor plasmid)
Generation of six Cre driver rats allowing for the controlled gene expression or conditional $\mathrm{KO}$ in a temporal and spatial manner through the Cre-ERT2/loxP system.
Wnt1

Pomc

Mnx1

Drd1a

Gad67

Tie2
Zhang et al. (2021) [150]

\begin{tabular}{|c|c|c|c|c|c|}
\hline $\begin{array}{c}\text { MI } \\
\text { mRNA/gRNA/ssODN }\end{array}$ & $\begin{array}{l}\text { CRISPR/Cas9 } \\
(\mathrm{KI})\end{array}$ & $\begin{array}{c}\text { SD } \\
\text { F344 }\end{array}$ & $\begin{array}{l}\text { KI rats (carrying a T300A } \\
\text { mutation) generated as a model } \\
\text { for Crohn's disease (CD); } \\
\text { showing morphological } \\
\text { abnormalities in both Paneth } \\
\text { and goblet cells, but do not } \\
\text { develop spontaneous intestinal } \\
\text { permeability or inflammatory } \\
\text { bowel disease; can be used for } \\
\text { the study of both autophagy } \\
\text { and CD susceptibility. }\end{array}$ & Atg16l1 & $\begin{array}{l}\text { Chesney et al. } \\
\text { (2021) [151] }\end{array}$ \\
\hline $\begin{array}{c}\text { MI } \\
\text { mRNA/gRNA }\end{array}$ & $\begin{array}{l}\text { CRISPR/Cas9 } \\
\text { (indels) }\end{array}$ & SD & $\begin{array}{l}\text { KO rats generated to examine } \\
\text { the function of dynein } \\
\text { axonemal heavy chain } 17 \\
\text { (Dnah17) in spermatogenesis; } \\
\text { showing infertility with } \\
\text { significantly decreased number } \\
\text { of sperm; DNAH17 is critical } \\
\text { for spermatogenesis. }\end{array}$ & Dnah17 & $\begin{array}{c}\text { Chen et al. (2021) } \\
\text { [152] }\end{array}$ \\
\hline
\end{tabular}


Table 1. Cont.

\begin{tabular}{|c|c|c|c|c|c|}
\hline $\begin{array}{l}\text { Method for Gene } \\
\text { Modification }\end{array}$ & $\begin{array}{c}\text { GE Tool (Mode } \\
\text { for Gene } \\
\text { Modification) }\end{array}$ & Rat Strain & Outcome & Target Gene & References \\
\hline $\begin{array}{c}\text { MI } \\
\text { PB vector carrying } \\
\text { DdCBE pair } / \mathrm{PB} \\
\text { transposase } \\
\text { mRNA }\end{array}$ & $\begin{array}{c}\text { DdCBE } \\
\text { (gene correction) }\end{array}$ & SD & $\begin{array}{l}\text { DddA-derived cytosine base } \\
\text { editor (DdCBE) was applied to } \\
\text { explore the possible production } \\
\text { of GE rats as a mitochondrial } \\
\text { disease model with pathogenic } \\
\text { mitochondrial DNA (mtDNA) } \\
\text { mutations; MI of piggyBack } \\
\text { transposon (PB) vector carrying } \\
\text { DdCBE pair with PB } \\
\text { transposase mRNA resulted in } \\
\text { production of pups with } \\
\text { mtDNA mutations with } 36 \% \\
\text { efficiency. }\end{array}$ & G7755 & $\begin{array}{l}\text { Qi et al. (2021) } \\
\text { [153] }\end{array}$ \\
\hline
\end{tabular}

\section{Delivery Method}

For the production of GE rats, the choice of the delivery method for GE components in rat zygotes is important. The methods for the production of GE rats achieved by delivering GE reagents can be largely divided into six groups: the first is MI of GE reagents (in the form of DNA, mRNA, or protein) into the cytoplasm or nucleus of a zygote (Figure 1A); the second is in vitro EP of zygotes in the presence of GE reagents (Figure 1B); the third is in vivo EP of zygotes after instillation of GE reagents into the oviductal lumen of a pregnant female (Figure 1C); the fourth is in vitro viral infection of zygotes with recombinant adenoassociated virus (rAAV) (Figure 1D); the fifth is SSC-mediated production of GE rats (Figure 1E); the sixth is ES cell-mediated production of GE rats (Figure 1F).

In the following sections, each of these methods is described in detail.

\subsection{MI-Based Production of GE Rats}

Since the first development of pronuclear MI in mice by Gordon et al. [154], numerous GM mice and other animals such as rats, pigs, cows, and nonhuman primates have been created (reviewed by Clark et al. [155]). These animals are mainly produced by the introduction of exogenous DNA called "transgene", which comprises a tissue-specific or ubiquitous promoter, intron, cDNA as a gene of interest (GOI), and polyadenine tails (poly(A) site), into a male pronucleus of a zygote. The mode of transgene integration into the host chromosomes is generally random, leading to frequent transgene silencing. In contrast with this transgenic (Tg) system, GE-based modulation of endogenous target genes does not always require the chromosomal integration of the GE components.

In 2009, ZFN-based GE in rats was first reported by Guerts et al. [28], who performed a single pronuclear injection (PI) of plasmid DNA (ranging from 0.4 to $10 \mathrm{ng} / \mu \mathrm{L}$ ) or mRNA (ranging from 0.4 to $10 \mathrm{ng} / \mu \mathrm{L}$ ) or intracytoplasmic injection (IC) of mRNA (from 2 to $10 \mathrm{ng} / \mu \mathrm{L}$ ) encoding ZFNs in rat zygotes (from Dahl salt-sensitive (SS), Sprague-Dawley (SD), or Fawn-hooded hypertensive (FHH) strains) to induce indels in different target genes (coding for integrated reporter green fluorescent protein (GFP), immunoglobulin M (IgM), or Ras-related protein Rab-38 (Rab38)). The PN of mRNA, PN of plasmid DNA, or IC of mRNA resulted in production of pups with the GE efficiencies of $5-29 \%, 6-11 \%$, or $6-75 \%$, respectively. These GE efficiencies shown in this first study accelerated the researchers to generate more numbers of GM rats with these technologies. For example, rat models for X-linked severe combined immunodeficiency (X-SCID) were successfully created by PI of mRNAs encoding custom-designed ZFNs (targeted to interleukin 2 receptor gamma (Il2rg) locus) with GE efficiencies of over $20 \%$ [29].

In 2011, TALEN-based GE in rats was first reported by Tesson et al. [32], who intended to disrupt the rat $I g M$ locus to create heritable mutations that could eliminate $I g M$ function. 
Seven out of seventy-four (10\%) rat zygotes injected with plasmid DNA $(0.4$ to $10 \mathrm{ng} / \mu \mathrm{L})$ and $51 / 88(58 \%)$ of rat embryos injected with mRNA (4 and $10 \mathrm{ng} / \mu \mathrm{L})$ were modified at IgM. Of the IgM-mutated mRNA-injected rats, the frequency of biallelically modified rats was dose-dependent: $8 / 15(53 \%)$ of rats injected with $10 \mathrm{ng} / \mu \mathrm{L} \mathrm{mRNA}, 5 / 27$ (19\%) at $4 \mathrm{ng} / \mu \mathrm{L}$, and none at $0.8 \mathrm{ng} / \mu \mathrm{L}$.

In 2011, the 2nd wave of production of ZFN-based GE was brought by Cui et al. [33], who developed a conditional KI system in rats. They used ZFN technology in embryos to introduce sequence-specific modifications (KI) through homologous recombination (HR) in SD and Long-Evans (LE) rats. Briefly, Cui et al. [33] first constructed donors with an eight-base pair (bp) Not I restriction site inserted between the ZFN-binding sites, flanked by $\sim 800$ bp of immediate homology on each side. Donor plasmid DNA $(1 \mathrm{ng} / \mu \mathrm{L})$ and respective ZFN mRNA $(2.5 \mathrm{ng} / \mu \mathrm{L})$ were co-injected into the pronucleus of rat zygotes. The loci targeted were rat multidrug resistance protein $1 \mathrm{a}(M d r 1 a)$ and pregnane $\times$ receptor (Pxr) loci. When ZFN-treated fetuses were examined, 1 of $15(7 \%)$ and 1 of $8(13 \%)$ were GM fetuses with KI at the Mdr1a or Pxr loci, respectively. Notably, successful germline transmission of the indel mutations that occurred in the born founder rats was also confirmed. Next, they constructed GFP donors, replacing the Not I site with a 1.5-kilobase $(\mathrm{kb})$ human phosphoglycerate kinase $(P G K)$ promoter-driven GFP cassette. GFP is in the opposite orientation of transcription for the rat $M d r 1 a$ and Pxr loci. In the case of MI with GFP cassette into the Mdr1a locus of SD rats, of the 439 embryos transferred to recipients, 83 pups were born, and $2(2 \%)$ were pups with successful KI and $21(25 \%)$ were those having NHEJ-based mutations, suggesting that NHEJ occurs at a higher rate than targeted integration. In the eyes of founder Mdr1a pup No. 3, PGK-GFP was expressed and visually detectable.

In contrast, Brown et al. [36] first provided a system enabling the conditional ablation of a target gene by the ZFN/Cre system through MI of ZFNs into rat zygotes. Briefly, they first generated GM rats with loxP-flanked (floxed) alleles at the glutamate ionotropic receptor N-methyl-D-aspartate (NMDA) type subunit 1 (Grin1) or corticotropin releasing hormone receptor 1 (Crhr1) locus by co-injecting mRNA encoding two pairs of ZFNs for each gene and two donors (plasmids carrying the fragment in which loxP site is surrounded by left homology arm (800 bp) and right homology arm (800 bp) in both sides) for each target into the pronucleus of zygotes. Each ZFN pair cleaved in an intron flanking the exons of interest and delivered one loxP site. In case of Grin1 targeting, among 80 live births, 6 (8\%) were identified as those containing loxP in both insertion sites. Additionally, 48 animals had single loxP insertions, and another 17 had only NHEJ events. Brown et al. [36] also generated a GM rat expressing Cre under the control of an endogenous tyrosine hydroxylase (Th) promoter by inserting an internal ribosomal entry site (IRES)-Cre cassette immediately after the translational stop site of the Th open reading frame by pronuclear $\mathrm{MI}$ of a pair of ZFNs along with a donor plasmid. Of the 41 live-born pups, 9 (22\%) were founders. Through crossing between these two lines (the floxed line and the Cre-expressing line), Cre-dependent and tissue-specific gene disruption successfully occurred in vivo in the bigenic offspring.

In 2013, the production of GE rats using the CRISPR/Cas9 system was reported [37,38]. This CRISPR/Cas9 system enables multigene KO in one shot of gene delivery to mice [156,157]. This property is especially beneficial for the purpose of creating disease model animals, as certain types of diseases are known to be caused by multigene defects. Li et al. [37] first attempted to generate $\mathrm{KO}$ rats with multiple mutations (at least in two different genes) using a CRISPR/Cas9 system. They injected two sgRNAs (12.5 ng/ $\mu \mathrm{L}$ for each) (targeting rat melanocortin 3 receptor $(M c 3 r)$ and melanocortin 4 receptor $(M c 4 r))$ and Cas 9 mRNA $(25 \mathrm{ng} / \mu \mathrm{L})$ into rat zygotes. The efficiency of indel formation caused by the Cas 9 nuclease was considerably different because 13 of 15 (87\%) F0 pups exhibited the KO phenotype for $M c 4 r$, while 1 of 15 (7\%) exhibited the KO phenotype for Mc3r. The authors concluded that a single injection can induce disruption of at least two different genes in the rat and also suggested that targeting efficiency depends on the choice of suitable gRNA. Furthermore, 
$\mathrm{Li}$ et al. [37] first demonstrated successful germ-line transmission of the $\mathrm{KO}$ phenotype obtained through the CRISPR/Cas9 system, although germ-line transmission has already been known using ZFNs and TALENs by others [28,32,33]. Similar to Li et al. [37], Li et al. [38] attempted to generate multiple gene mutations in rats in a germ-line competent manner using a CRISPR/Cas9 system. They designed six sgRNAs targeting six different genomic sites encoding rat Tet methylcytosine dioxygenase 1 (Tet1) (sgTet1-1 and sgTet1-2), Tet methylcytosine dioxygenase 2 (Tet2) (sgTet2-1 and sgTet2-2), and Tet methylcytosine dioxygenase 3 (Tet3) (sgTet3-1 and sgTet3-2) to increase the likelihood of successful targeting. Co-injection of sgRNAs for the three Tet genes (sgTet1-1, sgTet2-1, and sgTet3-1) together with Cas 9 mRNA into rat zygotes resulted in the generation of a total of 22 newborn pups. Of these pups, $13(59 \%)$ contained mutations of all three Tet genes. Notably, $\sim 60 \%$ of them had a biallelic or monoallelic mutation for each targeted locus. Li et al. [38] also demonstrated that mutations in the founder rats were transmitted to the next generation.

Ménoret et al. [35] demonstrated, for the first time, that meganucleases-naturally occurring restriction enzymes derived from lower-order animals and plants—can be used as a fourth editing platform. They microinjected a plasmid encoding an engineered meganuclease for recombination, activating gene 1 (Rag1) into the pronuclei of rat zygotes. Of the microinjected zygotes, $0.6 \%$ were found to be mutated rats. However, this technique exhibits design complexity and associated costs, making it accessible to only a few laboratories.

Although MI of GE reagents into zygotes is one of the most useful tools for generating GM animals, it has advantages as well as disadvantages. The advantages of this technology include the delivery of known quantities of nucleic acids into a zygote irrespective of the type of zygote and the introduction of a large-size cargo (carrying a GOI), which is a significant limiting factor when using viral vectors for gene delivery, as suggested by Sato et al. [158]. The disadvantages of this technology include the requirement of a micromanipulator system and egg transfer (ET) to pseudo-pregnant females for allowing the further development of MI-treated embryos.

Notably, the detailed protocols for MI-based GE in rats have been described by Shao et al. [159], Ménoret et al. [160], and Tesson et al. [161].

\subsection{In Vitro EP-Based Production of GE Rats}

$\mathrm{EP}$ is known to be a useful and powerful gene delivery tool which can enable the transfer of exogenous substances (i.e., DNA, mRNA, and protein) into a cell by forming transient pores into the cell membranes under electrical stimulation in vitro and in vivo (reviewed by Young and Dean [162]). 
A. MI
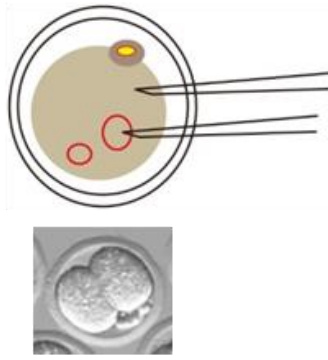

B. In vitro $\mathrm{EP}$
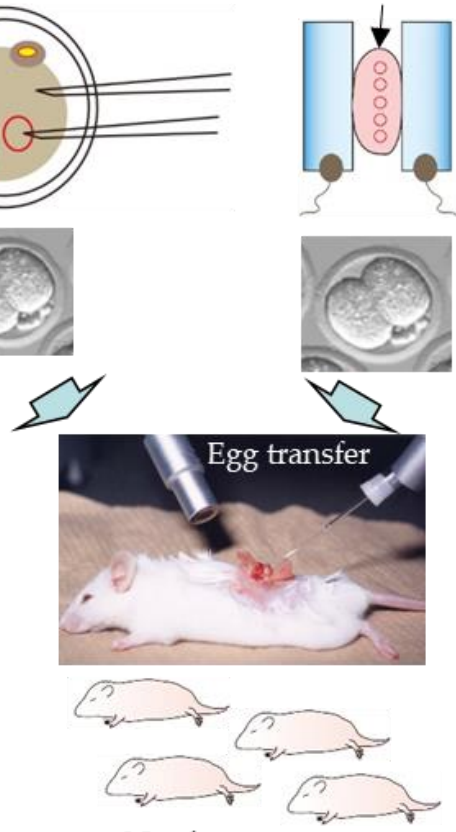

Newborn pups

\section{AAV-based GE}

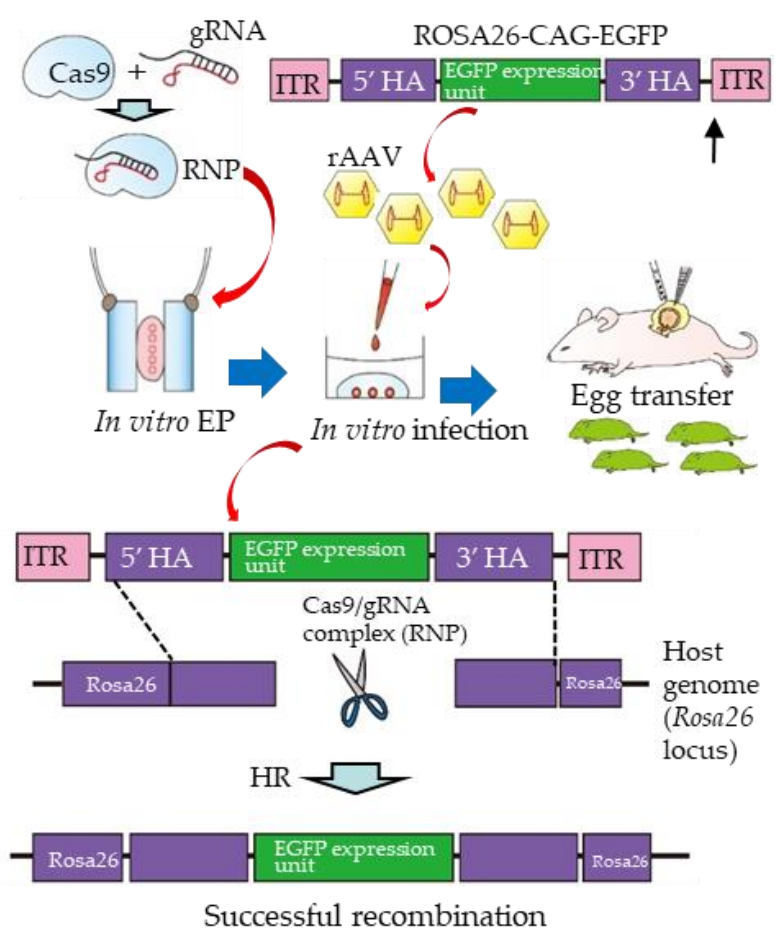

C. GONAD/i-GONAD

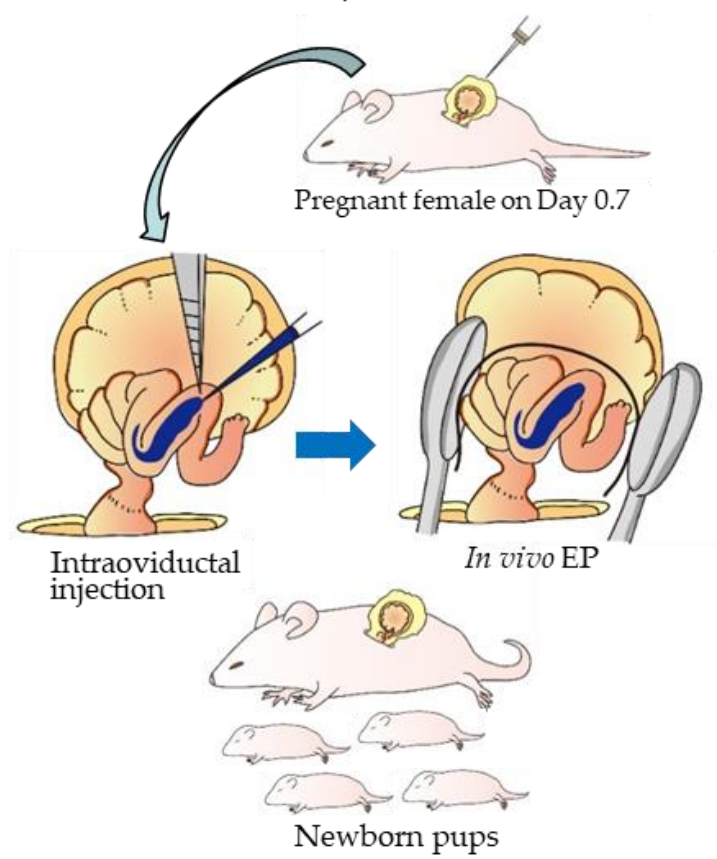

E. SSC-mediated GE

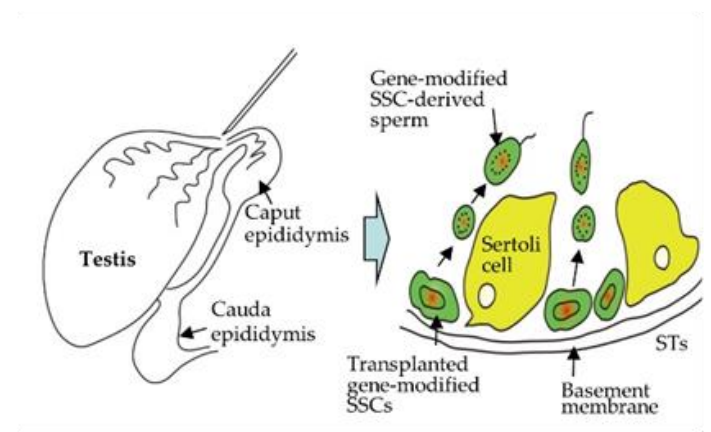

F. ES cell-mediated GE

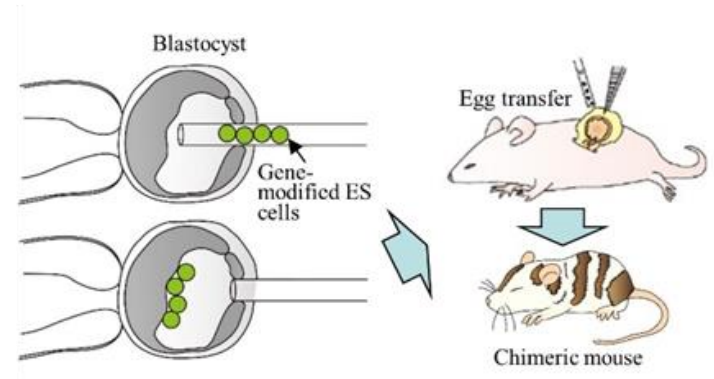

Figure 1. Schematic illustration of genome-edited (GE) rat production through microinjection (MI) (A), in vitro electroporation (EP) (B), genome-editing via oviductal nucleic acids delivery (GONAD) (or improved genome-editing via oviductal nucleic acids delivery (i-GONAD)) (C), adeno-associated virus (AAV)-based GONAD, a technique enabling in vitro viral infection of zygotes with recombinant AAV (rAAV) (D), spermatogonial stem cell (SCC)-mediated transgenesis (E), and embryonic stem (ES) cell-mediated transgenesis (F). This figure was drawn in-house, based on the data shown in the paper of Sato et al. [158]. 
In 2014, Kaneko et al. [43] first demonstrated that rat zygotes can be genome-edited by in vitro EP, which is shown in Figure 1B, schematically. Since then, many researchers have successfully induced gene edits using this technology in mice [163-168], rats [95,111], bovines [169], and pigs [170-172]. The merit of this technology is that it is simple, rapid, and convenient for GE in zygotes, compared to the previous MI-based technique. Notably, approximately 30 to 50 zygotes can be edited with one shot of in vitro EP. Furthermore, EP only requires a square pulse generator, called an electroporator, and not a more expensive micromanipulator system. According to Kaneko et al. [43], intact F344/Stm rat zygotes were subjected to in vitro EP using an NEPA21 electroporator (NEPA GENE Co. Ltd. Chiba, Japan) in the presence of a phosphate-buffered saline (PBS)-based solution containing ZFN $(40 \mu \mathrm{g} / \mathrm{mL})$ mRNA (targeted to the rat Il2rg gene) under the EP condition of a poring pulse (Pp) (voltage: $225 \mathrm{~V}$; pulse interval: $50 \mathrm{~ms}$; pulse width: 1.5 and $2.5 \mathrm{~ms}$; number of pulses: 4). The NEPA21 electroporator employs a 3-step pulse system. In the first step, the Pp makes micro-holes in the ZP and oolemma. In the second step, several first transfer pulses (Tp) transfer mRNA into the cytoplasm. In the third step, the polaritychanged second Tp increase the chance of transferring mRNA into embryos. When rat embryos were electroporated with a pulse width adjusted to 1.5 or $2.5 \mathrm{~ms}, 73$ and $75 \%$ of the resulting offspring, respectively, had an edited $I l 2 \mathrm{rg}$ locus. Notably, they reported no appreciable reduction in the developmental ability of the EP-treated embryos. Furthermore, the germ-line transmission of the ZFN EP-induced editing was also confirmed in the next generation. They named this technology "Technique for Animal Knockout system by Electroporation (TAKE)". Since then, many GE rats have been produced using EPbased GE technology [54,90,91,95,111,117,121,125,131,140,141,144]. Notably, in vitro EP can also be applied to frozen mouse and rat zygotes for the efficient introduction of CRISPR components, without affecting the embryo viability or development $[173,174]$. This will facilitate GE rat production in a more convenient manner.

At the initial stages of GE rat production, mRNAs encoding ZFNs, TALENs, or Cas9 have been frequently used [28-34,36-42]. However, mRNA transfection still relies on the translation of the mRNA into protein, resulting in variability of GE efficiency with timing. In the case of CRISPR/Cas9-based GE, instead of using Cas9 mRNA, the use of the Cas9 protein allows transient and faster editing [175]. For example, the recombinant Cas9 protein and the chemically synthesized guide RNA (gRNA) can be combined on the bench before being delivered into embryos; this Cas9-gRNA complex, which is called a ribonucleoprotein (RNP), is active immediately. If the RNP enters the nuclei of cells, GE should commence quickly, which will, in turn, lead to increased GE efficiency. Using this RNP-based GE system, a number of GE rats have been produced to date $[57,58,68,90,91,95,111,113,115,117,121,126,131,142,150]$.

Although in vitro EP enables the effective delivery of a short $(<1 \mathrm{~kb})$ single-stranded DNA (ssDNA) or synthetic single-stranded oligodeoxynucleotide (ssODN) into mouse zygotes, it has been difficult to introduce longer $(>1 \mathrm{~kb})$ double-stranded DNA (dsDNA) such as plasmid DNA. Only a few laboratories have successfully achieved this, although extensive exploration of optimal EP conditions, which is very laborious and time-consuming, is strictly required [176]. Notably, Bagheri et al. [177] overcame this limitation by first injecting all GE components, including long plasmid-sized DNA templates, into the subzona pellucida (ZP) space, called the "peri-vitelline space". Therefore, they were retained, supporting subsequent in vitro EP. Bagheri et al. [177] suggest that this simple and welltolerated method achieves intracellular reagent concentrations sufficient to provide precise gene edits.

As for the HDR-based KI by in vitro EP, Miyasaka et al. [95] first designed long singlestranded DNA (lssDNA) (constructed using a simple method including custom-made plasmids using nicking endonucleases as previously reported by Yoshimi et al. [64]) as the HDR template. The lssDNA comprises a targeted exon (exon 2 of the rat vesicle-associated membrane protein-associated protein B/C (Vapb) gene with a P56S mutation, which is associated with amyotrophic lateral sclerosis (ALS) in humans) flanked by two loxP sites. 
In vitro EP of rat zygotes was performed in the presence of Cas9 mRNA (400 ng/ $\mu \mathrm{L}$ ), lssDNA $(40 \mathrm{ng} / \mu \mathrm{L})$, and two gRNAs $(200 \mathrm{ng} / \mu \mathrm{L})$ in a chamber with $40 \mu \mathrm{L}$ of serum-free media (Opti-MEM) with a 5-mm gap electrode in a NEPA21 electroporator under the following conditions: Pp of voltage $225 \mathrm{~V}$, pulse width-2.0 ms, pulse interval $-50 \mathrm{~ms}$, and number of pulses-4. The first and second Tp were of voltage $20 \mathrm{~V}$, pulse width $-50 \mathrm{~ms}$, pulse interval 50-ms, and number of pulses - 5. Consequently, of six pups born, three showed floxed alleles with the P56S mutation. They called this technology "CRISPR with lssDNA inducing conditional knockout alleles (CLICK)". The CLICK technology will be useful as a tool for producing GM zygotes carrying transgenes driving tissue-specific Cre recombinase, which, in turn, will be applicable to the one-step generation of conditional $\mathrm{KO}$ animals.

When compared to the MI-based technique, in vitro EP allows the simultaneous processing of many zygotes in a short time (e.g., a batch of 30 to 50 zygotes in few seconds) without requiring expensive equipment and operators with extensive training and expertise. The disadvantages of this technology include the requirement of ET of the EP-treated embryos to pseudo-pregnant females to allow further development of the treated embryos.

Notably, the detailed protocols for in vitro EP-based GE in rats have been reported by Kaneko [178] and Remy et al. [179].

\subsection{GONAD-Based Production of GE Rats}

In 2015, a novel method (termed “GONAD") enabling in situ CRISPR/Cas9-based GE toward early embryos was first reported by Takahashi et al. [180] using mice. In this system, both Cas9 mRNA (up to $1.1 \mu \mathrm{g} / \mu \mathrm{L})$ and sgRNA $(0.6 \mu \mathrm{g} / \mu \mathrm{L}$ ) were co-injected into the oviductal lumen of pregnant females at Day 1.4 of pregnancy (corresponding to the 2cell stage). Technically, this was simply achieved by inserting a glass micropipette through the oviductal wall under observation using a dissecting microscope, as shown in Figure $1 \mathrm{C}$ schematically. Next, a small amount of a solution $(1-1.5 \mu \mathrm{L})$ containing GE components was injected into the oviductal lumen with the aid of a mouthpiece-controlled micropipette. Subsequently, in vivo EP was performed using tweezer-type electrodes and a square-wave pulse generator (T820; BTX Genetronics Inc. San Diego, CA, USA) under the EP condition of eight square-wave pulses with a pulse duration of $5 \mathrm{~ms}$ and an electric field intensity of $50 \mathrm{~V}$. GE occurrence in the 2-cell embryos can be later checked by molecular analysis of the mid-gestational fetuses dissected after the GONAD. The KO efficiency of these fetuses was approximately $29 \%$. Later, this technology was elaborated by the same group, who injected a solution containing RNP (comprising Cas9 protein $(1 \mu \mathrm{g} / \mu \mathrm{L}$ Integrated DNA Technologies, Inc. Coralville, IA, USA) and sgRNA $(30 \mu \mathrm{M})$ ) (for KO experiment), RNP $+\operatorname{ssODN}(1-2 \mu \mathrm{g} / \mu \mathrm{L})$ (for KI experiment), or RNP + ssDNA $(0.85-1.4 \mu \mathrm{g} / \mu \mathrm{L})$ (for KI experiment) at Day 0.7 of pregnancy (corresponding to the late 1-cell stage) [181]. In vivo EP using the NEPA21 electroporator was performed under the following conditions: Pp: $50 \mathrm{~V}$, 5-ms pulse, 50-ms pulse interval, three pulses, $10 \%$ decay ( \pm pulse orientation); Tp: $10 \mathrm{~V}, 50 \mathrm{~ms}$ pulse, $50 \mathrm{~ms}$ pulse interval, three pulses, and $40 \%$ decay ( \pm pulse orientation). This modification resulted in $97 \%$ of the embryos exhibiting indels in the target locus and approximately $50 \%$ of embryos containing KI alleles. Thus, this improved technology was re-named the "improved GONAD ( $i$-GONAD)". Since the successful development of GONAD/ $i$-GONAD in mice, the technology has proven useful for other species, such as rats [90,91,121] and hamsters [182].

Successful $i$-GONAD in rats was first reported in $2018[90,91]$. For examples, Takabayashi et al. [90] demonstrated that the appearance of non-pigmented eyes in fetuses (showing the KO phenotype due to indels at the tyrosinase gene (Tyr), a gene coding for protein essential for eye pigmentation) was induced with an efficiency of $56 \%$, when F1 embryos from pigmented Brown Norway $(B N) \times$ albino SD rat crosses were used for $i$-GONAD targeting of Tyr. In this case, the in vivo EP condition used was almost the same as that used for $i$-GONAD in mice. They also tested the possibility of KI (targeted Tyr locus) using albino Lewis (LEW) rats. The $i$-GONAD-mediated KI efficiency, which was evaluated 
by the presence of fetuses with pigmented eyes, was as low as 5\%. Kobayashi et al. [91] provided data similar to that of Takabayashi et al. [90] using the NEPA21 electroporator under the following EP conditions: Pp: 30, 40, or $50 \mathrm{~V}, 5-\mathrm{ms}$ pulse, 50-ms pulse interval, number of pulses 3 , and $10 \%$ decay ( \pm pulse orientation); Tp: $10 \mathrm{~V}, 50-\mathrm{ms}$ pulse, 50 -ms pulse, number of pulses 6 , and $40 \%$ decay ( \pm pulse orientation). According to Kobayashi et al. [91], intraoviductal injection of RNP $(1 \mu \mathrm{g} / \mu \mathrm{L}$ of Cas 9 protein $+30 \mu \mathrm{M}$ of sgRNA) targeted to Tyr into oviducts of pregnant albino WKY females (which had been successfully mated with dark agouti (DA) males) or pigmented DA females (which had been successfully mated to Wistar-Kyoto (WKY) males) resulted in the production of GE pups with efficiencies of 59\% or $42 \%$, respectively, when $50 \mathrm{~V}$ of the voltage $(\mathrm{Pp})$ was employed. These results suggest no significant difference in the gene-editing efficiency between these two strains. They also attempted to recover the coat-color mutation in WKY females using an ssODN-based KI approach. Consequently, the KI efficiency was $27 \%$ in the pups born. They named this rat-based $i$-GONAD as "rGONAD".

For performing $i$-GONAD (or rGONAD) in rats, the exploration of optimal EP conditions is strictly required. For example, when a current of $>500 \mathrm{~mA}$ was employed, albino SD and albino LEW rats were successfully genome-edited; however, the acquisition of offspring derived from pigmented BN rats (fetuses/newborns) failed. In contrast, $i$-GONAD under a current of 100-300 mA using the NEPA21 electroporator led to the production of GE BN rats with efficiencies of $75 \%$ to $100 \%$ [90]. Similarly, $i$-GONAD under a current of 150-200 mA using another electroporator CUY21EDIT II (BEX Co., Tokyo, Japan) led to the production of genome-edited BN rats with efficiencies of $24 \%$ to $55 \%$ [121].

The advantages of this technology are that GONAD/ $i$-GONAD requires an electroporator but no other special equipment. Furthermore, no recipients are required unlike the case of MI- or in vitro EP-based GE rat production. Disadvantages of this technology are that technical skill may be required for intraoviductal injection of a solution into the lumen of oviducts under a dissecting microscope using a mouthpiece-controlled glass micropipette.

The detailed protocols for GONAD/ $i$-GONAD have been reported by Gurumurthy et al. [183] and Ohtsuka and Sato [184] in mice. The GONAD/i-GONAD-based production of GE rats is also possible using the same approach shown in mice. Notably, Namba et al. [185] demonstrated the protocols for GONAD/ $i$-GONAD in rats.

\section{4. rAAV-Mediated Production of GE Rats}

rAAVs are non-pathogenic and non-enveloped ssDNA viruses enabling highly efficient transduction of both dividing and non-dividing cells (reviewed by Daya and Berns [186]). Unlike other viral vectors such as retroviruses and adenoviruses, rAAVs have been used for manipulating the target genome sequences through simple co-incubation with ZPenclosed preimplantation mammalian embryos for the production of GM animals such as mice [168,187-191]. For example, Mizuno et al. [187] observed that, among the rAAVs tested, the rAAV with serotype 6 (which is hereinafter referred to as rAAV-6) showed the highest transduction efficiency when ZP-intact murine embryos were co-cultured with rAAVs. More importantly, Mizuno et al. [187] demonstrated successful CRISPR-based KI in mice. As shown in Figure 1D, zygotes were first subjected to in vitro EP in the presence of RNP and then infected with rAAV-6 carrying a 1.8-kb GFP expression cassette flanked by two 100-bp Rosa26 homology arms. The KI efficiencies in the Rosa26 locus were 16\% and $6 \%$, when assessed at the blastocyst and newborn stages, respectively. Notably, Mizuno et al. [187] demonstrated that both ZP-intact rat and bovine embryos were effectively infected by rAAV-6, suggesting that rat genome can be effectively edited through the simple incubation of ZP-intact rat zygotes with a solution containing rAAVs.

This rAAV-based gene delivery system to early embryos was also observed in vivo. Yoon et al. [188] injected a solution containing two vectors, rAAV6-Cas9 (carrying spCas 9 gene derived from Streptococcus pyogenes) and rAAV6-gTyr (carrying gRNA expression unit targeted Tyr), into the oviducts of pregnant female mice at Day 0.5 of pregnancy, similar to GONAD/ $i$-GONAD. Out of the 29 pups that were obtained, three $(10 \%)$ were found to 
have indels. All mutated founder mice generated albino offspring, indicating germ-line transmission. These results suggest that AAV is a powerful tool for inducing GE in the ZP-enclosed early embryos in vivo. According to Sato et al. [158], this in vivo approach is referred to as "AAV-based GONAD".

The advantages of this technology are that no special equipment is required in the case of using the AAV-based GONAD. Notably, the use of highly concentrated rAAV would be one of the key factors for achieving a high rate of transduction of preimplantation embryos. According to Yoon et al. [188], zygotes treated with $6 \times 10^{8}$ genome copies (GCs) for one day in vitro resulted in live births with $100 \%$ indel frequency after ET. However, the editing frequency dropped to $25 \%$ for fetuses and $20 \%$ for newborns at $6 \times 10^{7}$ GCs. No edited animals were detected from the $6 \times 10^{6} \mathrm{GC}$ treatment group. These results clearly suggest that gene delivery and GE efficiency are rAAV dose-dependent.

\subsection{SSC-Mediated Production of GE Rats}

Cultured SSCs can display long-term sperm-forming potential when they are transplanted into the seminiferous tubules (STs) of sterile rat testes (shown in Figure 1E). It is now possible to culture SSCs for a long time and perform gene modification toward SSCs derived from mice and rats (reviewed by Sato et al. [158]).

Chapman et al. [60] first demonstrated that CRISPR/Cas9-mediated GE can be successfully applied in SSCs to create KO rats. They used SSCs isolated from tgGCS-EGFP rats (with the genetic background of SD) showing germ cell-specific expression of enhanced green fluorescent protein (EGFP) [192]. The SSCs were then transfected with the pX330 vector (conferring expression of both Cas9 and gRNA targeted epithelial stromal interaction 1 (Epsti1) gene) together with a neomycin resistance gene expression plasmid. The surviving clones after G418 selection were then transplanted into the STs of recipient sterile rats to promote spermatogenesis. When the recipient rats transplanted with G418-selected cells were mated with WT females at $\sim 65$ days post-transplantation, a total of 87 pups were obtained. Of these, $\sim 10 \%$ (9) were found to harbor Epsti1 mutants. A similar attempt was also made by Noto et al. [102], who successfully obtained immunodeficient rats by grafting recombination activating gene $2(\operatorname{Rag} 2) \mathrm{KO}$ SSCs into rat testes.

\subsection{ES Cell-Mediated Production of GE Rats}

As mentioned previously, acquisition of a rat ES cell line is now possible. Yamamoto et al. [14] first succeeded in producing KI rats using CRISPR/Cas9-engineered ES cells. Initially, they obtained GM ES cell clones using a conventional gene-targeting technology but failed because of no recombinant ES cells were obtained. Next, in vitro EP of a Cas9expressing plasmid, gRNA-expressing plasmid, and KI vector (carrying two homology arms) in rat ES cells was performed. Consequently, the number of drug-resistant colonies increased and the HR efficiency was considerably enhanced from 0 to $36 \%$. These recombinant clones resulted in the successful production of chimeras, which were later proven to have the ability to transmit the KI allele to their offspring after mating with WT rats (as shown in Figure 1F). According to Yamamoto et al. [14], the methodology presented can overcome the problem encountered in conventional gene targeting that prevented the production of humanized rats. Later, successful GM rat production through ES cells carrying CRISPR/Cas9-based KI of the Discosoma coral red fluorescent protein (dsRed) gene at the Sry-box transcription factor 10 (Sox10) locus was reported by Chen et al. [15].

\section{Other Techniques and Factors to Modify the Rat Genome}

As shown above, GE tools such as ZFNs, TALENs, and CRISPR/Cas9 are considered useful for the production of GE rats. However, several techniques and factors still influence their performance, which must be addressed. These include the allele-specific GE using ssODNs, large genomic fragment deletion, ssODN-mediated KI without the need to construct homology arms, the use of inhibitors for efficient KI, the importance of 
choosing the appropriate gRNA for efficient KI, and base editor systems enabling precise genome modifications.

In this section, these techniques or factors are described in detail.

\subsection{Allele-Specific GE for the Correction of Mutated Phenotypes}

Numerous reports have demonstrated that CRISPR/Cas9 editors combined with $\sim 100 \mathrm{bp}$ ssODNs, instead of using a relatively long template $(\sim 1 \mathrm{~kb})$, allow for precise HDR-mediated GE in mice $[156,157,193]$. These results suggest that ssODNs co-injected as donor templates preferentially support the activation of HDR relative to the NHEJ pathway.

To explore the applications of ssODN-mediated GE in rats, Yoshimi et al. [46] successfully used ssODNs to manipulate the coat-color genetics of F344 rats. They used a WT ssODN to exchange a single base pair in Tyr, thus reverting the albino allele back to the WT sequence and restoring a non-albino pigmentation pattern. A similar strategy using ssODN for the correction of mutated phenotypes in rats was also employed by others $[64,90,91,106,114,125-127,129,141,142]$.

\subsection{Large Genomic Fragment Deletion}

The GE system has enabled the creation of targeted deletion spanning the large genomic region over $10 \mathrm{~kb}$ in size via the direct MI of two sgRNAs $(\sim 10-30 \mathrm{ng} / \mu \mathrm{L})$ and TALEN mRNA (45 $\mathrm{ng} / \mu \mathrm{L})$ or Cas9 mRNA ( 67-100 $\mathrm{ng} / \mu \mathrm{L})$ into the pronuclei or cytoplasm of mouse zygotes [194,195]. Wang et al. [58] achieved 53-kb deletion of a fragment spanning long non-coding RNA (lncRNA) GM14005 genomic DNA by injecting the Cas9 protein $(30 \mathrm{nM})$ into the cytoplasm of mouse zygotes together with two sgRNAs $(12.5 \mathrm{ng} / \mu \mathrm{L})$. Among five F0 pups, one founder was confirmed as a mouse with a large deletion. Wang et al. [58] also showed that the 53-kb deletion was efficiently transmitted to the F1 generation.

Yoshimi et al. [46] succeeded in the deletion of a 7-kb fragment from the rat genome. They used two flanking gRNAs to delete a 7098-bp endogenous retroviral element (ERV) within the first intron of the Kit gene, using ssODN containing homology arms on either side of the junction to bridge across the deletion (Figure 2). They injected $100 \mathrm{ng} / \mu \mathrm{L}$ Cas 9 mRNA, $50 \mathrm{ng} / \mu \mathrm{L}$ gRNAs (targeted Kit), and $120 \mathrm{bp}$ ssODNs ( $50 \mathrm{ng} / \mu \mathrm{L}$ ) into the pronuclei of Long-Evans hooded (LEH) rat zygotes. Thus, GE rats exhibited restoration of the function of the Kit gene with a non-hooded pigmentation pattern. The frequency of the appropriately edited pups was $4 \%$, showing the feasibility of performing template-directed correction of mutated portions using ssODNs.

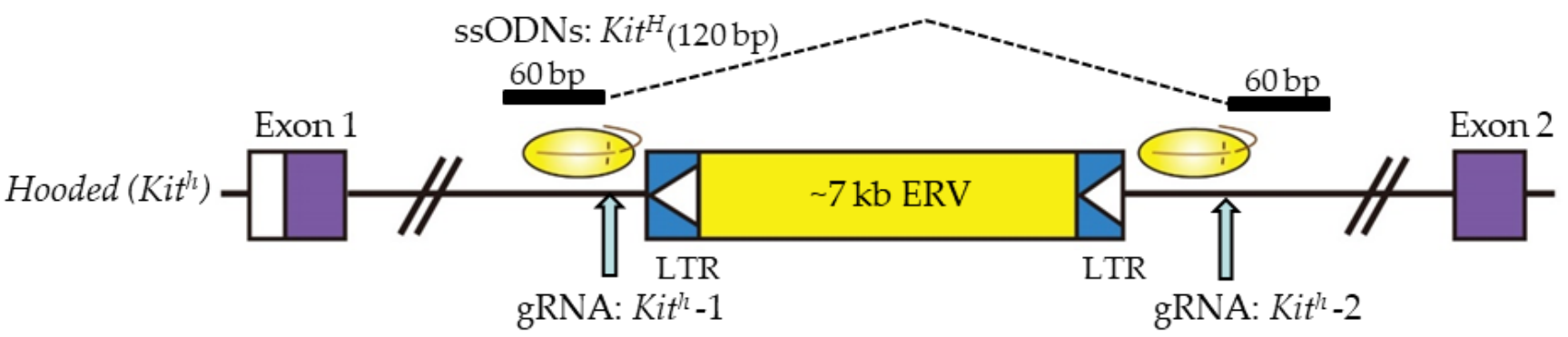

Figure 2. Schematic illustration of single-stranded oligodeoxynucleotide (ssODN)-based deletion of a large fragment spanning a 7,098-bp endogenous retrovirus (ERV) element within the first intron of the Kit gene. This figure was drawn in-house, based on the data shown in the paper of Yoshimi et al. [46].

If both DSBs occur at the same time, the result will be a large deletion of the region of interest. To the best of our knowledge, the biggest deletion achieved to date in rats is 24.4 mega base pairs (Mb) [196]. 


\section{3. ssODN-Mediated KI with CRISPR/Cas9 for Large Genomic Regions in Rat Zygotes}

Although the CRISPR/Cas9 system is recognized as a powerful tool for generating GM animals, the creation of targeted KI animals via HR is still challenging. Yoshimi et al. [64] developed a novel KI method without the need to construct homology arms, thus simplifying the process of genome engineering in living organisms. In other words, they tried to knock-in longer plasmids (including the 1.2-kb chicken $\beta$-actin-based promoter (called "CAG") and a 0.8-kb GFP cassette sequence) at the targeted site (rat Rosa26 locus) (Figure 3). In more detail, they constructed two gRNAs: one targeting the rat Rosa26 locus to cleave genomic DNA, and the other targeting the $5^{\prime}$ end of the CAG promoter sequence for concurrent cleavage of the plasmid DNA (Figure 3). Two 80-bp ssODNs (ssODN-1 and -2) were designed to ligate the two cut ends, as shown in (Figure 3). A mixture of $100 \mathrm{ng} / \mu \mathrm{L}$ of the Cas9-poly $(A)$ mRNA (which appended an 81-bp poly(A) to the transcription terminator to increase the efficacy of GE with the CRISPR/Cas9 system), $50 \mathrm{ng} / \mu \mathrm{L}$ of each of the two gRNAs (gRNA:rRosa26 and gRNA:CAGGS), $50 \mathrm{ng} / \mu \mathrm{L}$ of each of the two ssODNs (ssODN-1 and -2), and $5 \mathrm{ng} / \mu \mathrm{L}$ of the CAG-GFP plasmid was co-microinjected into the pronuclei of rat zygotes. Of the 17 pups obtained, four (\#6,\#7, \#8, and \#11) were selected as candidates with successful KI. Sequence analysis revealed that \#11 had accurate conjunction at both of the two cut ends, \#6 had a 6-bp deletion on one side, and \#7 had several base-pair deletions and insertions on both sides. They confirmed germ-line transmission of the GFP allele. No off-target effect was observed at any candidate sites in these rats. Furthermore, uniform expression of the GFP gene in most cells and tissues examined was confirmed. Based on these observations, this strategy was called "two-hit by gRNA and two-oligo with plasmid (2H2OP)".

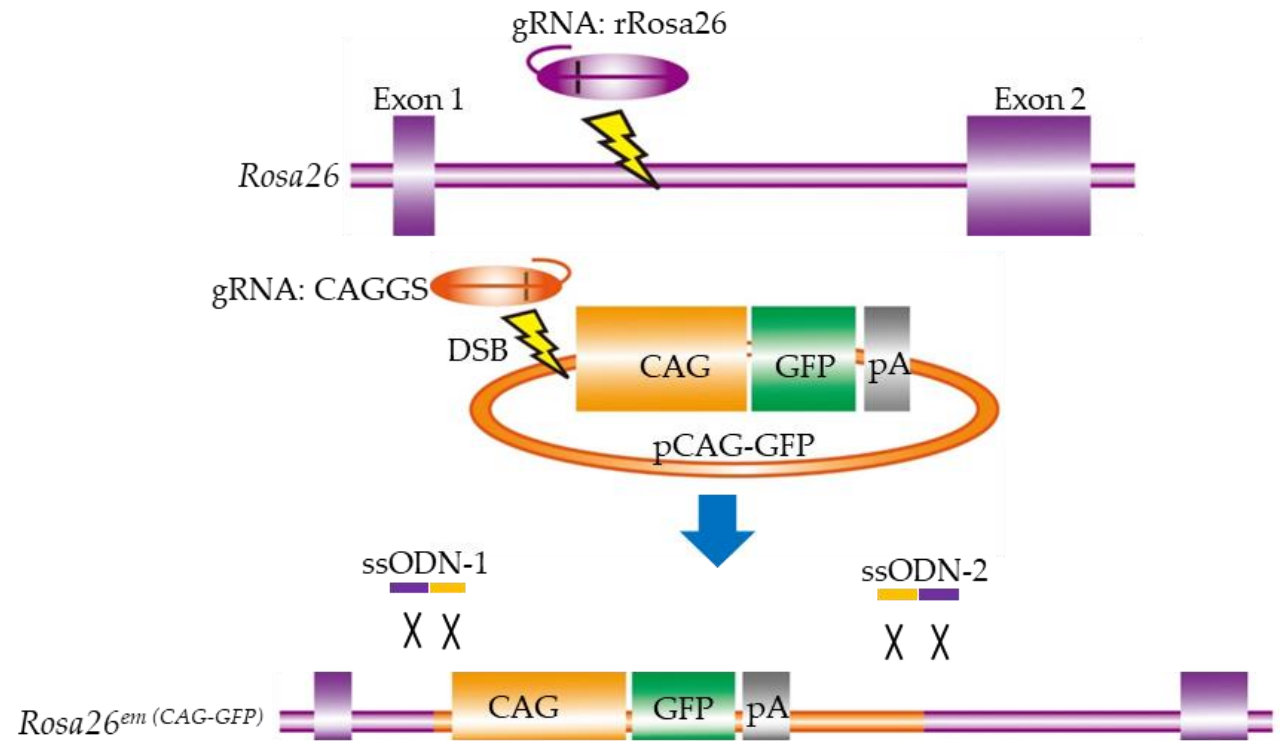

Figure 3. Schematic representation of the two-hit by gRNA and two-oligo with plasmid (2H2OP) method for the production of CAG-GFP knock-in (KI) rats generated using the CRISPR/Cas9 system. In the first step, Cas9, together with two gRNAs targeting the rat Rosa26 locus and the CAG promoter in the GFP plasmids, cuts the target sites. In the second step, two ssODNs ligate each cut end to join the genomic DNA and the plasmid DNA via HDR. This figure was drawn in-house, based on the data shown in the paper of Yoshimi et al. [64]. Abbreviations: CAG, chicken $\beta$-actin-based promoter; GFP, green fluorescent protein; KI, knock-in; ssODNs, single-stranded oligodeoxynucleotides; pA, poly(A) sites.

\subsection{Use of Inhibitor for Efficient KI}

$\mathrm{KI}$ is an event of precise modifications at a target locus and is often mediated by HR in the presence of donor DNA, as exemplified by ssODN. Generally, HDR-mediated KI is more difficult than NHEJ-based indels. For example, in proliferating human cells, NHEJ 
has been reported to repair 75\% DSBs, whereas HDR repaired the remaining 25\% [197]. To enhance the HDR efficiency, several approaches are now being attempted. In the case of a CRISPR/Cas9-mediated KI event, Scr7, which was first identified as an anticancer compound and was considered a potential NHEJ inhibitor, was used to increase the HR-mediated precise genetic modification $[198,199]$. For example, co-injection of murine zygotes with a mixture containing Cas 9 mRNA, sgRNA, template ssODNs, and Scr7 significantly improved the efficiency of HDR-mediated insertional mutagenesis [198]. Chu et al. [200] also demonstrated the usefulness of Scr7 for abolishing NHEJ activity and increasing HDR in both human and mouse cell lines. However, the function of Scr7 in promoting HDR remains controversial. Some researchers have demonstrated that Scr7 failed to increase HDR rates in rabbit embryos [201] and porcine fetal fibroblasts [202].

In rats, Ma et al. [68] first demonstrated that both Scr7 and Cas9 protein can increase the precise modification in rat embryos when the fatty acid binding protein 2 (Fabp2) and dysbindin (dystrobrevin binding protein 1 ) domain containing 1 (Dbndd1) loci were selected to perform KI of a fragment containing Cre or Cre-ERT2 (Cre recombinase-estrogen receptor T2) gene, respectively. For example, when a mixture containing Cas 9 mRNA $(25 \mathrm{ng} / \mu \mathrm{L})$, sgRNA (10 ng/ $\mu \mathrm{L}$; targeting Fabp2), plasmid template (4 ng/ $\mu \mathrm{L}$; for Fabp2), and Scr7 (0, 0.5, 1 or $2 \mu \mathrm{M})$ was injected into both the cytoplasm and pronuclei of rat zygotes, two (18\%) of 11 pups born exhibited KI in the absence of Scr7. In contrast, three (33\%) of 9 and 11 (39\%) of 28 pups were found to exhibit KI after MI with 2 or $1 \mu \mathrm{M}$ Scr7, respectively.

However, the opposite results were recently achieved by Takabayashi et al. [90] and Aoshima et al. [141]. Takabayashi et al. [90] performed $i$-GONAD using a solution containing $1 \mu \mathrm{M}$ Scr7, RNP $(1 \mu \mathrm{g} / \mu \mathrm{L}$ of Cas 9 protein $+30 \mu \mathrm{M}$ of sgRNA), and $2 \mu \mathrm{g} / \mu \mathrm{L}$ of ssODN resulted in the production of 27 fetuses, of which only two ( $7 \%$ ) had pigmented eyes. Notably, in the absence of Scr7, $i$-GONAD-mediated KI efficiency was as low as $\sim 5 \%$, suggesting that addition of Scr7 appeared not to affect $i$-GONAD-mediated KI efficiency in rats. Aoshima et al. [141] examined whether commercially available KI-enhancing drugs (including Scr7, L755,507, RS-1, and HDR enhancer), all of which are known to enhance $\mathrm{KI}$ efficiency, can increase the KI efficiency using $i$-GONAD in rats. Aoshima et al. [141] demonstrated that some drugs (e.g., Scr7, L755,507, and HDR enhancer) were found to be slightly effective in vivo, but their effects were not statistically significant when compared to those in the control group (without any KI-enhancing drugs).

\subsection{Choice of gRNA Is Very Important for Achieving High KI Efficiency in Rats}

According to Raveux et al. [203], ssODN-mediated KI efficiency varied from $0 \%$ to $40 \%$, depending on the type of Cas 9 , the injection site, the length of the homology arm, and the gRNA-binding site. The nucleotide composition of a target sequence is one of the most important factors determining KI and KO efficiency. For example, Graf et al. [204] screened the published gRNA activity datasets and demonstrated that TT- and GCC-motifs located in the four PAM-proximal bases of the targeting sequence (the efficiency-modulating sequence) were sufficient to block CRISPR/Cas9-mediated KI. Moreover, the presence of these motifs in gRNAs resulted in a 10-fold reduction in gene $\mathrm{KO}$ frequencies.

Aoshima et al. [141] constructed three gRNAs showing high efficiencies, ranging from $51 \%$ to $57 \%$, based on the CHOPCHOP predictions [205]. These three gRNAs (termed crRNA1, crRNA2, and crRNA3) used here recognize the Tyr sequence containing a point mutation ( $\mathrm{G}$ to $\mathrm{A}$ ) and overlap with each other (Figure 4). When KI-based $i$-GONAD was performed using ssODN $(2 \mu \mathrm{g} / \mu \mathrm{L})$, Cas9 protein $(1 \mu \mathrm{g} / \mu \mathrm{L})$, and gRNA (crRNA1, 2 or 3) $(30 \mu \mathrm{M})$, the KI efficiency in fetuses generated after $i$-GONAD with crRNA2 was significantly higher (24\%) than that obtained after $i$-GONAD with crRNA1 $(5 \%)$ or crRNA3 $(0 \%)$. The discrepancy between predicted and actual efficiencies was unexpected. Notably, no inhibitory sequences exist in the gRNAs used, unlike the suggestion of Graf et al. [204]. Furthermore, in the case of in vitro GE, the GE efficiency is known to vary, with predicted efficiencies typically higher than observed levels [156,206,207]. The data of Aoshima 
et al. [141] suggest the importance of selecting the appropriate gRNA for effective KI in rats.

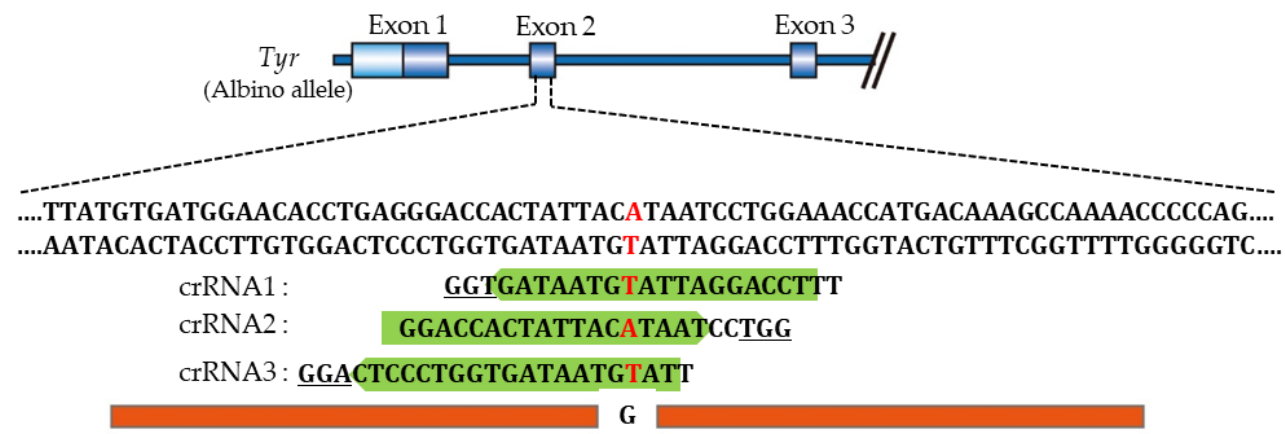

Figure 4. Schematic representation of knock-in (KI) experiment in rats toward the mutated Tyr locus performed by Aoshima et al. [141]. The target sequence (exon 2 of Tyr) recognized by crRNA1, 2, and 3 is shown in green. The PAM sequences are underlined. Single-stranded oligodeoxynucleotide (ssODN) (containing wild-type nucleotide " $\mathrm{G}$ " that corresponds to mutated nucleotide " $\mathrm{A}$ ") is shown in orange below the target sequence. The nucleotide " $\mathrm{A} / \mathrm{T}$ " marked in red is the mutation causative of the albino phenotype. This figure was drawn in-house, based on the data shown in the paper of Aoshima et al. [141].

\subsection{Base Editor Systems as an Efficient Tool Enabling Precise Genome Modifications}

Single-base editing systems without the induction of DSB or template DNA, mediated by cytidine deaminase combined with Cas9 nickase (nCas9) or dead Cas9 (dCas9), were recently developed to modify mammalian genomic DNA. This system is called the "cytosine base editor (CBE)" which achieves $C \cdot G$ to $T \cdot A$ conversion with a window of approximately five nucleotides [208,209]. Furthermore, Gaudelli et al. [210] developed a new base-editing (BE)-based system, called the "adenine base editor (ABE)", which efficiently enables the induction of A.T to G.C conversion through fusion of an engineered tRNA adenosine deaminase (ecTadA) with nCas9. Thus, together with CBE, ABE enables the introduction of all four nucleotide transitions ( $C$ to $T, A$ to $G, T$ to $C$, and $G$ to $A$ ) in the target genomic sequence [210]. Indeed, using these systems, the correction of genetic disease has been successfully performed in mice [211,212].

With respect to the production of GM rats using the BE systems, Yang et al. [97] reported the successful production of $\mathrm{KO}$ rats through $\mathrm{MI}$ of $\mathrm{ABE}$ mRNA together with sgRNA (targeted glycogen storage disease type 2 ( Gsd2) gene) to generate an animal model for glycogen storage disease type II. Consequently, $85 \%(28 / 33)$ of rats had single or multiple $A>G$ substitutions between position A3 and A7 in the target protein (GSD2), leading to I646V or D645G mutations. Similarly, Ma et al. [104] injected ABE mRNA together with the sgRNA-targeted hemogen (Hemgn), N-deacetylase (Ndst1), or N-sulfotransferase 4 $(N d s t 4)$ gene into rat zygotes. For Hemgn targeting, the zygotes were microinjected with ABE mRNA and sgRNA (targeted Hemgn); a total of 99 injected zygotes were transferred to three pseudo-pregnant female rats, and 15 pups were born. Consequently, fourteen rats $(14 / 15)$ contained an A to G conversion at the 14th base distal from the PAM, indicating the high base-editing efficiency. According to Ma et al. [104], these BE tools can provide a much safer approach compared with the WT CRISPR/Cas9 system for the gene correction of human disease.

Recently, Qi et al. [153] demonstrated that a bacterial toxin deaminase (DddA) from Burkholderia cenocepacia, which can convert cytosine to uracil specifically within dsDNA, can be used for mediating mitochondrial DNA (mtDNA) editing in rats. It has been demonstrated that the toxin domain of DddA (DddAtox, 1264-1427 amino acids) is engineered and incorporated with the mitoTALE system to efficiently achieve C $\cdot \mathrm{G}$-to-T $\cdot$ A conversion in mtDNA of human cell lines [213]. This system is therefore termed "DddA-derived cytosine base editor (DdCBE)" [213]. Qi et al. [153] injected mRNAs of a DdCBE pair with 
the best performance in rat zygotes, but the DdCBE-mediated BE failed. They reasoned that this failure was due to the inactive mtDNA replication in zygotes because this system works during the period when mtDNA replication is active. To overcome this problem, the DdCBE pair was cloned into the piggyBack (PB) transposon vector, and then, the resulting $\mathrm{PB}$ vector was co-injected into rat zygotes with PB transposase mRNA. Thus, one out of four pups obtained was successfully edited with $36 \%$ efficiency for one target locus. According to Qi et al. [153], almost all DdCBE pairs failed to integrate into the rat genome by the transposon system; however, the expression of the DdCBE pair from the PB vector might have lasted longer than that from mRNA injection, facilitating C $\cdot$ G-to-T $\cdot A$ conversion in mtDNA. Using the DdCBE system, animals with precise mtDNA mutations can be produced on demand.

\section{Disease Models in Rats}

For a decade, the advent of genetic engineering tools such as ZFNs, TALENs, and CRISPR/Cas9 has led to a revolution in obtaining specific and targeted genetic mutations in rats for the study of human genetic diseases. Several important genetic diseases have been modeled in rats. A brief description of the most useful models is provided below.

\subsection{Models for Cardiovascular Diseases}

Monoallelic mutations in the gene encoding bone morphogenetic protein receptor 2 (Bmpr2) are the main genetic risk factors for heritable pulmonary arterial hypertension (PAH) with incomplete penetrance. Several Bmpr2 Tg mice have been reported to develop mild spontaneous PAH. Ranchoux et al. [53] generated Bmpr2 KO rats using the ZFN technology. The resulting $\mathrm{KO}$ rats with a heterozygous 140 bp deletion in the first exon of Bmpr 2 displayed intense pulmonary vascular remodeling. The same group [116] also generated rat lines with mutations (deletion of $71 \mathrm{bp}$ in exon 1 of Bmpr2) and showed that the heterozygous rats developed age-dependent spontaneous PAH with a low penetrance (16-27\%), similar to that in humans. They concluded that this new genetic rat model represents a promising tool to study $\mathrm{PAH}$ pathogenesis. Concerning the pathogenesis of $\mathrm{PAH}$, mutations in the potassium channel subfamily $\mathrm{K}$ member 3 (KCNK3) gene, which encodes an outward rectifier $\mathrm{K}+$ channel, have been identified in PAH patients. Lambert et al. [109] generated Kcnk3 KO rats through the CRISPR/Cas9 technology. The resulting rats developed age-dependent PAH associated with low serum-albumin concentrations. Lambert et al. [109] concluded that KCNK3 loss of function is a key event in PAH pathogenesis.

\subsection{Models for Neurological Diseases}

Animal models are required to understand the pathogenesis of autism spectrum disorder (ASD). Despite the apparent advantages of mice for neural studies, rats have not been widely used for ASD studies, probably owing to the lack of convenient genome manipulation tools. Hamilton et al. [42] generated two rat models for ASD, one syndromic and one non-syndromic model, through the ZFN system, by destroying a gene (Fmr1) coding the Fragile $X$ mental retardation protein (FMRP), the protein responsible for the pathogenesis of Fragile $X$ syndrome (FXS), or a gene $(\mathrm{Ng} \ln 3)$ coding for Neuroligin3 (NLGN3), a member of the neuroligin synaptic cell-adhesion protein family, respectively. Both FMRP and NLGN3 have been implicated in the pathogenesis of human ASD. Both $\mathrm{KO}$ rat lines exhibited abnormalities in ASD-relevant phenotypes including juvenile play, perseverative behaviors, and sensorimotor gating, suggesting the utility of these rats as genetic models for investigating ASD-relevant genes. Later, Tian et al. [77] produced Fmr1 $\mathrm{KO}$ rats through the CRISPR/Cas9 technology targeted to exon 4 of Fmr1. Consistent with the previous reports, deletion of the Fmr1 gene in rats specifically impairs long-term synaptic plasticity and hippocampus-dependent learning in a manner resembling the key symptoms of FXS.

DEP-domain containing 5 gene (Depdc5), encoding a repressor of the mechanistic target of rapamycin complex 1 (mTORC1) signaling pathway, has recently emerged as 
a major gene mutated in familial focal epilepsies and focal cortical dysplasia. Marsan et al. [67] produced a Depdc5 KO rat using the TALEN technology. Homozygous KO embryos died from Day 14.5 of pregnancy. Heterozygous KO rats developed normally and exhibited no spontaneous electroclinical seizures; however, they showed altered cortical neuron excitability and firing patterns. This rat model is considered a relevant model to study pathogenic mechanisms underlying those disorders.

One subtype of ASD is associated with mutations in the methyl-CpG-binding protein 2 (Mecp2) gene, causing an X-linked neurodevelopmental disorder called Rett syndrome (RS). Patients with RS have cognitive defects and circadian clock dysfunction, as exemplified by abnormal sleep patterns. According to Zhai et al. [61], there is an urgent need for new animal models for RS because the existing Mecp2 KO mouse models fail to fully mimic the pathogenesis and symptoms of patients with RS. Mecp2 KO rats were successfully produced by the two groups using ZFN [62] and CRISPR/Cas9 [61] technologies. The resulting $\mathrm{KO}$ rats exhibited significant abnormalities in growth (body weight loss) as well as behavioral function (anxiety tendency and cognitive deficits) [61,62]. Because these phenotypes well recapitulate the major symptoms of RS patients, these Mecp2 KO rats will provide an alternative tool for future studies of MeCP2 functions.

Mutations in fused in sarcoma (Fus), a nuclear DNA/RNA-binding protein, cause familial ALS and occasionally frontotemporal dementia. Zhang et al. [87] produced KI rats expressing a Fus point mutation (R521C) as a model for ALS using the CRISPR/Cas9 technology. The mutant animals developed adult-onset learning and memory behavioral deficits, with reduced spine density in the hippocampal neurons. Remarkably, the sleep-wake cycle and circadian abnormalities preceded the onset of cognitive deficits. These results suggest a new role of Fus in sleep and circadian regulation and demonstrate that functional changes in FUS could cause sleep-wake and circadian disturbances as early symptoms.

Emmert et al. [113] produced a novel rat model of X-linked hydrocephalus (XLH) by CRISPR-mediated mutation in the L1 cell-adhesion molecule ( $1 \mathrm{cam})$ gene on the X chromosome. Hemizygous male mutants developed hydrocephalus and delayed development. The mutant rats did not show reactive gliosis, but exhibited hypomyelination and increased extracellular fluid in the corpus callosum.

GABAergic dysfunctions have been implicated in the pathogenesis of schizophrenia, especially the associated cognitive impairments. The level of the GABA synthetic enzyme glutamate decarboxylase $67 \mathrm{kDa}$ isoform (GAD67) encoded by the GAD1 gene is downregulated in the brains of schizophrenia patients. Furthermore, a schizophrenia patient harboring a homozygous mutation of GAD1 has recently been discovered. Gad1 KO mice exhibited perinatal lethality [214], which precluded characterization at adult stages. Fujihara et al. [125] generated Gad1 KO rats using the CRISPR/Cas9 technology. Surprisingly, 33\% Gad1 KO rats survived to adulthood, which made further characterization possible. The Gad1 KO rats exhibited impairments in both spatial reference and working memory without affecting adult neurogenesis in the hippocampus. In addition, Gad1 KO rats showed a wide range of behavioral alterations, such as enhanced sensitivity to an NMDA receptor antagonist, hypoactivity in a novel environment, and decreased preference for social novelty. These results suggest that Gad1 $\mathrm{KO}$ rats could be a novel model for studying cognitive deficits. Furthermore, Fujihara et al. [125] claimed the necessity to check species differences in the mode of phenotype manifestation when animal models of human diseases are considered.

Angelman syndrome (AS) is a rare genetic disorder characterized by severe intellectual disability, seizures, lack of speech, and ataxia. The gene responsible for AS is the ubiquitin protein ligase E3A (Ube3a) gene, which encodes for ubiquitin ligase E6-associated protein (E6AP). Dodge et al. [122] generated Ube3a KO rats using the CRISPR/Cas9 system. The resulting $\mathrm{KO}$ rats phenotypically mirrored human AS with deficits in motor coordination as well as learning and memory. This model can, thus, offer a new avenue for the study of AS. 
Koster et al. [142] produced a pigmented KO rat model for lecithin retinol acyltransferase (LRAT) using the CRISPR/Cas9 system. The introduced mutation (c.12delA) is based on a patient group harboring a homozygous frameshift mutation in the Lrat gene (c.12delC), causing a dysfunctional visual (retinoid) cycle. The resulting KO rats exhibited progressively reduced electroretinography potentials from two weeks of age onwards and overall retinal thinning. Vision-based behavioral assays confirmed the reduced vision. These KO rats are a novel animal model for retinal dystrophy, especially for early-onset retinal dystrophies.

\subsection{Models for Muscular Diseases}

Duchenne muscular dystrophy (DMD) is an X-linked lethal muscle disorder caused by mutations in the Duchenne muscular dystrophy $(D m d)$ gene encoding dystrophin. DMD model animals, such as $M d x$ (X-linked muscular dystrophy) mice and canine X-linked muscular dystrophy dogs, have been widely utilized in the development of a treatment for DMD. However, according to Larcher et al. [51], large animal models such as dogs are expensive and difficult to handle. In contrast, $M d x$ mice only partially mimic the human disease, with limited chronic muscular lesions and muscle weakness. Their small size also imposes limitations on analyses. In this context, a rat model could represent a useful alternative because rats are bigger than mice and could better reflect the lesions and functional abnormalities observed in DMD patients.

Dmd KO rats were successfully produced by two groups using CRISPR/Cas9 technology targeting two exons of the rat Dmd [50] or using TALENs targeting exon 23 [51]. These resulting $\mathrm{KO}$ rats exhibited a decline in muscle strength and the emergence of degenerative/regenerative phenotypes in the skeletal muscle, heart, and diaphragm. Furthermore, these phenotypes were transmitted to the next generation [50]. Notably, Dmd KO rats, but not mice, present cardiovascular alterations close to those observed in humans, which are the main cause of death of patients [51].

Desminopathy is a clinically heterogeneous muscle disease caused by over 60 different mutations in the desmin $(D E S)$ gene. The most common mutation with a clinical phenotype in humans is an exchange of arginine to proline at position 350 of desmin leading to p.R350P. Langer et al. [126] first produced a KI rat model for a muscle disease through the CRISPR/Cas9 technology using ssODN carrying the missense mutation Des c.10451046 (AGG > CCG) in exon 6 of Des. While muscle weights did not differ between the mutant rats and WT rats, the levels of many muscle-related proteins such as dystrophin, syntrophin, dysferlin, and annexin A2 increased in the mutant rats, showing the phenotype of desminopathy. This rat model will be a useful tool for furthering our understanding of the disease and testing therapeutic approaches to delay disease progression.

\subsection{Models for Pulmonary Diseases}

Cystic fibrosis (CF) is characterized by airway and digestive pathology with a reduced life expectancy and is one of the most common genetic diseases in western populations. The most common mutation is the missense mutation p.Phe508del (or F508del) in the cystic fibrosis transmembrane conductance regulator (CFTR) gene, which leads to abnormal CFTR function and mucus accumulation. Tuggle et al. [52] first generated Cftr KO rats using the ZFN technology. The resulting KO rats lacked CFTR activity and exhibited abnormalities in the ileum and increased intracellular mucus in the proximal nasal septa. Airway surface liquid and periciliary liquid depths were reduced, and the submucosal gland size was abnormal. Similar results have also been observed in another Cftr KO rat developed by Dreano et al. [106] using the CRISPR/Cas9 technology. Furthermore, Dreano et al. [106] produced another KI rats (carrying F508del mutation). These rats showed residual CFTR activity and milder phenotype than the Cftr KO rats. These findings suggest that these rat models can be a CF animal model that recapitulates various aspects of the human disease. Notably, a humanized CF rat strain expressing the G551D variant was produced through 
KI of the human CFTR cDNA carrying the G551D mutation downstream of the endogenous Cftr promoter using the ZFN technology [130].

\subsection{Models for Metabolic Diseases}

The low-density lipoprotein receptor $(L D L R)$ and apolipoprotein $\mathrm{E}(A P O E)$ genes control normal levels of cholesterol and other forms of fat in the blood. A deficiency in $A p o E$ is involved in several age-related fatty acid diseases. Wei et al. [56] established ApoE $\mathrm{KO}$ rats through TALEN-mediated gene targeting. After being fed with a high-cholesterol $\operatorname{diet}(\mathrm{HCD})$ for 12 weeks, the ApoE KO rats displayed typical dyslipidemia, although there was no obvious atherosclerotic lesion in the en face aortas. Notably, partial ligation caused the formation of plaques consisting of lipids and macrophages in carotid arteries from $A p o E \mathrm{KO}$ rats. Wei et al. [56] concluded that the ApoE KO rats can be a novel model for dyslipidemia. Lee et al. [110] produced ApoE KO rats using Cas12a (previously named Cpf1), an RNA-guided endonuclease, as a part of the CRISPR system. The resulting KO rats displayed hyperlipidemia and aortic lesions.

A deficiency in $L D L R$ is a cause of familial hypercholesterolemia (FH). Zhao et al. [92] and Lee et al. [110] created Ldlr KO rats. These ApoE and Ldlr KO rats mimic pathological changes observed in hyperlipidemia and atherosclerosis in humans with genetic deficiencies and in normal individuals, suggesting usefulness in the research of atherosclerosis.

Melanocortin-3 and -4 receptors (MC3R and MC4R) regulate energy homeostasis. You et al. [70] generated Mc3r and Mc4r single- and double-KO (DKO) rats using the CRISPR/Cas9 system. Mc3r KO rats displayed hypophagia and decreased body weight, whereas $M c 4 r \mathrm{KO}$ and DKO rats exhibited hyperphagia and increased body weight. All three mutants showed increased white adipose tissue mass and adipocyte size. These mutant rats will be important in defining the complicated signaling pathways of MC3R and MC4R. According to You et al. [70], both Mc4r KO and DKO rats are good models for obesity and diabetes research.

Hereditary tyrosinemia type I (HT1) is caused by a deficiency in fumarylacetoacetate hydrolase (FAH) enzyme. Fah-deficient mice and pigs are phenotypically analogous to human HT1, but do not recapitulate all chronic features of the human disorder, especially liver fibrosis and cirrhosis. Zhang et al. [63] produced Fah $\mathrm{KO}$ rats through MI of CRISPR/Cas9 components to obtain HT1 models. The Fah KO rats faithfully represented hypertyrosinemia, liver failure, and renal tubular damage. More importantly, they developed remarkable liver fibrosis and cirrhosis, which have not been observed in Fah mutant mice or pigs. These data suggest that Fah KO rats may be used as an animal model of HT1 with liver cirrhosis.

Pseudoxanthoma elasticum (PXE) — a heritable ectopic mineralization disorder-is caused by mutations in the ATP-binding cassette subtype $C$ number 6 (ABCC6) gene primarily expressed in the liver and kidneys. These mutations result in generalized arterial calcification throughout the body in infancy. Li et al. [75] generated Abcc6 $\mathrm{KO}$ rats as models of PXE using the ZFN technology. The plasma inorganic pyrophosphate (PPi) level was reduced $(<30 \%)$, leading to a lowered $\mathrm{PPi} /$ inorganic phosphate plasma ratio. When in situ liver and kidney perfusions were performed, the PPi levels in the perfusates were significantly reduced, but those in the liver of WT rats remained high. Li et al. [75] speculate that hepatic ABCC6 may play a critical role in contributing to plasma PPi levels, identifying the liver as a target of molecular correction to counteract ectopic mineralization in PXE.

Wolfram syndrome (WS) is a rare autosomal-recessive disorder caused by mutations in the Wolfram syndrome 1 (WFS1) gene and characterized by juvenile-onset diabetes, optic atrophy, hearing loss, and a number of other complications. According to Plaas et al. [76], no mutant $W f_{s} 1$ mice displayed fasting hyperglycemia. In other words, previous mouse models of WS involved only partial diabetes and other disease symptoms. Plaas et al. [76] generated $W f s 1 \mathrm{KO}$ rats, in which exon 5 of the $W f s 1$ gene was deleted, resulting in a loss of 27 amino acids from the WFS1 protein. The resulting KO rats showed progressive glucose intolerance, glycosuria, hyperglycemia, and severe body weight loss by 12 months of age. They also exhibited neuronal abnormality such as axonal degeneration and disorganization 
of the myelin. The phenotype of these $\mathrm{KO}$ rats indicates that they have the core symptoms of WS.

Leptin is a cytokine-like hormone principally produced by white adipose tissues. Defects in leptin production cause severe obesity. Leptin receptor (Lepr) encoded by the diabetes $(d b)$ gene is highly expressed in the choroid plexus. Bao et al. [59] produced Lepr $\mathrm{KO}$ rats through the CRISPR/Cas9 technology. The resulting KO rats exhibited obesity, hyperphagia, hyperglycemia, glucose intolerance, hyperinsulinemia, and dyslipidemia. In contrast, Chen et al. [79] generated Lepr KO rats through the TALEN technology. These rat models could complement the existing models ( $d b / d b$ mice and Zucker rats) $[215,216]$ and be useful for biomedical and pharmacological research in obesity and diabetes.

Angiopoietin-like protein 8 (ANGPTL8) is a liver- and adipocyte-derived protein that controls plasma triglyceride levels. Izumi et al. [89] generated Angptl8 KO rats through the CRISPR/Cas9 technology to clarify the roles of Angptl8 in glucose and lipid metabolism. The resulting $\mathrm{KO}$ rats exhibited decreased body weight and fat content, associated with impaired lipogenesis in adipocytes. Izumi et al. [89] suggest that ANGPTL8 might be an important therapeutic target for obesity and dyslipidemia.

Hereditary aceruloplasminemia (HA) is a genetic disease characterized by iron accumulation in the liver and brain. The mutation of the ceruloplasmin ( $C p$ gene is thought to be related to HA pathogenesis. Kenawi et al. [115] generated $C p$ KO rats through the CRISPR/Cas9 system. The C $p$ KO rats exhibited decreased iron concentration, transferrin saturation, plasma ceruloplasmin, and ferroxidase activity, which is considered essential for macrophage iron release. Thus, $\mathrm{C} p \mathrm{KO}$ rats can mimic the iron hepatosplenic phenotype in HA, which will form the basis to understand and treat the disease.

\subsection{Models for Kidney Diseases}

The renin (REN)-angiotensin system plays an important role in the control of blood pressure and renal function. Moreno et al. [31] produced Ren KO rats through ZFNmediated GE system targeted to exon 5 of Ren. The resulting rats exhibited reduced body weight, lower blood pressure, and abnormal renal morphology (as exemplified by cortical interstitial fibrosis and abnormally shaped glomeruli). These results suggest the role of REN in the regulation of blood pressure and kidney function.

Primary hyperoxaluria type 1 (PH1) is an inherited disease caused by mutations in the mitochondrial localized alanine-glyoxylate aminotransferase $(A g x t)$ gene, leading to abnormal metabolism of glyoxylic acid in the liver, subsequent endogenous oxalate overproduction, and deposition of oxalate in multiple organs, mainly the kidney. Patients with PH1 often suffer from recurrent urinary tract stones and finally renal failure. There is no effective treatment other than combined liver-kidney transplantation. Zheng et al. [94] produced Agxt KO rats as PH1 models through the CRISPR/Cas9 system. The resulting Agxt $\mathrm{KO}$ rats excreted more oxalate in the urine than WT animals and exhibited crystalluria with mild fibrosis in the kidney. These data suggest that Agxt-deficiency in mitochondria impairs glyoxylic acid metabolism and leads to PH1 in rats. This rat strain would be a valuable tool for developing innovative drugs and therapeutics.

Urate oxidase (uricase) encoded by UOX gene is a key enzyme whose disfunction causes hyperuricemia. Because of the low survival rate of Uox-deficient mice [217], Yu et al. [128] generated Uox KO rats through the CRISPR/Cas9 system targeting the exons 2 to 4 of Uox. The resulting Uox KO rats, called "Kunming-DY rats", were apparently healthy, with more than a $95 \%$ survival up to one year. The male rats' serum uric acid increased at levels significantly higher than those of WT rats. Kunming-DY rats exhibited histological renal changes including mild glomerular/tubular lesions, suggesting an alternative model animal to study hyperuricemia and associated diseases mimicking human conditions.

\subsection{Models for Ophthalmology Diseases}

The aryl hydrocarbon receptor (AHR) is a ligand-activated transcription factor which plays a role in the development of multiple tissues and is activated by a large number of 
ligands, including 2,3,7,8-tetrachlorodibenzo-p-dioxin. To examine the roles of the AHR in both normal biological development and response to environmental chemicals, Harrill et al. [40] produced $A h r \mathrm{KO}$ rats through the ZFN technology targeting exon 2 of the $A h r$ and compared with an existing Ahr KO mouse model. Ahr KO rats, but not Ahr KO mice, displayed pathological alterations to the urinary tract, as exemplified by bilateral renal dilation (hydronephrosis). In contrast, abnormalities in vascular development were observed in Ahr KO mice, but not in rats. These findings suggest the differences in the role of AHR in tissue development, homeostasis, and toxicity between rats and mice.

\subsection{Models for Hematological Systems}

Hemophilia $\mathrm{A}$ is a genetic bleeding disorder resulting from factor VIII (FVIII or F8) deficiency. In preclinical hemophilia research, an animal model that reflects both the phenotype and pathology of the disease is required. Nielsen et al. [41] produced KO rats lacking detectable F8 activity through the ZFN technology targeting exon 16 of the F8 gene. Episodes of spontaneous bleeding requiring treatments were observed in $70 \%$ of $F 8$ $\mathrm{KO}$ rats. Shi et al. [120] produced $F 8 \mathrm{KO}$ rats in which nearly the entire rat $F 8$ gene was inverted, causing translational stop six amino acids after the signal sequence, through the CRISPR/Cas9 technology to examine whether platelet F8 expression can prevent severe spontaneous bleeding in F8 KO rats. They showed that the severe spontaneous bleeding phenotype in $F 8 \mathrm{KO}$ rats was successfully rescued by platelet-specific F8 expression through bone marrow cell transplantation.

Autoimmune regulator (AIRE) deficiency in humans induces a life-threatening generalized autoimmune disease called autoimmune polyendocrinopathy-candidiasis-ectodermal dystrophy (APECED), and no curative treatments are available. Several models of AIREdeficient mice have been generated; although they have been useful in understanding the role of AIRE in central tolerance, they do not reproduce the APECED symptoms accurately and, thus, there is still a need for an animal model displaying APECED-like disease. Ossart et al. [86] produced an Aire KO rat model using ZFN technology. The resulting KO rats exhibited several of the key symptoms of APECED disease, including alopecia, skin depigmentation, and nail dystrophy, which are much more pronounced than those in Aire $\mathrm{KO}$ mice and closer to manifestations in humans.

\subsection{Others}

Estrogens play pivotal roles in the development and function of many organ systems, including the reproductive system. Rumi et al. [48] generated estrogen receptor 1 (Esr1) $\mathrm{KO}$ rats using the ZFN system targeting exon 3 of Esr1. Both male and female Esr1 KO rats were infertile. Esr1 KO males had small testes with distended and dysplastic STs, whereas Esr1 KO females possessed large polycystic ovaries, thread-like uteri, and poorly developed mammary glands. In addition, the uteri of Esr1 KO rats failed to $17 \beta$-estradiol treatment. This rat model provides a new experimental tool for investigating the pathophysiology of estrogen action.

The forkhead box N1 (FOXN1) gene is known as a critical factor for the differentiation of thymic and skin epithelial cells. Goto et al. [69] generated Foxn1 KO rats through the CRISPR/Cas9 technology. The resulting Foxn1 KO rats exhibited thymus deficiency and incomplete hairless, which was characterized by splicing variants.

Multidrug resistance 1 (MDR1; also known as P-glycoprotein) is a key efflux transporter that plays an important role not only in the transport of endogenous and exogenous substances, but also in tumor MDR, one of the most important impediments to the effective chemotherapy of cancer. In rodents, two isoforms, Mdr1a and Mdr1b, encode MDR1. Liang et al. [112] produced DKO rats (in which both $M d r 1 a$ and $M d r 1 b$ had been disrupted) through the CRISPR/Cas9 system. Pharmacokinetic studies of digoxin, a typical substrate of MDR1, confirmed the deficiency of MDR1 in resulting KO rats. This rat model is a useful tool for studying the function of MDR1 in drug absorption, tumor MDR, and drug-target validation. 


\section{Perspective}

Genome-engineering technology, especially the CRISPR/Cas9 system, has opened ways to create $\mathrm{KO}$ at the specific genes and targeted $\mathrm{KI}$, perform gene replacement, and conditionally ablate gene expression with more ease. Furthermore, recently, CRISPR-based new tools such as use of other types of Cas9 endonucleases (i.e., Staphylococcus aureus Cas9 (SaCas9), Francisella novicida Cas9 (FnCas9), Neisseria meningitidis Cas9 (NmCas9), Streptococcus thermophilus Cas9 (St1Cas9), and Brevibacillus laterosporus Cas9 (BlatCas9)) and Cas12a (Cpf1) endonucleases (i.e., Acidaminococcus sp. Cpf1 (AsCpf1) and Lachnospiraceae bacterium Cpf1 (LbCpf1)) (reviewed by Nakade et al. [218]), prime editing (PE), and BE have emerged. For example, BE systems, as exemplified by ABE, have already been applied in rats $[97,104]$. The PE system is the latest addition to the CRISPR genome-engineering toolkit and represents a novel approach to expand the scope of donor-free precise DNA editing [219]. PE-based manipulation of mouse genome has already been successfully performed [220]. This approach will soon be applied to modify the rat genome. Manipulation of mtDNA by DdCBE coupled with the PB transposon system has become possible in rats [153]. These new technologies, together with the newly developed gene delivery tools such as in vitro or in vivo EP-based gene delivery (TAKE and $i$-GONAD/rGONAD), will accelerate the creation of more GM rats, which will shed light on the new role of the previously known genes, whose function had been investigated using mouse models but was judged as being far from the function inferred from human diseases.

\section{Conclusions}

To date, tools for modifying the mouse genome as exemplified by traditional genetargeting-based $\mathrm{KO}$ and $\mathrm{KI}$ technologies have been extensively employed in mice and have proven useful for understanding the molecular mechanism underlying human diseases. However, despite these efforts, the consequences obtained from the $\mathrm{KO}$ or $\mathrm{KI}$ mice were often different from those observed in human diseases. According to Barbaric et al. [221], discrepancies between the symptoms of human diseases and mouse phenotypes may be ascribed to redundant gene networks or alternative pathways or modifiers. This point was further strengthened when a number of GM rats were successfully produced through newly developed GE technologies (see Table 1). For example, Dmd KO rats (but not mice) presented cardiovascular alterations close to those observed in humans, which are the main cause of death in patients. Furthermore, Fah $\mathrm{KO}$ rats developed remarkable liver fibrosis and cirrhosis, which have not been observed in Fah mutant mice or pigs. These findings encourage the speculation that rats may better mimic the human situation than mice.

Author Contributions: M.S. and S.T. drafted the manuscript; S.N. and E.I. reviewed the manuscript. All authors have read and agreed to the published version of the manuscript.

Funding: This study was partly supported by JSPS KAKENHI (No. 24580411 for M.S.; No. 16H05049 for S.N.; No. 21K10165 for E.I.; No. 16K07087 for S.T.).

Institutional Review Board Statement: Not applicable.

Informed Consent Statement: Not applicable.

Data Availability Statement: Not applicable.

Acknowledgments: We thank Kazusa Inada for her support for in-house drawing of the Figures, shown in Figures 1-4.

Conflicts of Interest: The founding sponsors had no role in the design of the study, the collection, analyses, or interpretation of data, the writing of the manuscript, or the decision to publish the results. 
Abbreviations

\begin{tabular}{|c|c|}
\hline Abcc6 & ATP binding cassette subtype C number 6 \\
\hline $\mathrm{ABE}$ & Adenine base editor \\
\hline Abhd6 & Alpha/beta-hydrolase domain 6 \\
\hline Adora $2 a$ & Adenosine 2 a receptor \\
\hline$\alpha-G a l A$ & $\alpha$-galactosidase $\mathrm{A}$ \\
\hline $\operatorname{Agxt}$ & Alanine-glyoxylate aminotransferase \\
\hline Ahr & Aryl hydrocarbon receptor \\
\hline Aire & Autoimmune regulator \\
\hline ALS & Amyotrophic lateral sclerosis \\
\hline Angptl8 & Angiopoietin-like protein 8 \\
\hline Anks3 & Ankyrin repeat and sterile alpha motif domain containing 3 \\
\hline APECED & Autoimmune polyendocrinopathy-candidiasis-ectodermal dystrophy \\
\hline ApoE & Apolipoprotein E \\
\hline AS & Angelman syndrome \\
\hline AsCpf1 & Acidaminococcus sp. Cpf1 \\
\hline ASD & Autism spectrum disorder \\
\hline Asip & Agouti signaling protein \\
\hline Atg16l1 & Autophagy-related 16-like 1 \\
\hline$B 2 m$ & Beta-2-microglobulin \\
\hline $\mathrm{BE}$ & Base-editing \\
\hline BlatCas9 & Brevibacillus laterosporus Cas9 \\
\hline Bmpr2 & Bone morphogenetic protein receptor 2 \\
\hline $\mathrm{BN}$ & Brown Norway \\
\hline C3 & Complement C3 \\
\hline C9orf72 & Chromosome 9 open reading frame 72 \\
\hline Cas12a & CRISPR-associated protein 12a \\
\hline Calb2 & Calbindin 2 \\
\hline Carns1 & Carnosine synthase 1 \\
\hline Cas9n & Cas9 nickase \\
\hline $\mathrm{CBE}$ & Cytosine base editor \\
\hline Ccdc $85 c$ & Coiled-coil domain containing 85C \\
\hline Cck & Cholecystokinin \\
\hline $\mathrm{CD}$ & Crohn's disease \\
\hline CES2 & Carboxylesterase 2 \\
\hline $\operatorname{Ces} 2 a$ & Carboxylesterase 2A \\
\hline CF & Cystic fibrosis \\
\hline Cftr & Cystic fibrosis transmembrane conductance regulator \\
\hline CIPN & Chemotherapy-induced peripheral neuropathy \\
\hline Cirp & Cold-inducible RNA-binding protein \\
\hline CLICK & CRISPR with lssDNA inducing conditional knockout alleles \\
\hline$C p$ & Ceruloplasmin \\
\hline Cpf1 & CRISPR from Prevotella and Francisella1 \\
\hline Cplx1 & Complexin I \\
\hline Cre-ERT2 & Cre recombinase-estrogen receptor $\mathrm{T} 2$ \\
\hline Crhr1 & Corticotropin releasing hormone receptor 1 \\
\hline CRISPR/Cas9 & Clustered regularly interspaced palindrome repeats (CRISPR)/Caspase 9 (Cas9) \\
\hline Cas12a & Type V CRISPR-effector protein (formerly Cpf1) \\
\hline crRNA & CRISPR RNA \\
\hline CS & Cockayne syndrome \\
\hline$C s b$ & Cockayne syndrome B \\
\hline Cyp2c11 & Cytochrome P450, subfamily 2, polypeptide 11 \\
\hline Cyp2d & Cytochrome P450 family 2 subfamily D member 6 \\
\hline Cyp2e1 & Cytochrome P450 2E1 \\
\hline Cyp2J2 & Cytochrome P450 family 2 subfamily J member 2 \\
\hline Сур2J3 & Cytochrome P450, family 2 , subfamily $\mathrm{j}$, polypeptide 3 \\
\hline
\end{tabular}


Cyp2J10 Cytochrome P450, family 2, subfamily $\mathrm{j}$, polypeptide 10

Cyp3a1 Cytochrome P4503A1

Cyp3a2 Cytochrome P450 3A2

Cyp24a1 Cytochrome P450 family 24 subfamily A member 1

Cyp27b1 Cytochrome P450 family 27 subfamily B member 1

DA Dark agouti

Dat Dopamine transporter

db Diabetes

Dbndd1 Dysbindin (dystrobrevin binding protein 1) domain containing 1

Defb23 Defensin beta 23

Defb26 Defensin beta 26

Defb42 Defensin beta 42

dCas9 Dead Cas9

DdCBE DddA-derived cytosine base editor

DddA Bacterial toxin deaminase

Depdc5 DEP domain-containing 5

Des Desmin

DdCBE DddA-derived cytosine base editor

DMD Duchenne muscular dystrophy

Dmd Dystrophin-coding gene (dystrophin)

DKO Double KO

$D N A-P K c s \quad$ DNA-dependent protein kinase catalytic subunits

Dnah17 Dynein axonemal heavy chain 17

Drd1a Dopamine receptor D1A

DSB Double-stranded break

dsDNA Double-stranded DNA

dsRed Discosoma coral red fluorescent protein

EGFP Enhanced green fluorescent protein

EndoMT Endothelial-to-mesenchymal transition

EP Electroporation

Epsti1 Epithelial stromal interaction 1

Erbb3 Erb-B2 receptor tyrosine kinase 3

ERV Endogenous retroviral element

ES Embryonic stem

Esr1 Estrogen receptor 1

ET Egg transfer

F344 Fisher 344

F8 Factor 8

Fabp2 Fatty acid binding protein 2

Fah Fumarylacetoacetate hydrolase

FD Fabry disease

Fh Fumarate hydratase

FH Familial hypercholesterolemia

FHH Fawn-hooded hypertensive

Fmr1 Fragile $\mathrm{X}$ mental retardation 1

FMRP Fragile $X$ mental retardation protein

FnCas9 Francisella novicida Cas9

Foxp3 Forkhead box P3

Foxn1 Forkhead box N1

FSG F344-scid gamma

Fus Fused in sarcoma

FXS Fragile $X$ syndrome

Gaa Acid alpha-glucosidase

Gad1 Glutamate decarboxylase 1

GAD67 Glutamate decarboxylase 67-kDa isoform

GE Genome editing or genome-edited

GFP Green fluorescent protein

G6pd Glucose-6-phosphate dehydrogenase 


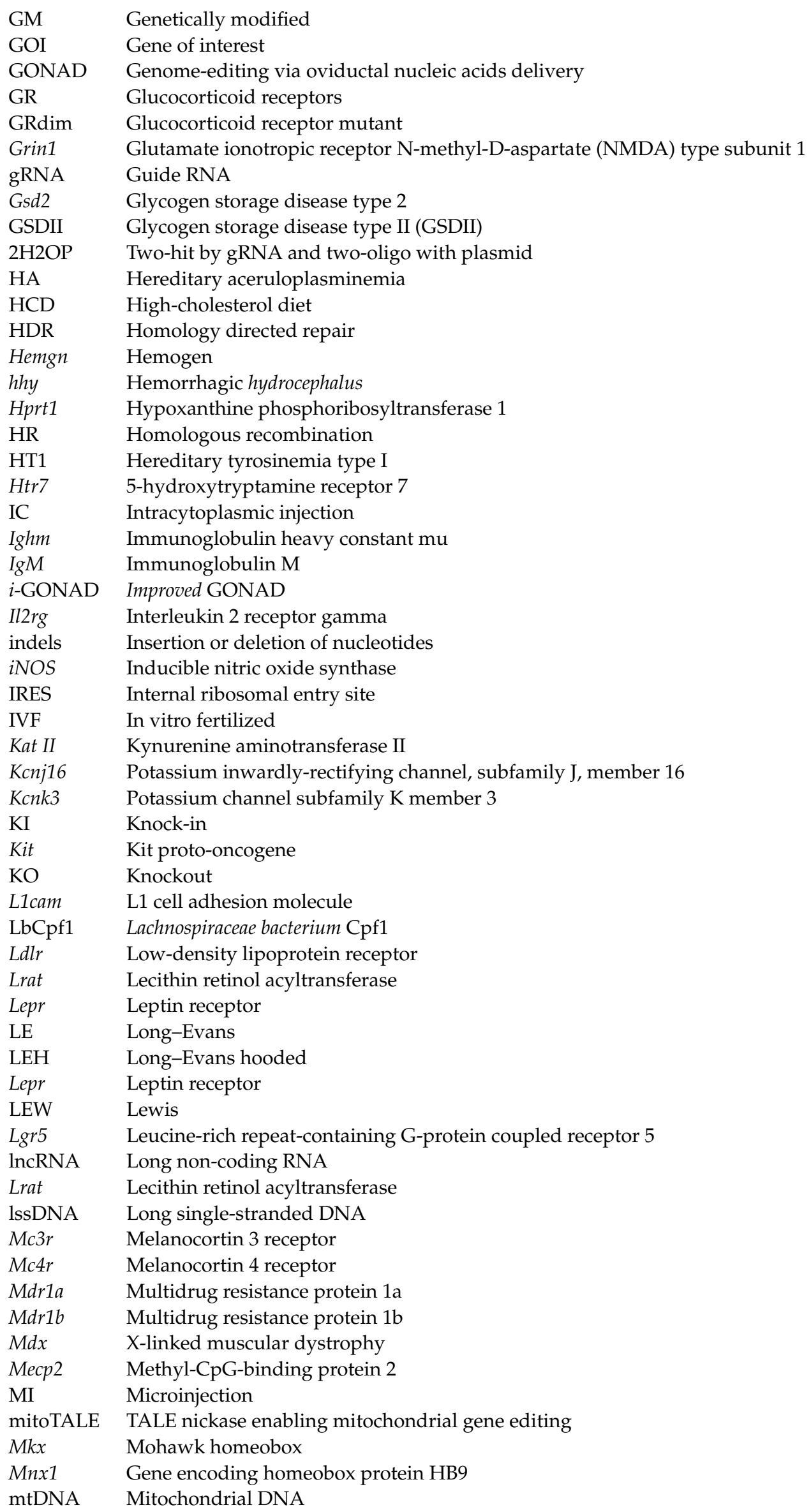




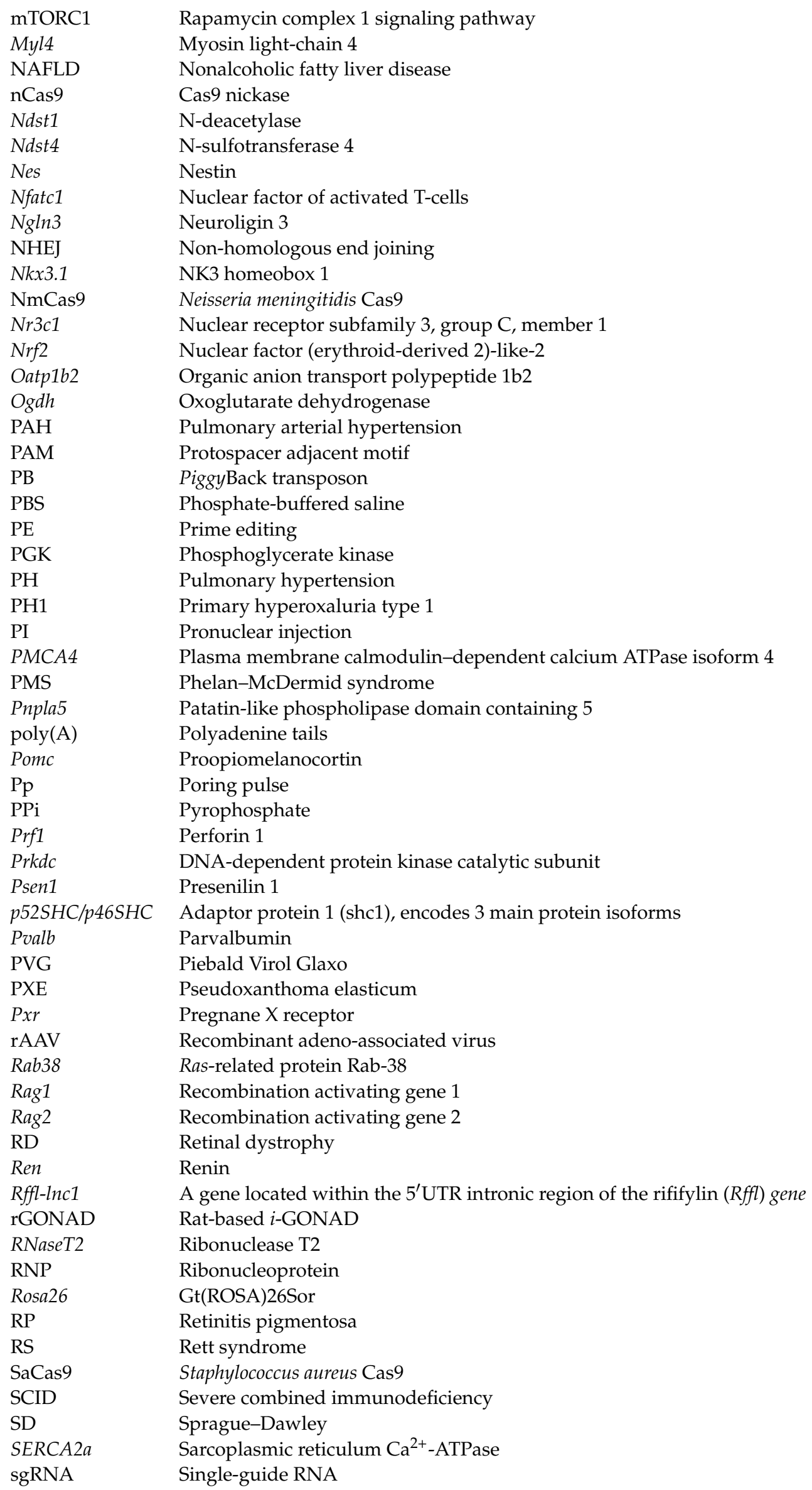




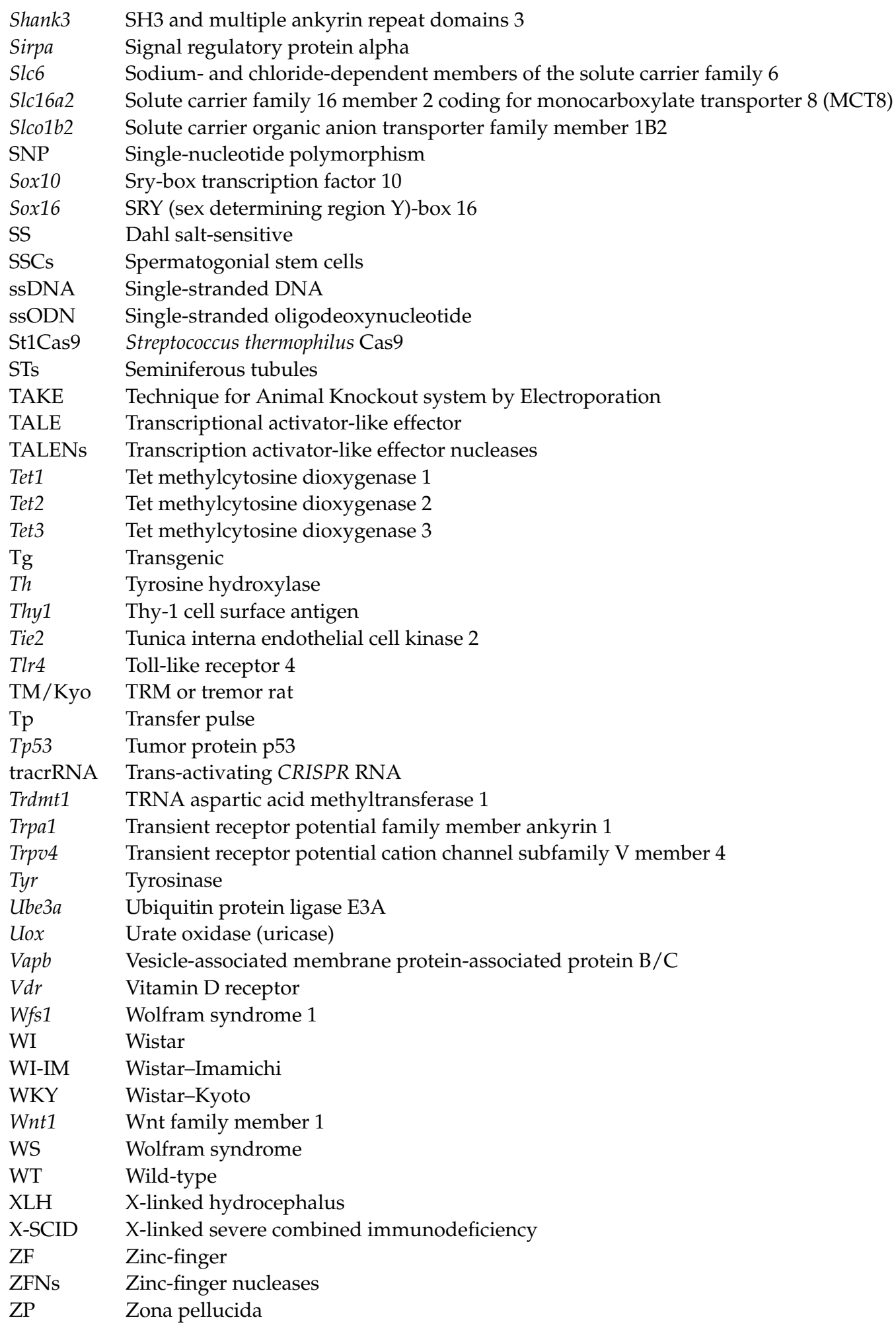

\section{References}

1. Kjell, J.; Olson, L. Rat models of spinal cord injury: From pathology to potential therapies. Dis. Models Mech. 2016, 9, 1125-1137. [CrossRef] [PubMed]

2. Jacob, H.J. The Rat: A model used in biomedical research. In Rat Genomics: Methods and Protocols Methods in Molecular Biology; Anegon, I., Ed.; Humana Press: Totowa, NJ, USA, 2010; pp. 1-11. [CrossRef]

3. Hammes, A.; Oberdorf-Maass, S.; Rother, T.; Nething, K.; Gollnick, F.; Linz, K.W.; Meyer, R.; Hu, K.; Han, H.; Gaudron, P.; et al. Overexpression of the sarcolemmal calcium pump in the myocardium of transgenic rats. Circ. Res. 1998, 83, 877-888. [CrossRef] [PubMed] 
4. Vetter, R.; Rehfeld, U.; Reissfelder, C.; Weifl, W.; Wagner, K.D.; Günther, J.; Hammes, A.; Tschöpe, C.; Dillmann, W.; Paul, M. Transgenic overexpression of the sarcoplasmic reticulum $\mathrm{Ca}^{2+}$ ATPase improves reticular $\mathrm{Ca}^{2+}$ handling in normal and diabetic rat hearts. FASEB J. 2002, 16, 1657-1659. [CrossRef] [PubMed]

5. Thomas, K.R.; Capecchi, M.R. Site-directed mutagenesis by gene targeting in mouse embryo-derived stem cells. Cell 1987, 51, 503-512. [CrossRef]

6. Doetschman, T.; Gregg, R.G.; Maeda, N.; Hooper, M.L.; Melton, D.W.; Thompson, S.; Smithies, O. Targetted correction of a mutant HPRT gene in mouse embryonic stem cells. Nature 1987, 330, 576-578. [CrossRef]

7. Buehr, M.; Meek, S.; Blair, K.; Yang, J.; Ure, J.; Silva, J.; McLay, R.; Hall, J.; Ying, Q.L.; Smith, A. Capture of authentic embryonic stem cells from rat blastocysts. Cell 2008, 135, 1287-1298. [CrossRef]

8. Li, P.; Tong, C.; Mehrian-Shai, R.; Jia, L.; Wu, N.; Yan, Y.; Maxson, R.E.; Schulze, E.N.; Song, H.; Hsieh, C.L.; et al. Germline competent embryonic stem cells derived from rat blastocysts. Cell 2008, 135, 1299-1310. [CrossRef]

9. Kawamata, M.; Ochiya, T. Generation of genetically modified rats from embryonic stem cells. Proc. Natl. Acad. Sci. USA 2010, 107, 14223-14228. [CrossRef]

10. Meek, S.; Buehr, M.; Sutherland, L.; Thomson, A.; Mullins, J.J.; Smith, A.J.; Burdon, T. Efficient gene targeting by homologous recombination in rat embryonic stem cells. PLoS ONE 2010, 5, e14225. [CrossRef]

11. Tong, C.; Li, P.; Wu, N.L.; Yan, Y.; Ying, Q.L. Production of p53 gene knockout rats by homologous recombination in embryonic stem cells. Nature 2010, 467, 211-213. [CrossRef]

12. Lan, H.; Li, S.; Guo, Z.; Men, H.; Wu, Y.; Li, N.; Bryda, E.C.; Capecchi, M.R.; Wu, S. Efficient generation of selection-gene-free rat knockout models by homologous recombination in ES cells. FEBS Lett. 2016, 590, 3416-3424. [CrossRef] [PubMed]

13. Kobayashi, T.; Yamaguchi, T.; Hamanaka, S.; Kato-Itoh, M.; Yamazaki, Y.; Ibata, M.; Sato, H.; Lee, Y.S.; Usui, J.; Knisely, A.S.; et al Generation of rat pancreas in mouse by interspecific blastocyst injection of pluripotent stem cells. Cell 2010, 142, 787-799. [CrossRef] [PubMed]

14. Yamamoto, S.; Ooshima, Y.; Nakata, M.; Yano, T.; Nishimura, N.; Nishigaki, R.; Satomi, Y.; Matsumoto, H.; Matsumoto, Y.; Takeyama, M. Efficient gene-targeting in rat embryonic stem cells by CRISPR/Cas and generation of human kynurenine aminotransferase II (KAT II) knock-in rat. Transgenic Res. 2015, 24, 991-1001. [CrossRef] [PubMed]

15. Chen, Y.; Spitzer, S.; Agathou, S.; Karadottir, R.T.; Smith, A. Gene editing in rat embryonic stem cells to produce in vitro models and in vivo reporters. Stem Cell Rep. 2017, 9, 1262-1274. [CrossRef]

16. Zan, Y.; Haag, J.D.; Chen, K.S.; Shepel, L.A.; Wigington, D.; Wang, Y.R.; Hu, R.; Lopez-Guajardo, C.C.; Brose, H.L.; Porter, K.I.; et al. Production of knockout rats using ENU mutagenesis and a yeast-based screening assay. Nat. Biotechnol. 2003, 21, 645-651. [CrossRef]

17. Harrison, M.M.; Jenkins, B.V.; O'Connor-Giles, K.M.; Wildonger, J.A. CRISPR view of development. Genes Dev. 2014, 28, 1859-1872. [CrossRef]

18. Hsu, P.D.; Lander, E.S.; Zhang, F. Development and applications of CRISPR-Cas9 for genome engineering. Cell 2014, 157, 1262-1278. [CrossRef]

19. Sonoda, E.; Hochegger, H.; Saberi, A.; Taniguchi, Y.; Takeda, S. Differential usage of non-homologous end-joining and homologous recombination in double strand break repair. DNA Repair 2006, 5, 1021-1029. [CrossRef]

20. Kim, Y.G.; Cha, J.; Chandrasegaran, S. Hybrid restriction enzymes: Zinc finger fusions to Fok I cleavage domain. Proc. Natl. Acad. Sci. USA 1996, 93, 1156-1160. [CrossRef]

21. Wolfe, S.A.; Nekludova, L.; Pabo, C.O. DNA recognition by Cys2His2 zinc finger proteins. Annu. Rev. Biophys. Biomol. Struct. 2000, 29, 183-212. [CrossRef]

22. Moscou, M.J.; Bogdanove, A.J. A simple cipher governs DNA recognition by TAL effectors. Science 2009, 326, 1501. [CrossRef] [PubMed]

23. Christian, M.; Cermak, T.; Doyle, E.L.; Schmidt, C.; Zhang, F.; Hummel, A.; Bogdanove, A.J.; Voytas, D.F. Targeting DNA double-strand breaks with TAL effector nucleases. Genetics 2010, 186, 757-761. [CrossRef] [PubMed]

24. Li, T.; Huang, S.; Jiang, W.Z.; Wright, D.; Spalding, M.H.; Weeks, D.P.; Yang, B. TAL nucleases (TALNs): Hybrid proteins composed of TAL effectors and FokI DNA-cleavage domain. Nucleic Acids Res. 2011, 39, 359-372. [CrossRef] [PubMed]

25. Jinek, M.; Chylinski, K.; Fonfara, I.; Hauer, M.; Doudna, J.A.; Charpentier, E. A programmable dual-RNA-guided DNA endonuclease in adaptive bacterial immunity. Science 2012, 337, 816-821. [CrossRef]

26. Gaj, T.; Gersbach, C.A.; Barbas, C.F., III. ZFN, TALEN, and CRISPR/Cas-based methods for genome engineering. Trends Biotechnol. 2013, 31, 397-405. [CrossRef]

27. Doudna, J.A.; Charpentier, E. Genome editing. The new frontier of genome engineering with CRISPR-Cas9. Science 2014, 346, 1258096. [CrossRef]

28. Geurts, A.M.; Cost, G.J.; Freyvert, Y.; Zeitler, B.; Miller, J.C.; Choi, V.M.; Jenkins, S.S.; Wood, A.; Cui, X.; Meng, X.; et al. Knockout rats via embryo microinjection of zinc-finger nucleases. Science 2009, 325, 433. [CrossRef]

29. Mashimo, T.; Takizawa, A.; Voigt, B.; Yoshimi, K.; Hiai, H.; Kuramoto, T.; Serikawa, T. Generation of knockout rats with X-linked severe combined immunodeficiency (X-SCID) using zinc-finger nucleases. PLoS ONE 2010, 5, e8870. [CrossRef]

30. Ménoret, S.; Iscache, A.L.; Tesson, L.; Rémy, S.; Usal, C.; Osborn, M.J.; Cost, G.J.; Brüggemann, M.; Buelow, R.; Anegon, I. Characterization of immunoglobulin heavy chain knockout rats. Eur. J. Immunol. 2010, 40, 2932-2941. [CrossRef] 
31. Moreno, C.; Hoffman, M.; Stodola, T.J.; Didier, D.N.; Lazar, J.; Geurts, A.M.; North, P.E.; Jacob, H.J.; Greene, A.S. Creation and characterization of a renin knockout rat. Hypertension 2011, 57, 614-619. [CrossRef]

32. Tesson, L.; Usal, C.; Ménoret, S.; Leung, E.; Niles, B.J.; Remy, S.; Santiago, Y.; Vincent, A.I.; Meng, X.; Zhang, L.; et al. Knockout rats generated by embryo microinjection of TALENs. Nat. Biotechnol. 2011, 29, 695-696. [CrossRef] [PubMed]

33. Cui, X.; Ji, D.; Fisher, D.A.; Wu, Y.; Briner, D.M.; Weinstein, E.J. Targeted integration in rat and mouse embryos with zinc-finger nucleases. Nat. Biotechnol. 2011, 29, 64-67. [CrossRef]

34. Mashimo, T.; Takizawa, A.; Kobayashi, J.; Kunihiro, Y.; Yoshimi, K.; Ishida, S.; Tanabe, K.; Yanagi, A.; Tachibana, A.; Hirose, J.; et al. Generation and characterization of severe combined immunodeficiency rats. Cell Rep. 2012, 2, 685-694. [CrossRef]

35. Ménoret, S.; Fontanière, S.; Jantz, D.; Tesson, L.; Thinard, R.; Rémy, S.; Usal, C.; Ouisse, L.H.; Fraichard, A.; Anegon, I. Generation of Rag1-knockout immunodeficient rats and mice using engineered meganucleases. FASEB J. 2013, 27, 703-711. [CrossRef] [PubMed]

36. Brown, A.J.; Fisher, D.A.; Kouranova, E.; McCoy, A.; Forbes, K.; Wu, Y.; Henry, R.; Ji, D.; Chambers, A.; Warren, J.; et al. Whole-rat conditional gene knockout via genome editing. Nat. Methods 2013, 10, 638-640. [CrossRef] [PubMed]

37. Li, D.; Qiu, Z.; Shao, Y.; Chen, Y.; Guan, Y.; Liu, M.; Li, Y.; Gao, N.; Wang, L.; Lu, X.; et al. Heritable gene targeting in the mouse and rat using a CRISPR-Cas system. Nat. Biotechnol. 2013, 31, 681-683. [CrossRef]

38. Li, W.; Teng, F.; Li, T.; Zhou, Q. Simultaneous generation and germline transmission of multiple gene mutations in rat using CRISPR-Cas systems. Nat. Biotechnol. 2013, 31, 684-686. [CrossRef]

39. Ferguson, C.; McKay, M.; Harris, R.A.; Homanics, G.E. Toll-like receptor 4 (Tlr4) knockout rats produced by transcriptional activator-like effector nuclease (TALEN)-mediated gene inactivation. Alcohol 2013, 47, 595-599. [CrossRef]

40. Harrill, J.A.; Hukkanen, R.R.; Lawson, M.; Martin, G.; Gilger, B.; Soldatow, V.; Lecluyse, E.L.; Budinsky, R.A.; Rowlands, J.C.; Thomas, R.S. Knockout of the aryl hydrocarbon receptor results in distinct hepatic and renal phenotypes in rats and mice. Toxicol. Appl. Pharmacol. 2013, 272, 503-518. [CrossRef]

41. Nielsen, L.N.; Wiinberg, B.; Häger, M.; Holmberg, H.L.; Hansen, J.J.; Roepstorff, K.; Tranholm, M. A novel F8 ${ }^{-/-}$rat as a translational model of human hemophilia A. J. Thromb. Haemost. 2014, 12, 1274-1282. [CrossRef]

42. Hamilton, S.M.; Green, J.R.; Veeraragavan, S.; Yuva, L.; McCoy, A.; Wu, Y.; Warren, J.; Little, L.; Ji, D.; Cui, X.; et al. Fmr1 and Nlgn3 knockout rats: Novel tools for investigating autism spectrum disorders. Behav. Neurosci. 2014, 128, 103-109. [CrossRef] [PubMed]

43. Kaneko, T.; Sakuma, T.; Yamamoto, T.; Mashimo, T. Simple knockout by electroporation of engineered endonucleases into intact rat embryos. Sci. Rep. 2014, 4, 6382. [CrossRef] [PubMed]

44. Remy, S.; Tesson, L.; Menoret, S.; Usal, C.; De Cian, A.; Thepenier, V.; Thinard, R.; Baron, D.; Charpentier, M.; Renaud, J.B.; et al. Efficient gene targeting by homology-directed repair in rat zygotes using TALE nucleases. Genome Res. 2014, 24, 1371-1383. [CrossRef] [PubMed]

45. Ma, Y.; Ma, J.; Zhang, X.; Chen, W.; Yu, L.; Lu, Y.; Bai, L.; Shen, B.; Huang, X.; Zhang, L. Generation of eGFP and Cre knockin rats by CRISPR/Cas9. FEBS J. 2014, 281, 3779-3790. [CrossRef]

46. Yoshimi, K.; Kaneko, T.; Voigt, B.; Mashimo, T. Allele-specific genome editing and correction of disease-associated phenotypes in rats using the CRISPR-Cas platform. Nat. Commun. 2014, 5, 4240. [CrossRef]

47. Ma, Y.; Shen, B.; Zhang, X.; Lu, Y.; Chen, W.; Ma, J.; Huang, X.; Zhang, L. Heritable multiplex genetic engineering in rats using CRISPR/Cas9. PLoS ONE 2014, 9, e89413. [CrossRef]

48. Rumi, M.A.K.; Dhakal, P.; Kubota, K.; Chakraborty, D.; Lei, T.; Larson, M.A.; Wolfe, M.W.; Roby, K.F.; Vivian, J.L.; Soares, M.J. Generation of Esr1-knockout rats using zinc finger nuclease-mediated genome editing. Endocrinology 2014, 155, 1991-1999. [CrossRef]

49. De León, V.P.; Anne-Marie, M.; Laurent, T.; Ignacio, A.; Edith, H. Generation of TALEN-mediated GRdim knock-in rats by homologous recombination. PLOS ONE 2014, 9, e88146. [CrossRef]

50. Nakamura, K.; Fujii, W.; Tsuboi, M.; Tanihata, J.; Teramoto, N.; Takeuchi, S.; Naito, K.; Yamanouchi, K.; Nishihara, M. Generation of muscular dystrophy model rats with a CRISPR/Cas system. Sci. Rep. 2014, 4, 5635. [CrossRef]

51. Larcher, T.; Lafoux, A.; Tesson, L.; Remy, S.; Thepenier, V.; François, V.; Le Guiner, C.; Goubin, H.; Dutilleul, M.; Guigand, L.; et al. Characterization of dystrophin deficient rats: A new model for Duchenne muscular dystrophy. PLoS ONE 2014, 9, e110371. [CrossRef]

52. Tuggle, K.L.; Birket, S.E.; Cui, X.; Hong, J.; Warren, J.; Reid, L.; Chambers, A.; Ji, D.; Gamber, K.; Chu, K.K.; et al. Characterization of defects in ion transport and tissue development in cystic fibrosis transmembrane conductance regulator (CFTR)-knockout rats. PLoS ONE 2014, 9, e91253. [CrossRef] [PubMed]

53. Ranchoux, B.; Antigny, F.; Rucker-Martin, C.; Hautefort, A.; Péchoux, C.; Bogaard, H.J.; Dorfmüller, P.; Remy, S.; Lecerf, F.; Planté, S.; et al. Endothelial-to-mesenchymal transition in pulmonary hypertension. Circulation 2015, 131, 1006-1018. [CrossRef] [PubMed]

54. Kaneko, T.; Mashimo, T. Simple genome editing of rodent intact embryos by electroporation. PLoS ONE 2015, 10 , e0142755. [CrossRef] [PubMed]

55. Li, J.; Xie, D.; Huang, J.; Lv, F.; Shi, D.; Liu, Y.; Lin, L.; Geng, L.; Wu, Y.; Liang, D.; et al. Cold-inducible RNA-binding protein regulates cardiac repolarization by targeting transient outward potassium channels. Circ. Res. 2015, 116, 1655-1659. [CrossRef] [PubMed] 
56. Wei, S.; Zhang, Y.; Su, L.; He, K.; Wang, Q.; Zhang, Y.; Yang, D.; Yang, Y.; Ma, S. Apolipoprotein E-deficient rats develop atherosclerotic plaques in partially ligated carotid arteries. Atherosclerosis 2015, 243, 589-592. [CrossRef] [PubMed]

57. Ménoret, S.; De Cian, A.; Tesson, L.; Remy, S.; Usal, C.; Boulé, J.B.; Boix, C.; Fontanière, S.; Crénéguy, A.; Nguyen, T.H.; et al. Homology-directed repair in rodent zygotes using Cas9 and TALEN engineered proteins. Sci. Rep. 2015, 5, 14410. [CrossRef] [PubMed]

58. Wang, L.; Shao, Y.; Guan, Y.; Li, L.; Wu, L.; Chen, F.; Liu, M.; Chen, H.; Ma, Y.; Ma, X.; et al. Large genomic fragment deletion and functional gene cassette knock-in via Cas9 protein mediated genome editing in one-cell rodent embryos. Sci. Rep. $2015,5,17517$. [CrossRef]

59. Bao, D.; Ma, Y.; Zhang, X.; Guan, F.; Chen, W.; Gao, K.; Qin, C.; Zhang, L. Preliminary characterization of a leptin receptor knockout rat created by CRISPR/Cas9 system. Sci. Rep. 2015, 5, 15942. [CrossRef]

60. Chapman, K.M.; Medrano, G.A.; Jaichander, P.; Chaudhary, J.; Waits, A.E.; Nobrega, M.A.; Hotaling, J.M.; Ober, C.; Hamra, F.K. Targeted germline modifications in rats using CRISPR/Cas9 and spermatogonial stem cells. Cell Rep. 2015, 10, 1828-1835. [CrossRef]

61. Zhai, W.; Hu, H.; Le, L.; Zhuang, F.; Wang, K.; Zhao, Y.; Wang, K.Z.; Liu, X.M.; Sun, D.; Wang, X.Y.; et al. Generation and analysis of the Rett syndrome-associated MeCP2-null rat model. Yi Chuan 2016, 38, 1004-1011. [CrossRef]

62. Patterson, K.C.; Hawkins, V.E.; Arps, K.M.; Mulkey, D.K.; Olsen, M.L. MeCP2 deficiency results in robust Rett-like behavioural and motor deficits in male and female rats. Hum. Mol. Genet. 2016, 25, 3303-3320. [CrossRef]

63. Zhang, L.; Shao, Y.; Li, L.; Tian, F.; Cen, J.; Chen, X.; Hu, D.; Zhou, Y.; Xie, W.; Zheng, Y.; et al. Efficient liver repopulation of transplanted hepatocyte prevents cirrhosis in a rat model of hereditary tyrosinemia type I. Sci. Rep. 2016, 6, 31460. [CrossRef] [PubMed]

64. Yoshimi, K.; Kunihiro, Y.; Kaneko, T.; Nagahora, H.; Voigt, B.; Mashimo, T. ssODN-mediated knock-in with CRISPR-Cas for large genomic regions in zygotes. Nat. Commun. 2016, 7, 10431. [CrossRef] [PubMed]

65. Renaud, J.B.; Boix, C.; Charpentier, M.; De Cian, A.; Cochennec, J.; Duvernois-Berthet, E.; Perrouault, L.; Tesson, L.; Edouard, J.; Thinard, R.; et al. Improved genome editing efficiency and flexibility using modified oligonucleotides with TALEN and CRISPR-Cas9 nucleases. Cell Rep. 2016, 14, 2263-2272. [CrossRef] [PubMed]

66. Yu, D.; Zhong, Y.; Li, X.; Li, Y.; Li, X.; Cao, J.; Fan, Z.; Fan, H.; Yuan, L.; Xu, B.; et al. Generation of TALEN-mediated FH knockout rat model. Oncotarget 2016, 7, 61656-61669. [CrossRef]

67. Marsan, E.; Ishida, S.; Schramm, A.; Weckhuysen, S.; Muraca, G.; Lecas, S.; Liang, N.; Treins, C.; Pende, M.; Roussel, D.; et al. Depdc5 knockout rat: A novel model of mTORopathy. Neurobiol. Dis. 2016, 89, 180-189. [CrossRef]

68. Ma, Y.; Chen, W.; Zhang, X.; Yu, L.; Dong, W.; Pan, S.; Gao, S.; Huang, X.; Zhang, L. Increasing the efficiency of CRISPR/Cas9mediated precise genome editing in rats by inhibiting NHEJ and using Cas9 protein. RNA Biol. 2016, 13, 605-612. [CrossRef]

69. Goto, T.; Hara, H.; Nakauchi, H.; Hochi, S.; Hirabayashi, M. Hypomorphic phenotype of Foxn1 gene-modified rats by CRISPR/Cas9 system. Transgenic Res. 2016, 25, 533-544. [CrossRef]

70. You, P.; Hu, H.; Chen, Y.; Zhao, Y.; Yang, Y.; Wang, T.; Xing, R.; Shao, Y.; Zhang, W.; Li, D.; et al. Effects of melanocortin 3 and 4 receptor deficiency on energy homeostasis in rats. Sci. Rep. 2016, 6, 34938. [CrossRef]

71. Priestley, J.R.C.; Kautenburg, K.E.; Casati, M.C.; Endres, B.T.; Geurts, A.M.; Lombard, J.H. The NRF2 knockout rat: A new animal model to study endothelial dysfunction, oxidant stress, and microvascular rarefaction. Am. J. Physiol. Heart Circ. Physiol. 2016, 310, H478-H487. [CrossRef]

72. Taguchi, K.; Takaku, M.; Egner, P.A.; Morita, M.; Kaneko, T.; Mashimo, T.; Kensler, T.W.; Yamamoto, M. Generation of a new model rat: Nrf2 knockout rats are sensitive to aflatoxin B1 toxicity. Toxicol. Sci. 2016, 152, 40-52. [CrossRef] [PubMed]

73. Wang, X.; Tang, Y.; Lu, J.; Shao, Y.; Qin, X.; Li, Y.; Wang, L.; Li, D.; Liu, M. Characterization of novel cytochrome P450 2E1 knockout rat model generated by CRISPR/Cas9. Biochem. Pharmacol. 2016, 105, 80-90. [CrossRef] [PubMed]

74. Suzuki, H.; Ito, Y.; Shinohara, M.; Yamashita, S.; Ichinose, S.; Kishida, A.; Oyaizu, T.; Kayama, T.; Nakamichi, R.; Koda, N.; et al. Gene targeting of the transcription factor Mohawk in rats causes heterotopic ossification of Achilles tendon via failed tenogenesi. Proc. Natl. Acad. Sci. USA 2016, 113, 7840-7845. [CrossRef] [PubMed]

75. Li, Q.; Kingman, J.; van de Wetering, K.; Tannouri, S.; Sundberg, J.P.; Uitto, J. Abcc6 knockout rat model highlights the role of liver in PPi homeostasis in Pseudoxanthoma elasticum. J. Investig. Dermatol. 2017, 137, 1025-1032. [CrossRef] [PubMed]

76. Plaas, M.; Seppa, K.; Reimets, R.; Jagomäe, T.; Toots, M.; Koppel, T.; Vallisoo, T.; Nigul, M.; Heinla, I.; Meier, R.; et al. Wfs1deficient rats develop primary symptoms of Wolfram syndrome: Insulin-dependent diabetes, optic nerve atrophy and medullary degeneration. Sci. Rep. 2017, 7, 10220. [CrossRef]

77. Tian, Y.; Yang, C.; Shang, S.; Cai, Y.; Deng, X.; Zhang, J.; Shao, F.; Zhu, D.; Liu, Y.; Chen, G.; et al. Loss of FMRP impaired hippocampal long-term plasticity and spatial learning in rats. Front. Mol. Neurosci. 2017, 10, 269. [CrossRef]

78. Peng, W.; Li, M.; Li, H.; Tang, K.; Zhuang, J.; Zhang, J.; Xiao, J.; Jiang, H.; Li, D.; Yu, Y.; et al. Dysfunction of myosin lightchain 4 (MYL4) leads to heritable atrial cardiomyopathy with electrical, contractile, and structural components: Evidence from genetically-engineered rats. J. Am. Heart Assoc. 2017, 6, e007030. [CrossRef]

79. Chen, Y.; Lu, W.; Gao, N.; Long, Y.; Shao, Y.; Liu, M.; Chen, H.; Ye, S.; Ma, X.; Liu, M.; et al. Generation of obese rat model by transcription activator-like effector nucleases targeting the leptin receptor gene. Sci. China Life Sci. 2017, 60, 152-157. [CrossRef]

80. Liu, Y.; Gao, Q.; Zhang, X.; Huang, L.; Xu, K.; Hu, Y.; Liu, L.; Mu, Y.; Li, K. PNPLA5-knockout rats induced by CRISPR/Cas9 exhibit abnormal bleeding and lipid level. J. Integr. Agric. 2017, 16, 169-180. [CrossRef] 
81. Harony-Nicolas, H.; Kay, M.; du Hoffmann, J.; Klein, M.E.; Bozdagi-Gunal, O.; Riad, M.; Daskalakis, N.P.; Sonar, S.; Castillo, P.E.; Hof, P.R.; et al. Oxytocin improves behavioral and electrophysiological deficits in a novel Shank3-deficient rat. eLife 2017, 6 , e18904. [CrossRef]

82. Cheng, X.; Waghulde, H.; Mell, B.; Morgan, E.E.; Pruett-Miller, S.M.; Joe, B. Positional cloning of quantitative trait nucleotides for blood pressure and cardiac QT-interval by targeted CRISPR/Cas9 editing of a novel long non-coding RNA. PLoS Genet. 2017, 13, e1006961. [CrossRef] [PubMed]

83. Shen, J.; Lai, D.H.; Wilson, R.A.; Chen, Y.F.; Wang, L.F.; Yu, Z.L.; Li, M.Y.; He, P.; Hide, G.; Sun, X.; et al. Nitric oxide blocks the development of the human parasite Schistosoma japonicum. Proc. Natl. Acad. Sci. USA 2017, 114, 10214-10219. [CrossRef] [PubMed]

84. Palygin, O.; Levchenko, V.; Ilatovskaya, D.V.; Pavlov, T.S.; Pochynyuk, O.M.; Jacob, H.J.; Geurts, A.M.; Hodges, M.R.; Staruschenko, A. Essential role of Kir5.1 channels in renal salt handling and blood pressure control. JCI Insight 2017, 2, e92331. [CrossRef] [PubMed]

85. Lu, J.; Shao, Y.; Qin, X.; Liu, D.; Chen, A.; Li, D.; Liu, M.; Wang, X. CRISPR knockout rat cytochrome P450 3A1/2 model for advancing drug metabolism and pharmacokinetics research. Sci. Rep. 2017, 7, 42922. [CrossRef] [PubMed]

86. Ossart, J.; Moreau, A.; Autrusseau, E.; Ménoret, S.; Martin, J.C.; Besnard, M.; Ouisse, L.H.; Tesson, L.; Flippe, L.; Kisand, K.; et al Breakdown of immune tolerance in AIRE-deficient rats induces a severe autoimmune polyendocrinopathy-candiasis-ectodermal dystrophy-like autoimmune disease. J. Immunol. 2018, 201, 874-887. [CrossRef] [PubMed]

87. Zhang, T.; Jiang, X.; Xu, M.; Wang, H.; Sang, X.; Qin, M.; Bao, P.; Wang, R.; Zhang, C.; Lu, H.; et al. Sleep and circadian abnormalities precede cognitive deficits in R521C FUS knockin rats. Neurobiol. Aging 2018, 72, 159-170. [CrossRef]

88. Ménoret, S.; Ouisse, L.-H.; Tesson, L.; Delbos, F.; Garnier, D.; Remy, S.; Usal, C.; Concordet, J.P.; Giovannangeli, C.; Chenouard, V.; et al. Generation of immunodeficient rats with Rag1 and Il2rg gene deletions and human tissue grafting models. Transplantation 2018, 102, 1271-1278. [CrossRef]

89. Izumi, R.; Kusakabe, T.; Noguchi, M.; Iwakura, H.; Tanaka, T.; Miyazawa, T.; Aotani, D.; Hosoda, K.; Kangawa, K.; Nakao, K. CRISPR/Cas9-mediated Angptl8 knockout suppresses plasma triglyceride concentrations and adiposity in rats. J. Lipid Res. 2018, 59, 1575-1585. [CrossRef]

90. Takabayashi, S.; Aoshima, T.; Kabashima, K.; Aoto, K.; Ohtsuka, M.; Sato, M. i-GONAD (improved genome-editing via oviductal nucleic acids delivery), a convenient in vivo tool to produce genome-edited rats. Sci. Rep. 2018, 8, 12059. [CrossRef]

91. Kobayashi, T.; Namba, M.; Koyano, T.; Fukushima, M.; Sato, M.; Ohtsuka, M.; Matsuyama, M. Successful production of genome-edited rats by the rGONAD method. BMC Biotechnol. 2018, 18, 19. [CrossRef]

92. Zhao, Y.; Yang, Y.; Xing, R.; Cui, X.; Xiao, Y.; Xie, L.; You, P.; Wang, T.; Zeng, L.; Peng, W.; et al. Hyperlipidemia induces typical atherosclerosis development in Ldlr and Apoe deficient rats. Atherosclerosis 2018, 271, 26-35. [CrossRef] [PubMed]

93. Shao, Y.; Wang, L.; Guo, N.; Wang, S.; Yang, L.; Li, Y.; Wang, M.; Yin, S.; Han, H.; Zeng, L.; et al. Cas9-nickase-mediated genome editing corrects hereditary tyrosinemia in rats. J. Biol. Chem. 2018, 293, 6883-6892. [CrossRef] [PubMed]

94. Zheng, R.; Fang, X.; He, L.; Shao, Y.; Guo, N.; Wang, L.; Liu, M.; Li, D.; Geng, H. Generation of a primary hyperoxaluria type 1 disease model via CRISPR/Cas9 system in rats. Curr. Mol. Med. 2018, 18, 436-447. [CrossRef]

95. Miyasaka, Y.; Uno, Y.; Yoshimi, K.; Kunihiro, Y.; Yoshimura, T.; Tanaka, T.; Ishikubo, H.; Hiraoka, Y.; Takemoto, N.; Tanaka, T.; et al CLICK: One-step generation of conditional knockout mice. BMC Genom. 2018, 19, 318. [CrossRef]

96. Sinkevicius, K.W.; Morrison, T.R.; Kulkarni, P.; Cagliostro, M.K.C.; Iriah, S.; Malmberg, S.; Sabrick, J.; Honeycutt, J.A.; Askew, K.L.; Trivedi, M.; et al. RNaseT2 knockout rats exhibit hippocampal neuropathology and deficits in memory. Dis. Models Mech. 2018, 11, dmm032631. [CrossRef] [PubMed]

97. Yang, L.; Zhang, X.; Wang, L.; Yin, S.; Zhu, B.; Xie, L.; Duan, Q.; Hu, H.; Zheng, R.; Wei, Y.; et al. Increasing targeting scope of adenosine base editors in mouse and rat embryos through fusion of TadA deaminase with Cas9 variants. Protein Cell 2018, 9 , 814-819. [CrossRef]

98. Miller, J.J.; Aoki, K.; Moehring, F.; Murphy, C.A.; O'Hara, C.L.; Tiemeyer, M.; Stucky, C.L.; Dahms, N.M. Neuropathic pain in a Fabry disease rat model. JCI Insight 2018, 3, e99171. [CrossRef] [PubMed]

99. Fan, Z.; Li, L.; Li, X.; Zhang, M.; Zhong, Y.; Li, Y.; Yu, D.; Cao, J.; Zhao, J.; Xiaoming, D.; et al. Generation of an oxoglutarate dehydrogenase knockout rat model and the effect of a high-fat diet. RSC Adv. 2018, 8, 16636-16644. [CrossRef]

100. Leo, D.; Sukhanov, I.; Zoratto, F.; Illiano, P.; Caffino, L.; Sanna, F.; Messa, G.; Emanuele, M.; Esposito, A.; Dorofeikova, M.; et al Pronounced hyperactivity, cognitive dysfunctions, and BDNF dysregulation in dopamine transporter knock-out rats. J. Neurosci. 2018, 38, 1959-1972. [CrossRef]

101. Xu, J.; Zhang, L.; Xie, M.; Li, Y.; Huang, P.; Saunders, T.L.; Fox, D.A.; Rosenquist, R.; Lin, F. Role of complement in a rat model of paclitaxel-induced peripheral neuropathy. J. Immunol. 2018, 200, 4094-4101. [CrossRef]

102. Noto, F.K.; Adjan-Steffey, V.; Tong, M.; Ravichandran, K.; Zhang, W.; Arey, A.; McClain, C.B.; Ostertag, E.; Mazhar, S.; Sangodkar, J.; et al. Sprague dawley Rag2-null rats created from engineered spermatogonial stem cells are immunodeficient and permissive to human xenografts. Mol. Cancer Ther. 2018, 17, 2481-2489. [CrossRef] [PubMed]

103. Zhang, C.; Zhou, Y.; Xie, S.; Yin, Q.; Tang, C.; Ni, Z.; Fei, J.; Zhang, Y. CRISPR/Cas9-mediated genome editing reveals the synergistic effects of $\beta$-defensin family members on sperm maturation in rat epididymis. FASEB J. 2018, 32, 1354-1363. [CrossRef] [PubMed] 
104. Ma, Y.; Yu, L.; Zhang, X.; Xin, C.; Huang, S.; Bai, L.; Chen, W.; Gao, R.; Li, J.; Pan, S.; et al. Highly efficient and precise base editing by engineered dCas9-guide tRNA adenosine deaminase in rats. Cell Discov. 2018, 4, 39. [CrossRef]

105. Wei, Y.; Yang, L.; Zhang, X.; Sui, D.; Wang, C.; Wang, K.; Shan, M.; Guo, D.; Wang, H. Generation and characterization of a CYP2C11-null rat model by using the CRISPR/Cas9 method. Drug Metab. Dispos. 2018, 46, 525-531. [CrossRef] [PubMed]

106. Dreano, E.; Bacchetta, M.; Simonin, J.; Galmiche, L.; Usal, C.; Slimani, L.; Sadoine, J.; Tesson, L.; Anegon, I.; Concordet, J.P.; et al. Characterization of two rat models of cystic fibrosis-KO and F508del CFTR-Generated by Crispr-Cas9. Anim. Models Exp. Med. 2019, 2, 297-311. [CrossRef]

107. Miller, J.J.; Aoki, K.; Mascari, C.A.; Beltrame, A.K.; Sokumbi, O.; North, P.E.; Tiemeyer, M.; Kriegel, A.J.; Dahms, N.M. $\alpha-$ Galactosidase A-deficient rats accumulate glycosphingolipids and develop cardiorenal phenotypes of Fabry disease. FASEB J. 2019, 33, 418-429. [CrossRef] [PubMed]

108. Song, T.J.; Lan, X.Y.; Wei, M.P.; Zhai, F.J.; Boeckers, T.M.; Wang, J.N.; Yuan, S.; Jin, M.Y.; Xie, Y.F.; Dang, W.W.; et al. Altered behaviors and impaired synaptic function in a novel rat model with a complete Shank3 deletion. Front. Cell. Neurosci. 2019, 13, 111. [CrossRef]

109. Lambert, M.; Capuano, V.; Boet, A.; Tesson, L.; Bertero, T.; Nakhleh, M.K.; Remy, S.; Anegon, I.; Pechoux, C.; Hautefort, A.; et al. Characterization of Kcnk3-mutated rat, a novel model of pulmonary hypertension. Circ. Res. 2019, 125, 678-695. [CrossRef]

110. Lee, J.G.; Ha, C.H.; Yoon, B.; Cheong, S.A.; Kim, G.; Lee, D.J.; Woo, D.C.; Kim, Y.H.; Nam, S.Y.; Lee, S.W.; et al. Knockout rat models mimicking human atherosclerosis created by Cpf1-mediated gene targeting. Sci. Rep. 2019, 9, 2628. [CrossRef]

111. Honda, A.; Tachibana, R.; Hamada, K.; Morita, K.; Mizuno, N.; Morita, K.; Asano, M. Efficient derivation of knock-out and knock-in rats using embryos obtained by in vitro fertilization. Sci. Rep. 2019, 9, 11571. [CrossRef]

112. Liang, C.; Zhao, J.; Lu, J.; Zhang, Y.; Ma, X.; Shang, X.; Li, Y.; Ma, X.; Liu, M.; Wang, X. Development and characterization of MDR1 (Mdr1a/b) CRISPR/Cas9 knockout rat model. Drug Metab. Dispos. 2019, 47, 71-79. [CrossRef] [PubMed]

113. Emmert, A.S.; Vuong, S.M.; Shula, C.; Lindquist, D.; Yuan, W.; Hu, Y.C.; Mangano, F.T.; Goto, J. Characterization of a novel rat model of X-linked hydrocephalus by CRISPR-mediated mutation in L1cam. J. Neurosurg. 2019, 132, 945-958. [CrossRef] [PubMed]

114. Xu, Y.; Wu, Z.; Liu, L.; Liu, J.; Wang, Y. Rat model of Cockayne syndrome neurological disease. Cell Rep. 2019, 29, 800-809.e5. [CrossRef] [PubMed]

115. Kenawi, M.; Rouger, E.; Island, M.L.; Leroyer, P.; Robin, F.; Rémy, S.; Tesson, L.; Anegon, I.; Nay, K.; Derbré, F.; et al. Ceruloplasmin deficiency does not induce macrophagic iron overload: Lessons from a new rat model of hereditary aceruloplasminemia. FASEB J. 2019, 33, 13492-13502. [CrossRef]

116. Hautefort, A.; Mendes-Ferreira, P.; Sabourin, J.; Manaud, G.; Bertero, T.; Rucker-Martin, C.; Riou, M.; Adão, R.; Manoury, B.; Lambert, M.; et al. Bmpr2 mutant rats develop pulmonary and cardiac characteristics of pulmonary arterial hypertension. Circulation 2019, 139, 932-948. [CrossRef]

117. Demireva, E.Y.; Xie, H.; Flood, E.D.; Thompson, J.M.; Seitz, B.M.; Watts, S.W. Creation of the 5-hydroxytryptamine receptor 7 knockout rat as a tool for cardiovascular research. Physiol. Genom. 2019, 51, 290-301. [CrossRef]

118. Scheimann, J.R.; Moloney, R.D.; Mahbod, P.; Morano, R.L.; Fitzgerald, M.; Hoskins, O.; Packard, B.A.; Cotella, E.M.; Hu, Y.C.; Herman, J.P. Conditional deletion of glucocorticoid receptors in rat brain results in sex-specific deficits in fear and coping behaviors. eLife 2019, 8, e44672. [CrossRef]

119. Pettibone, J.R.; Yu, J.Y.; Derman, R.C.; Faust, T.W.; Hughes, E.D.; Filipiak, W.E.; Saunders, T.L.; Ferrario, C.R.; Berke, J.D. Knock-in rat lines with Cre recombinase at the dopamine D1 and adenosine 2a receptor loci. eNeuro 2019, 6, ENEURO.0163-19.2019. [CrossRef]

120. Shi, Q.; Mattson, J.G.; Fahs, S.A.; Geurts, A.M.; Weiler, H.; Montgomery, R.R. The severe spontaneous bleeding phenotype in a novel hemophilia A rat model is rescued by platelet FVIII expression. Blood Adv. 2020, 4, 55-65. [CrossRef]

121. Takabayashi, S.; Aoshima, T.; Kobayashi, Y.; Takagi, H.; Akasaka, E.; Sato, M. Successful i-GONAD in Brown Norway rats by modification of in vivo electroporation conditions. OBM Genet. 2020, 4, 9. [CrossRef]

122. Dodge, A.; Peters, M.M.; Greene, H.E.; Dietrick, C.; Botelho, R.; Chung, D.; Willman, J.; Nenninger, A.W.; Ciarlone, S.; Kamath, S.G.; et al. Generation of a novel rat model of Angelman syndrome with a complete Ube3a gene deletion. Autism Res. 2020, 13, 397-409. [CrossRef] [PubMed]

123. Xu, Y.; Zhao, X.M.; Liu, J.; Wang, Y.Y.; Xiong, L.L.; He, X.Y.; Wang, T.H. Complexin I knockout rats exhibit a complex neurobehavioral phenotype including profound ataxia and marked deficits in lifespan. Pflugers Arch. 2020, 472, 117-133. [CrossRef] [PubMed]

124. Liu, Z.; Schiel, J.A.; Maksimova, E.; Strezoska, Z.; Zhao, G.; Anderson, E.M.; Wu, Y.; Warren, J.; Bartels, A.; van Brabant Smith, A.; et al. ErCas12a CRISPR-MAD7 for model generation in human cells, mice, and rats. CRISPR J. 2020, 3, 97-108. [CrossRef] [PubMed]

125. Fujihara, K.; Yamada, K.; Ichitani, Y.; Kakizaki, T.; Jiang, W.; Miyata, S.; Suto, T.; Kato, D.; Saito, S.; Watanabe, M.; et al. CRISPR/Cas9-engineered Gad1 elimination in rats leads to complex behavioral changes: Implications for schizophrenia. Transl. Psychiatry 2020, 10, 426. [CrossRef]

126. Langer, H.T.; Mossakowski, A.A.; Willis, B.J.; Grimsrud, K.N.; Wood, J.A.; Lloyd, K.; Zbinden-Foncea, H.; Baar, K. Generation of desminopathy in rats using CRISPR-Cas9. J. Cachexia Sarcopenia Muscle 2020, 11, 1364-1376. [CrossRef] 
127. Zheng, R.; Li, Y.; Wang, L.; Fang, X.; Zhang, J.; He, L.; Yang, L.; Li, D.; Geng, H. CRISPR/Cas9-mediated metabolic pathway reprogramming in a novel humanized rat model ameliorates primary hyperoxaluria type 1. Kidney Int. 2020, 98, 947-957. [CrossRef]

128. Yu, Y.; Zhang, N.; Dong, X.; Fan, N.; Wang, L.; Xu, Y.; Chen, H.; Duan, W. Uricase-deficient rat is generated with CRISPR/Cas9 technique. PeerJ 2020, 8, e8971. [CrossRef]

129. Nishikawa, M.; Yasuda, K.; Takamatsu, M.; Abe, K.; Okamoto, K.; Horibe, K.; Mano, H.; Nakagawa, K.; Tsugawa, N.; Hirota, Y.; et al. Generation of novel genetically modified rats to reveal the molecular mechanisms of vitamin D actions. Sci. Rep. 2020, 10, 5677. [CrossRef]

130. Birket, S.E.; Davis, J.M.; Fernandez-Petty, C.M.; Henderson, A.G.; Oden, A.M.; Tang, L.; Wen, H.; Hong, J.; Fu, L.; Chambers, A.; et al. Ivacaftor reverses airway mucus abnormalities in a rat model harboring a humanized G551D-CFTR. Am. J. Respir. Crit. Care Med. 2020, 202, 1271-1282. [CrossRef]

131. Bae, H.S.; Jin, Y.K.; Ham, S.; Kim, H.K.; Shin, H.; Cho, G.B.; Lee, K.J.; Lee, H.; Kim, K.M.; Koo, O.J.; et al. CRISRP/Cas9-mediated knockout of Mct8 reveals a functional involvement of Mct8 in testis and sperm development in a rat. Sci. Rep. 2020, 10, 11148. [CrossRef]

132. Sanna, F.; Bratzu, J.; Serra, M.P.; Leo, D.; Quartu, M.; Boi, M.; Espinoza, S.; Gainetdinov, R.R.; Melis, M.R.; Argiolas, A. Altered sexual behavior in dopamine transporter (DAT) knockout male rats: A behavioral, neurochemical and intracerebral microdialysis study. Front. Behav. Neurosci. 2020, 14, 58. [CrossRef] [PubMed]

133. Reese, R.M.; Dourado, M.; Anderson, K.; Warming, S.; Stark, K.L.; Balestrini, A.; Suto, E.; Lee, W.; Riol-Blanco, L.; Shields, S.D.; et al. Behavioral characterization of a CRISPR-generated TRPA1 knockout rat in models of pain, itch, and asthma. Sci. Rep. 2020, 10, 979. [CrossRef] [PubMed]

134. Lu, J.; Chen, A.; Ma, X.; Shang, X.; Zhang, Y.; Guo, Y.; Liu, M.; Wang, X. Generation and characterization of cytochrome P450 2J3/10 CRISPR/Cas9 knockout rat model. Drug Metab. Dispos. 2020, 48, 1129-1136. [CrossRef] [PubMed]

135. Konishi, S.; Tanaka, N.; Mashimo, T.; Yamamoto, T.; Sakuma, T.; Kaneko, T.; Tanaka, M.; Izawa, T.; Yamate, J.; Kuwamura, M. Pathological characteristics of Ccdc85c knockout rats: A rat model of genetic hydrocephalus. Exp. Anim. 2020, 69, 26-33. [CrossRef]

136. Tambini, M.D.; D'Adamio, L. Knock-in rats with homozygous PSEN1L435F Alzheimer mutation are viable and show selective $\gamma$-secretase activity loss causing low A $\beta 40 / 42$ and high A $\beta 43$. J. Biol. Chem. 2020, 295, 7442-7451. [CrossRef]

137. Dong, W.; Zhang, L.; Sun, C.; Gao, X.; Guan, F.; Li, J.; Chen, W.; Ma, Y.; Zhang, L. Knock in of a hexanucleotide repeat expansion in the C9orf72 gene induces ALS in rats. Anim. Models Exp. Med. 2020, 3, 237-244. [CrossRef]

138. Kitagawa, A.; Kizub, I.; Jacob, C.; Michael, K.; D’Alessandro, A.; Reisz, J.A.; Grzybowski, M.; Geurts, A.M.; Rocic, P.; Gupte, R.; et al. CRISPR-mediated single nucleotide polymorphism modeling in rats reveals insight into reduced cardiovascular risk associated with Mediterranean G6PD variant. Hypertension 2020, 76, 523-532. [CrossRef]

139. Ma, X.; Shang, X.; Qin, X.; Lu, J.; Liu, M.; Wang, X. Characterization of organic anion transporting polypeptide $1 \mathrm{~b} 2 \mathrm{knockout}$ rats generated by CRISPR/Cas9: A novel model for drug transport and hyperbilirubinemia disease. Acta Pharm. Sin. B 2020, 10, 850-860. [CrossRef]

140. Yoshimi, K.; Oka, Y.; Miyasaka, Y.; Kotani, Y.; Yasumura, M.; Uno, Y.; Hattori, K.; Tanigawa, A.; Sato, M.; Oya, M.; et al. Combi-CRISPR: Combination of NHEJ and HDR provides efficient and precise plasmid-based knock-ins in mice and rats. Hum. Genet. 2021, 140, 277-287. [CrossRef]

141. Aoshima, T.; Kobayashi, Y.; Takagi, H.; Iijima, K.; Sato, M.; Takabayashi, S. Modification of improved-genome editing via oviductal nucleic acids delivery (i-GONAD)-mediated knock-in in rats. BMC Biotechnol. 2021, 21, 63. [CrossRef]

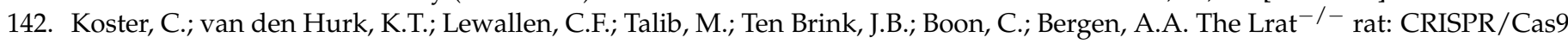
construction and phenotyping of a new animal model for retinitis pigmentosa. Int. J. Mol. Sci. 2021, 22, 7234. [CrossRef] [PubMed]

143. Yasuda, K.; Nishikawa, M.; Okamoto, K.; Horibe, K.; Mano, H.; Yamaguchi, M.; Okon, R.; Nakagawa, K.; Tsugawa, N.; Okano, T.; et al. Elucidation of metabolic pathways of 25-hydroxyvitamin D3 mediated by CYP24A1 and CYP3A using Cyp24a1 knockout rats generated by CRISPR/Cas9 system. J. Biol. Chem. 2021, 296, 100668. [CrossRef] [PubMed]

144. Lee, J.M.; Kim, U.; Yang, H.; Ryu, B.; Kim, J.; Sakuma, T.; Yamamoto, T.; Park, J.H. TALEN-mediated generation of Nkx3.1 knockout rat model. Prostate 2021, 81, 182-193. [CrossRef] [PubMed]

145. Noguchi, K.; Kadekawa, K.; Nishijima, S.; Sakanashi, M.; Okitsu-Sakurayama, S.; Higa-Nakamine, S.; Yamamoto, H.; Sugaya, K. Phenotypic characterization of the endocannabinoid-degrading enzyme alpha/beta-hydrolase domain 6 knockout rat. Cannabis Cannabinoid Res. 2021. [CrossRef]

146. Miller, B.; Kostrominova, T.Y.; Geurts, A.M.; Sorokin, A. Double p52Shc/p46Shc rat knockout demonstrates severe gait abnormalities accompanied by dilated cardiomyopathy. Int. J. Mol. Sci. 2021, 22, 5237. [CrossRef]

147. De Souza Gonçalves, L.; Sales, L.P.; Saito, T.R.; Campos, J.C.; Fernandes, A.L.; Natali, J.; Jensen, L.; Arnold, A.; Ramalho, L.; Bechara, L.; et al. Histidine dipeptides are key regulators of excitation-contraction coupling in cardiac muscle: Evidence from a novel CARNS1 knockout rat model. Redox Biol. 2021, 44, 102016. [CrossRef]

148. Soga, M.; Izumi, T.; Nanchi, I.; Horita, N.; Yamamoto, M.; Kawasaki, S.; Ogawa, K.; Fujita, M.; Morioka, Y. Suppression of joint pain in transient receptor potential vanilloid 4 knockout rats with monoiodoacetate-induced osteoarthritis. Pain Rep. 2021, 6, e951. [CrossRef] 
149. Liu, J.; Shang, X.; Huang, S.; Xu, Y.; Lu, J.; Zhang, Y.; Liu, Z.; Wang, X. Construction and characterization of CRISPR/Cas9 knockout rat model of carboxylesterase 2a gene. Mol. Pharmacol. 2021, 100, 480-490. [CrossRef]

150. Zhang, H.; Zheng, Q.; Chen-Tsai, R.Y. Establishment of a Cre-rat resource for creating conditional and physiological relevant models of human diseases. Transgenic Res. 2021, 30, 91-104. [CrossRef]

151. Chesney, K.L.; Men, H.; Hankins, M.A.; Bryda, E.C. The Atg1611 gene: Characterization of wild type, knock-in, and knock-out phenotypes in rats. Physiol. Genom. 2021, 53, 269-281. [CrossRef]

152. Chen, L.; Ouyang, J.; Li, X.; Xiao, X.; Sun, W.; Li, S.; Zhou, L.; Liao, Y.; Zhang, Q. DNAH17 is essential for rat spermatogenesis and fertility. J. Genet. 2021, 100, 14. [CrossRef] [PubMed]

153. Qi, X.; Chen, X.; Guo, J.; Zhang, X.; Sun, H.; Wang, J.; Qian, X.; Li, B.; Tan, L.; Yu, L.; et al. Precision modeling of mitochondrial disease in rats via DdCBE-mediated mtDNA editing. Cell Discov. 2021, 7, 95. [CrossRef] [PubMed]

154. Gordon, J.W.; Scangos, G.A.; Plotkin, D.J.; Barbosa, J.A.; Ruddle, F.H. Genetic transformation of mouse embryos by microinjection of purified DNA. Proc. Natl. Acad. Sci. USA 1980, 77, 7380-7384. [CrossRef]

155. Clark, J.F.; Dinsmore, C.J.; Soriano, P. A most formidable arsenal: Genetic technologies for building a better mouse. Genes Dev. 2020, 34, 1256-1286. [CrossRef] [PubMed]

156. Wang, H.; Yang, H.; Shivalila, C.S.; Dawlaty, M.M.; Cheng, A.W.; Zhang, F.; Jaenisch, R. One-step generation of mice carrying mutations in multiple genes by CRISPR/Cas-mediated genome engineering. Cell 2013, 153, 910-918. [CrossRef]

157. Cong, L.; Ran, F.A.; Cox, D.; Lin, S.; Barretto, R.; Habib, N.; Hsu, P.D.; Wu, X.; Jiang, W.; Marraffini, L.A.; et al. Multiplex genome engineering using CRISPR/Cas systems. Science 2013, 339, 819-823. [CrossRef]

158. Sato, M.; Takabayashi, S.; Akasaka, E.; Nakamura, S. Recent advances and future perspectives of in vivo targeted delivery of genome-editing reagents to germ cells, embryos, and fetuses in mice. Cells 2020, 9, 799. [CrossRef]

159. Shao, Y.; Guan, Y.; Wang, L.; Qiu, Z.; Liu, M.; Chen, Y.; Wu, L.; Li, Y.; Ma, X.; Liu, M.; et al. CRISPR/Cas-mediated genome editing in the rat via direct injection of one-cell embryos. Nat. Protoc. 2014, 9, 2493-2512. [CrossRef]

160. Ménoret, S.; Tesson, L.; Rémy, S.; Usal, C.; Thépenier, V.; Thinard, R.; Ouisse, L.H.; De Cian, A.; Giovannangeli, C.; Concordet, J.P.; et al. Gene targeting in rats using transcription activator-like effector nucleases. Methods 2014, 69, 102-107. [CrossRef]

161. Tesson, L.; Remy, S.; Ménoret, S.; Usal, C.; Thinard, R.; Savignard, C.; De Cian, A.; Giovannangeli, C.; Concordet, J.P.; Anegon, I. Genome editing in rats using TALE nucleases. Methods Mol. Biol. 2016, 1338, 245-259. [CrossRef]

162. Young, J.L.; Dean, D.A. Electroporation-mediated gene delivery. Adv. Genet. 2015, 89, 49-88. [CrossRef] [PubMed]

163. Hashimoto, M.; Takemoto, T. Electroporation enables the efficient mRNA delivery into the mouse zygotes and facilitates CRISPR/Cas9-based genome editing. Sci. Rep. 2015, 5, 11315. [CrossRef] [PubMed]

164. Qin, W.; Dion, S.L.; Kutny, P.M.; Zhang, Y.; Cheng, A.W.; Jillette, N.L.; Malhotra, A.; Geurts, A.M.; Chen, Y.G.; Wang, H. Efficient CRISPR/Cas9-mediated genome editing in mice by zygote electroporation of nuclease. Genetics 2015, 200, 423-430. [CrossRef] [PubMed]

165. Chen, S.; Lee, B.; Lee, A.Y.; Modzelewski, A.J.; He, L. Highly efficient mouse genome editing by CRISPR ribonucleoprotein electroporation of zygotes. J. Biol. Chem. 2016, 291, 14457-14467. [CrossRef] [PubMed]

166. Tröder, S.E.; Ebert, L.K.; Butt, L.; Assenmacher, S.; Schermer, B.; Zevnik, B. An optimized electroporation approach for efficient CRISPR/Cas9 genome editing in murine zygotes. PLoS ONE 2018, 13, e0196891. [CrossRef] [PubMed]

167. Teixeira, M.; Py, B.F.; Bosc, C.; Laubreton, D.; Moutin, M.J.; Marvel, J.; Flamant, F.; Markossian, S. Electroporation of mice zygotes with dual guide RNA/Cas9 complexes for simple and efficient cloning-free genome editing. Sci. Rep. 2018, 8, 474. [CrossRef]

168. Chen, S.; Sun, S.; Moonen, D.; Lee, C.; Lee, A.Y.; Schaffer, D.V.; He, L. CRISPR-READI: Efficient generation of knockin mice by CRISPR RNP electroporation and AAV donor infection. Cell Rep. 2019, 27, 3780-3789.e4. [CrossRef]

169. Wei, J.; Gaynor, P.; Cole, S.; Brophy, B.; Oback, B.; Laible, G. Developing the laboratory conditions for bovine zygote-mediated genome editing by electroporation. In Proceedings of the World Congress on Genetics Applied to Livestock Production; 2018. Available online: http:/ / www.wcgalp.org/system/files / proceedings/2018/developing-condition-bovine-zygote-mediatedgenome-editing-electroporation.pdf (accessed on 30 January 2022).

170. Tanihara, F.; Takemoto, T.; Kitagawa, E.; Rao, S.; Do, L.T.; Onishi, A.; Yamashita, Y.; Kosugi, C.; Suzuki, H.; Sembon, S.; et al. Somatic cell reprogramming-free generation of genetically modified pigs. Sci. Adv. 2016, 2, e1600803. [CrossRef]

171. Tanihara, F.; Hirata, M.; Nguyen, N.T.; Le, Q.A.; Wittayarat, M.; Fahrudin, M.; Hirano, T.; Otoi, T. Generation of CD163-edited pig via electroporation of the CRISPR/Cas9 system into porcine in vitro-fertilized zygotes. Anim. Biotechnol. 2021, 32, 147-154. [CrossRef]

172. Sato, M.; Jin, H.; Akasaka, E.; Miyoshi, M. In vitro electroporation in the presence of CRISPR/Cas9 reagents as a safe and useful method for producing biallelic knock out porcine embryos. OBM Genet. 2021, 5, 15. [CrossRef]

173. Nakagawa, Y.; Sakuma, T.; Takeo, T.; Nakagata, N.; Yamamoto, T. Electroporation-mediated genome editing in vitrified/warmed mouse zygotes created by IVF via ultra-superovulation. Exp. Anim. 2018, 67, 535-543. [CrossRef] [PubMed]

174. Kaneko, T.; Nakagawa, Y. Genome editing of rodents by electroporation of CRISPR/Cas9 into frozen-warmed pronuclear-stage embryos. Cryobiology 2020, 92, 231-234. [CrossRef] [PubMed]

175. Kim, S.; Kim, D.; Cho, S.W.; Kim, J.; Kim, J.S. Highly efficient RNA-guided genome editing in human cells via delivery of purified Cas9 ribonucleoproteins. Genome Res. 2014, 24, 1012-1019. [CrossRef] [PubMed]

176. Hakim, B.A.; Tyagi, V.; Agnihotri, S.K.; Amar Nath, A.; Agrawal, A.K.; Jain, A.; Singh, D.; Konwar, R.; Sachdev, M. Electroporation of mouse follicles, oocytes and embryos without manipulating zona pellucida. J. Dev. Biol. 2021, 9, 13. [CrossRef] [PubMed] 
177. Bagheri, H.; Friedman, H.; Shao, H.; Chong, Y.; Lo, C.A.; Emran, F.; Kays, I.; Yang, X.J.; Cooper, E.; Chen, B.E.; et al. TIE: A method to electroporate long DNA templates into preimplantation embryos for CRISPR-Cas9 gene editing. CRISPR J. 2018, 1, $223-229$. [CrossRef] [PubMed]

178. Kaneko, T. Genome editing of rat. Methods Mol. Biol. 2017, 1630, 101-108. [CrossRef]

179. Remy, S.; Chenouard, V.; Tesson, L.; Usal, C.; Ménoret, S.; Brusselle, L.; Heslan, J.M.; Nguyen, T.H.; Bellien, J.; Merot, J.; et al. Generation of gene-edited rats by delivery of CRISPR/Cas9 protein and donor DNA into intact zygotes using electroporation. Sci. Rep. 2017, 7, 16554. [CrossRef]

180. Takahashi, G.; Gurumurthy, C.B.; Wada, K.; Miura, H.; Sato, M.; Ohtsuka, M. GONAD: Genome-editing via Oviductal Nucleic Acids Delivery system: A novel microinjection independent genome engineering method in mice. Sci. Rep. 2015, 5, 11406. [CrossRef]

181. Ohtsuka, M.; Sato, M.; Miura, H.; Takabayashi, S.; Matsuyama, M.; Koyano, T.; Arifin, N.; Nakamura, S.; Wada, K.; Gurumurthy, C.B. $i$-GONAD: A robust method for in situ germline genome engineering using CRISPR nucleases. Genome Biol. $2018,19,25$. [CrossRef] [PubMed]

182. Hirose, M.; Honda, A.; Fulka, H.; Tamura-Nakano, M.; Matoba, S.; Tomishima, T.; Mochida, K.; Hasegawa, A.; Nagashima, K.; Inoue, K.; et al. Acrosin is essential for sperm penetration through the zona pellucida in hamsters. Proc. Natl. Acad. Sci. USA 2020, 117, 2513-2518. [CrossRef]

183. Gurumurthy, C.B.; Sato, M.; Nakamura, A.; Inui, M.; Kawano, N.; Islam, M.A.; Ogiwara, S.; Takabayashi, S.; Matsuyama, M.; Nakagawa, S.; et al. Creation of CRISPR-based germline-genome-engineered mice without ex vivo handling of zygotes by i-GONAD. Nat. Protoc. 2019, 14, 2452-2482. [CrossRef] [PubMed]

184. Ohtsuka, M.; Sato, M. i-GONAD: A method for generating genome-edited animals without ex vivo handling of embryos. Dev. Growth Differ. 2019, 61, 306-315. [CrossRef] [PubMed]

185. Namba, M.; Kobayashi, T.; Koyano, T.; Kohno, M.; Ohtsuka, M.; Matsuyama, M. GONAD: A new method for germline genome-editing in mice and rats. Dev. Growth Differ. 2021, 63, 439-447. [CrossRef] [PubMed]

186. Daya, S.; Berns, K.I. Gene therapy using adeno-associated virus vectors. Clin. Microbiol. Rev. 2008, 21, 583-593. [CrossRef]

187. Mizuno, N.; Mizutani, E.; Sato, H.; Kasai, M.; Ogawa, A.; Suchy, F.; Yamaguchi, T.; Nakauchi, H. Intra-embryo gene cassette knockin by CRISPR/Cas9-mediated genome editing with adeno-associated viral vector. iScience 2018, 9, 286-297. [CrossRef] [PubMed]

188. Yoon, Y.; Wang, D.; Tai, P.W.L.; Riley, J.; Gao, G.; Rivera-Pérez, J.A. Streamlined ex vivo and in vivo genome editing in mouse embryos using recombinant adeno-associated viruses. Nat. Commun. 2018, 9, 412. [CrossRef]

189. Edraki, A.; Mir, A.; Ibraheim, R.; Gainetdinov, I.; Yoon, Y.; Song, C.Q.; Cao, Y.; Gallant, J.; Xue, W.; Rivera-Pérez, J.A.; et al. A compact, high-accuracy Cas9 with a dinucleotide PAM for in vivo genome editing. Mol. Cell 2019, 73, 714-726.e4. [CrossRef]

190. Romeo, C.; Chen, S.H.; Goulding, E.; Van Gorder, L.; Schwartz, M.; Walker, M.; Scott, G.; Scappini, E.; Ray, M.; Martin, N.P. AAV diffuses across zona pellucida for effortless gene delivery to fertilized eggs. Biochem. Biophys. Res. Commun. 2020, 526, 85-90. [CrossRef]

191. Wang, D.; Niu, Y.; Ren, L.; Kang, Y.; Tai, P.W.L.; Si, C.; Mendonca, C.A.; Ma, H.; Gao, G.; Ji, W. Gene delivery to nonhuman primate preimplantation embryos using recombinant adeno-associated virus. Adv. Sci. 2019, 6, 1900440. [CrossRef]

192. Cronkhite, J.T.; Norlander, C.; Furth, J.K.; Levan, G.; Garbers, D.L.; Hammer, R.E. Male and female germline specific expression of anEGFP reporter gene in a unique strain of transgenic rats. Dev. Biol. 2005, 284, 171-183. [CrossRef]

193. Wu, Y.; Liang, D.; Wang, Y.; Bai, M.; Tang, W.; Bao, S.; Yan, Z.; Li, D.; Li, J. Correction of a genetic disease in mouse via use of CRISPR-Cas9. Cell Stem Cell 2013, 13, 659-662. [CrossRef] [PubMed]

194. Fujii, W.; Kawasaki, K.; Sugiura, K.; Naito, K. Efficient generation of large-scale genome-modified mice using gRNA and CAS9 endonuclease. Nucleic Acids Res. 2013, 41, e187. [CrossRef] [PubMed]

195. Brandl, C.; Ortiz, O.; Röttig, B.; Wefers, B.; Wurst, W.; Kühn, R. Creation of targeted genomic deletions using TALEN or CRISPR/Cas nuclease pairs in one-cell mouse embryos. FEBS Open Bio 2015, 5, 26-35. [CrossRef] [PubMed]

196. Birling, M.C.; Schaeffer, L.; André, P.; Lindner, L.; Maréchal, D.; Ayadi, A.; Sorg, T.; Pavlovic, G.; Hérault, Y. Efficient and rapid generation of large genomic variants in rats and mice using CRISMERE. Sci. Rep. 2017, 7, 43331. [CrossRef]

197. Mao, Z.; Bozzella, M.; Seluanov, A.; Gorbunova, V. Comparison of nonhomologous end joining and homologous recombination in human cells. DNA Repair 2008, 7, 1765-1771. [CrossRef]

198. Maruyama, T.; Dougan, S.K.; Truttmann, M.C.; Bilate, A.M.; Ingram, J.R.; Ploegh, H.L. Increasing the efficiency of precise genome editing with CRISPR-Cas9 by inhibition of nonhomologous end joining. Nat. Biotechnol. 2015, 33, 538-542. [CrossRef]

199. Singh, P.; Schimenti, J.C.; Bolcun-Filas, E. A mouse geneticist's practical guide to CRISPR applications. Genetics 2015, 199, 1-15. [CrossRef]

200. Chu, V.T.; Weber, T.; Wefers, B.; Wurst, W.; Sander, S.; Rajewsky, K.; Kühn, R. Increasing the efficiency of homology-directed repair for CRISPR-Cas9-induced precise gene editing in mammalian cells. Nat. Biotechnol. 2015, 33, 543-548. [CrossRef]

201. Song, J.; Yang, D.; Xu, J.; Zhu, T.; Chen, Y.E.; Zhang, J. RS-1 enhances CRISPR/Cas9- and TALEN-mediated knock-in efficiency. Nat. Commun. 2016, 7, 10548. [CrossRef]

202. Gerlach, M.; Kraft, T.; Brenner, B.; Petersen, B.; Niemann, H.; Montag, J. Efficient knock-in of a point mutation in porcine fibroblasts using the CRISPR/Cas9-GMNN fusion gene. Genes 2018, 9, 296. [CrossRef] 
203. Raveux, A.; Vandormael-Pournin, S.; Cohen-Tannoudji, M. Optimization of the production of knock-in alleles by CRISPR/Cas9 microinjection into the mouse zygote. Sci. Rep. 2017, 7, 42661. [CrossRef] [PubMed]

204. Graf, R.; Li, X.; Chu, V.T.; Rajewsky, K. sgRNA sequence motifs blocking efficient CRISPR/Cas9-mediated gene editing. Cell Rep. 2019, 26, 1098-1103. [CrossRef] [PubMed]

205. Labun, K.; Montague, T.G.; Gagnon, J.A.; Thyme, S.B.; Valen, E. CHOPCHOP v2: A web tool for the next generation of CRISPR genome engineering. Nucleic Acids Res. 2016, 44, W272-W276. [CrossRef] [PubMed]

206. Cho, S.W.; Kim, S.; Kim, J.M.; Kim, J.S. Targeted genome engineering in human cells with the Cas9 RNA-guided endonuclease. Nat. Biotechnol. 2013, 31, 230-232. [CrossRef] [PubMed]

207. Mali, P.; Yang, L.; Esvelt, K.M.; Aach, J.; Guell, M.; DiCarlo, J.E.; Norville, J.E.; Church, G.M. RNA-guided human genome engineering via Cas9. Science 2013, 339, 823-826. [CrossRef]

208. Komor, A.C.; Kim, Y.B.; Packer, M.S.; Zuris, J.A.; Liu, D.R. Programmable editing of a target base in genomic DNA without double-stranded DNA cleavage. Nature 2016, 533, 420-424. [CrossRef]

209. Nishida, K.; Arazoe, T.; Yachie, N.; Banno, S.; Kakimoto, M.; Tabata, M.; Mochizuki, M.; Miyabe, A.; Araki, M.; Hara, K.Y.; et al. Targeted nucleotide editing using hybrid prokaryotic and vertebrate adaptive immune systems. Science 2016, 353, aaf8729. [CrossRef]

210. Gaudelli, N.M.; Komor, A.C.; Rees, H.A.; Packer, M.S.; Badran, A.H.; Bryson, D.I.; Liu, D.R. Programmable base editing of A $\bullet T$ to $\mathrm{G} \bullet \mathrm{C}$ in genomic DNA without DNA cleavage. Nature 2017, 551, 464-471. [CrossRef]

211. Ryu, S.M.; Koo, T.; Kim, K.; Lim, K.; Baek, G.; Kim, S.T.; Kim, H.S.; Kim, D.E.; Lee, H.; Chung, E.; et al. Adenine base editing in mouse embryos and an adult mouse model of Duchenne muscular dystrophy. Nat. Biotechnol. 2018, 36, 536-539. [CrossRef]

212. Liu, Z.; Lu, Z.; Yang, G.; Huang, S.; Li, G.; Feng, S.; Liu, Y.; Li, J.; Yu, W.; Zhang, Y.; et al. Efficient generation of mouse models of human diseases via ABE- and BE-mediated base editing. Nat. Commun. 2018, 9, 2338. [CrossRef]

213. Mok, B.Y.; de Moraes, M.H.; Zeng, J.; Bosch, D.E.; Kotrys, V.; Raguram, A.; Hsu, F.; Radey, M.C.; Peterson, S.B.; Mootha, V.K.; et al. A bacterial cytidine deaminase toxin enables CRISPR-free mitochondrial base editing. Nature 2020, 583, 631-637. [CrossRef]

214. Asada, H.; Kawamura, Y.; Maruyama, K.; Kume, H.; Ding, R.G.; Kanbara, N.; Kuzume, H.; Sanbo, M.; Yagi, T.; Obata, K. Cleft palate and decreased brain gamma-aminobutyric acid in mice lacking the 67-kDa isoform of glutamic acid decarboxylase. Proc. Natl. Acad. Sci. USA 1997, 94, 6496-6499. [CrossRef] [PubMed]

215. Chua, S.C., Jr.; Chung, W.K.; Wu-Peng, X.S.; Zhang, Y.; Liu, S.M.; Tartaglia, L.; Leibel, R.L. Phenotypes of mouse diabetes and rat fatty due to mutations in the OB (leptin) receptor. Science 1996, 271, 994-996. [CrossRef]

216. Argilés, J.M. The obese Zucker rat: A choice for fat metabolism 1968-1988: Twenty years of research on the insights of the Zucker mutation. Prog. Lipid Res. 1989, 28, 53-66. [CrossRef]

217. Wu, X.; Wakamiya, M.; Vaishnav, S.; Geske, R.; Montgomery, C., Jr.; Jones, P.; Bradley, A.; Caskey, C.T. Hyperuricemia and urate nephropathy in urate oxidase-deficient mice. Proc. Natl. Acad. Sci. USA 1994, 91, 742-746. [CrossRef]

218. Nakade, S.; Yamamoto, T.; Sakuma, T. Cas9, Cpf1 and C2c1/2/3-What's next? Bioengineered 2017, 8, 265-273. [CrossRef] [PubMed]

219. Anzalone, A.V.; Randolph, P.B.; Davis, J.R.; Sousa, A.A.; Koblan, L.W.; Levy, J.M.; Chen, P.J.; Wilson, C.; Newby, G.A.; Raguram, A.; et al. Search-and-replace genome editing without double-strand breaks or donor DNA. Nature 2019, 576, 149-157. [CrossRef] [PubMed]

220. Liu, Y.; Li, X.; He, S.; Huang, S.; Li, C.; Chen, Y.; Liu, Z.; Huang, X.; Wang, X. Efficient generation of mouse models with the prime editing system. Cell Discov. 2020, 6, 27. [CrossRef] [PubMed]

221. Barbaric, I.; Gaynor Miller, G.; Dear, T.N. Appearances can be deceiving: Phenotypes of knockout mice. Brief. Funct. Genom. 2007, 6, 91-103. [CrossRef] 